\title{
Health and Climate Change: policy responses to protect public health
}

Nick Watts, W Neil Adger, Paolo Agnolucci, Jason Blackstock, Peter Byass, Wenjia Cai, Sarah Chaytor, Tim Colbourn, Mat Collins, Adam Cooper, Peter M Cox, Joanna Depledge, Paul Drummond, Paul Ekins, Victor Galaz, Delia Grace, Hilary Graham, Michael Grubb, Andy Haines, Ian Hamilton, Alasdair Hunter, Xujia Jiang, Moxuan Li, Ilan Kelman, Lu Liang, Melissa Lott, Robert Lowe, Yong Luo, Georgina Mace, Mark Maslin, Maria Nilsson, Tadj Oreszczyn, Steve Pye, Tara Quinn, My Svensdotter, Sergey Venevsky, Koko Warner, Bing Xu, Jun Yang, Yongyuan Yin, Chaoqing Yu, Qiang Zhang, Peng Gong*, Hugh Montgomery*, Anthony Costello*

\section{Executive summary}

The 2015 Lancet Commission on Health and Climate Change has been formed to map out the impacts of climate change, and the necessary policy responses, in order to ensure the highest attainable standards of health for populations worldwide. This Commission is multi-disciplinary and international in nature, with strong collabor-ation between academic centres in Europe and China.

The central finding from the Commission's work is that tackling climate change could be the greatest global health opportunity of the 21 st century. The key messages from the Commission are summarised below, accompanied by ten underlying recommendations to accelerate action in the next 5 years.

\section{The effects of climate change are being felt today, and future projections represent an unacceptably high and potentially catastrophic risk to human health}

The implications of climate change for a global population of 9 billion people threatens to undermine the last half century of gains in development and global health. The direct effects of climate change include increased heat stress, floods, drought, and increased frequency of intense storms, with the indirect threatening population health through adverse changes in air pollution, the spread of disease vectors, food insecurity and under-nutrition, displacement, and mental ill health.

Keeping the global average temperature rise to less than $2{ }^{\circ} \mathrm{C}$ to avoid the risk of potentially catastrophic climate change impacts requires total anthropogenic carbon dioxide $\left(\mathrm{CO}_{2}\right)$ emissions to be kept below 2900 billion tonnes $\left(\mathrm{GtCO}_{2}\right)$ by the end of the century. As of 2011 , total emissions since 1870 were a little over half of this, with current trends expected to exceed $2900 \mathrm{GtCO}_{2}$ in the next $15-30$ years. High-end emissions projection scenarios show global average warming of $2 \cdot 6-4 \cdot 8^{\circ} \mathrm{C}$ by the end of the century, with all their regional amplification and attendant impacts.

\section{Tackling climate change could be the greatest global health opportunity of the 21st century}

Given the potential of climate change to reverse the health gains from economic development, and the health co-benefits that accrue from actions for a sustainable economy, tackling climate change could be the greatest global health opportunity of this century. Many mitigation and adaptation responses to climate change are "no-regret" options, which lead to direct reductions in the burden of ill-health, enhance community resilience, alleviate poverty, and address global inequity. Benefits are realised by ensuring that countries are unconstrained by climate change, enabling them to achieve better health and wellbeing for their populations. These strategies will also reduce pressures on national health budgets, delivering potentially large cost savings, and enable investments in stronger, more resilient health systems.

\section{The Commission recommends that over the next 5 years, governments:}

1 Invest in climate change and public health research, monitoring, and surveillance to ensure a better understanding of the adaptation needs and the potential health co-benefits of climate mitigation at the local and national level.

2 Scale-up financing for climate resilient health systems world-wide. Donor countries have a responsibility to support measures which reduce the impacts of climate change on human wellbeing and support adaptation. This must enable the strengthening of health systems in lowincome and middle-income countries, and reduce the environmental impact of health care.

3 Protect cardiovascular and respiratory health by ensuring a rapid phase out of coal from the global energy mix. Many of the 2200 coalfired plants currently proposed for construction globally will damage health unless replaced with cleaner energy alternatives. As part of the transition to renewable energy, there will be a cautious transitional role for natural gas. The phase out of coal is prop osed as part of an early and decisive policy package which targets air pollution from the transport, agriculture, and energy sectors, and aims to reduce the health burden of particulate matter (especially $\mathrm{PM}_{2.5}$ ) and short-lived climate pollutants, thus yielding immediate gains for society.

4 Encourage a transition to cities that support and promote lifestyles that are healthy for the individual and for the planet. Steps to achieve this include development of a highly energy efficient building stock; ease of low-cost active transportation; and increased access to green spaces. Such measures improve adaptive capacity, whilst also reducing urban pollution, greenhouse gas emissions, and rates of cardiovascular disease, cancer, obesity, diabetes, mental illness, and respiratory disease.

\section{Achieving a decarbonised global economy and securing the public health benefits it offers is no longer primarily a technical or economic question-it is now a political one}

Major technical advances have made buildings and vehicles more efficient and renewable energy sources far more cost effective. Globally, there is plentiful financial resource available, however much of it is still being directed towards the fossil-fuel industry. Bold political commitment can ensure that the technical expertise, technology, and finance to prevent further significant climate change is readily available, and is not a barrier to action.

\section{The Commission recommends that over the next 5 years, governments:}

5 Establish the framework for a strong, predictable, and international carbon pricing mechanism.

6 Rapidly expand access to renewable energy in low-income and middle-income countries, thus providing reliable electricity for communities and health facilities; unlocking substantial economic gains; and promoting health equity. Indeed, a global development pathway that fails to achieve this expansion will come at a detriment to public health, and will not achieve long-term economic growth.

7 Accurate quantification of the avoided burden of disease, reduced health-care costs, and enhanced economic productivity is essential, and will be most effective when combined with adequate local capacity and political support to develop low-carbon healthy energy choices.

\section{The health community has a vital part to play in accelerating progress to tackle climate change}

Health professionals have worked to protect against health threats, such as tobacco, HIV/AIDS, and polio, and have often confronted powerful entrenched interests in doing so. Likewise, they must be leaders in responding to the health threat of climate change. A public health perspective has the potential to unite all actors behind a common cause - the health and wellbeing of our families, communities, and countries. These concepts are far more tangible and visceral than tonnes of atmospheric $\mathrm{CO}_{2}$, and are understood and prioritised across all populations irrespective of culture or development status.

Reducing inequities within and between countries is crucial to promoting climate change resilience and improving global health. Neither can be delivered without accompanying sustainable development that addresses key health determinants: access to safe water and clean air, food security, 
strong and accessible health systems, and reductions in social and economic inequity. Any prioritisation in global health must therefore place sustainable development and climate change front and centre.

\section{The Commission recommends that over the next 5 years, governments:}

8 Adopt mechanisms to facilitate collaboration between Ministries of Health and other government departments, empowering health professionals and ensuring that health and climate considerations are thoroughly integrated in government-wide strategies. A siloed approach to protecting human health from climate change will not work. This must acknowledge and seek to addres s the extent to which additional global environmental changes, such as deforestation, biodiversity loss, and ocean acidification, will impact on hu man health and decrease resilience to climate change.

9 Agree and implement an international agreement that supports countries in transitioning to a low-carbon economy. Whilst the negotiations are very complex, their goals are very simple: agree on ambitious and enforceable global mitigation targets, on adaptation of finance to protect countries' rights to sustainable development, and on the policies and mechanisms that enable these measures. To this end, international responsibility for reducing greenhouse gas emissions is shared: interventions that reduce emissions and promote global public health must be prioritised irrespective of national boundaries.

Responding to climate change could be the greatest global health opportunity of the 21 st century.

\section{To help drive this transition, the 2015 Lancet Commission on Health and Climate Change will:}

10 Develop a new, independent Countdown to 2030: Global Health and Climate Action, to provide expertise in implementing policies that mitigate climate change and promote public health, and to monitor progress over the next 15 years. The Collaboration will be led by this Commission, reporting in The Lancet every 2 years, tracking, supporting, and communicating progress and success along a range of indicators in global health and climate change

\section{Introduction}

In 2009, the UCL-Lancet Commission on Managing the Health Effects of Climate Change called climate change "the biggest global health threat of the 21 st century". ${ }^{1} 6$ years on, a new multidisciplinary, international Commission reaches the same conclusion, whilst adding that tackling climate change could be the greatest global opportunity of the 21 st century.

The Commission represents a collaboration between European and Chinese climate scientists and geographers, social and environmental scientists, biodiversity experts, engineers and energy policy experts, economists, political scientists and public policy experts, and health professionals - all seeking a response to climate change that is designed to protect and promote human health.

\section{The physical basis}

The Intergovernmental Panel on Climate Change (IPCC) has described the physical basis for, the impacts of, and the response options to climate change. ${ }^{2}$ In brief, short-wave solar radiation passes through the Earth's atmosphere to warm its surface, which emits longer wavelength (infrared) radiation. Greenhouse gases (GHGs) in the atmosphere absorb this radiation and re-emit it, sharing it with other atmospheric elements, and with the Earth below. Without this effect, surface temperatures would be more than $30^{\circ} \mathrm{C}$ lower than they are today. ${ }^{3}$ One such GHG is carbon dioxide $\left(\mathrm{CO}_{2}\right)$, primarily released when fossil fuels (ie, oil, coal, and natural gas) are burned. Others, such as methane $\left(\mathrm{CH}_{4}\right)$ and nitrous oxide $\left(\mathrm{N}_{2} \mathrm{O}\right)$, are generated through fossil-fuel use and human agricultural practice. GHG emissions have steadily climbed since the industrial revolution. ${ }^{4} \mathrm{CO}_{2}$ remains in the atmosphere for a long time, with a part remaining for thousands of years or longer. ${ }^{5}$ As a result, atmospheric GHG concentrations have risen steeply in the industrial age, those of $\mathrm{CO}_{2}$ reaching more than 400 parts per million (ppm) in 2014, for the first time since humans walked the planet. Every additional ppm is equivalent to about 7.5 billion tonnes of atmospheric $\mathrm{CO}_{2 .}{ }^{6,7}$

In view of their proven physical properties, such rising concentrations must drive a net positive energy balance, the additional heat distributing between gaseous atmosphere, land surface, and ocean. The IPCC's 2014 report confirms that such global warming, and the role of human activity in driving it, are unequivocal. The oceans have absorbed the bulk ( $90 \%$ or more) of this energy in recent years and ocean surface temperatures have risen. ${ }^{8}$ However, temperatures at the Earth's surface have also risen, with each of the last three decades being successively warmer than any preceding decade since 1850. Indeed, 2014 was the hottest year on record. Overall, the Earth (global average land and ocean temperature) has warmed by some $0.85^{\circ} \mathrm{C}$ between 1880 and $2012 .{ }^{8}$ Arctic sea ice is disappearing at a rate of up to $50000 \mathrm{~km}^{2}$ per year, the Antarctic ice sheet is now losing 159 billion tonnes of ice each year, and sea levels are rising inexorably. ${ }^{9}$

Much of past emissions remain in the atmosphere and will drive continued warming in the future. GHG concentrations in the atmosphere are continuing to rise at a rate that is incompatible with limiting warming to $2^{\circ} \mathrm{C}$ in the coming 35 years (by 2050), and which exceeds the IPCC's "worst case scenario". ${ }^{10} \mathrm{We}$ are on track for a global average temperature rise of more than $4^{\circ} \mathrm{C}$ above pre-industrial temperatures in the next 85 years, at which point global temperature will still be increasing by roughly $0.7^{\circ} \mathrm{C}$ per decade (due to the lag in reaching equilibrium). This distribution will not be even: the so-called polar amplification phenomena might cause temperatures in parts of the Arctic to increase by $11^{\circ} \mathrm{C}$ in this timeframe. ${ }^{8}$

\section{The health impacts of climate change}

The resultant climate change poses a range of threats to human health and survival in multiple, interacting ways (figure 1). Impacts can be direct (eg, heatwaves and extreme weather events such as a storm, forest fire, flood, or drought) or indirectly mediated through the effects of climate change on ecosystems (eg, agricultural losses and changing patterns of disease), economies, and social structure (eg, migration and conflict). After only $0.85^{\circ} \mathrm{C}$ warming, many anticipated threats have already become real-world impacts. Table 1 summarises the evidence attributing climate change to specific extreme weather events, outlining the role that climate change is playing in the present day (2013). It demonstrates increasing certainty that climate change significantly alters the probability of extreme weather, most often in directions that have dangerous health consequences.

Some population groups are particularly vulnerable to the health effects of climate change, whether because of existing socioeconomic inequalities, cultural norms, or intrinsic physiological factors. These groups include women, young children and older people, people with existing health problems or disabilities, and poor and marginalised communities. Such inequalities are often also present in relation to the causes of climate change: women and children both suffer the majority of the health impacts of indoor air pollution from inefficient cookstoves and kerosene lighting, and so mitigation measures can help to reduce existing health inequities such as these.

\section{Non-linearities, interactions, and unknown unknowns}

The magnitude and nature of health impacts are hard to predict with precision; however, it is clear that they are pervasive and reflect effects on key determinants of health, including food availability. There are real risks that the effects will become non-linear as emissions and global temperatures increase. First, large-scale disruptions to the climate system are not included in climate modelling and impact assessments. ${ }^{18}$ As we 
proceed rapidly towards $4^{\circ} \mathrm{C}$ warming by the end of the century, the likelihood of crossing thresholds and tipping points rises, threatening further warming and accelerated sea-level rise. Second, small risks can interact to produce larger-than-expected chances of catastrophic outcomes, especially if they are correlated (panel 1).22,23

Such impacts (and their interactions) are unlikely to be trivial and could be sufficient to trigger a discontinuity in the long-term progression of humanity. ${ }^{24}$ Whilst the poorest and most vulnerable communities might suffer first, the interconnected nature of climate systems, ecosystems, and global society means that none will be immune. Indeed, on the basis of current emission trajectories, temperature rises in the next 85 years may be incompatible with an organised global community. ${ }^{25}$

\section{The health co-benefits of emissions reduction}

Acting to reduce GHG emissions evidently protects human health from the direct and indirect impacts of climate change. However, it also benefits human health through mechanisms quite independent of those relating to modifying climate risk: so-called health co-benefits of mitigation. ${ }^{26}$

Reductions in emissions (eg, from burning fossil fuels) reduce air pollution and respiratory disease, whilst safer active transport cuts road traffic accidents and reduces rates of obesity, diabetes, coronary heart disease, and stroke. These are just some of the many health co-benefits of mitigation, which often work through several causal pathways via the social and environmental determinants of health. Protecting our ecosystems will create the wellbeing we gain from nature and its diversity. ${ }^{27}$

Affordable renewable energy will also have huge benefits for the poorest. WHO found that in 11 sub-Saharan African countries, $26 \%$ of health facilities had no energy at all and only $33 \%$ of hospitals had what could be called "reliable electricity provision", defined as no outages of more than $2 \mathrm{~h}$ in the past week..$^{28}$ Solar power is proposed as an ideal alternative energy solution, providing reliable energy that does not harm cardiovascular or respiratory health in the same way that diesel generators do. Clean cookstoves and fuels will not only protect the climate from black carbon (a very short-lived climate pollutant), but also cut deaths from household air pollution - a major killer in low-income countries. Buildings and houses designed to provide better insulation, heating efficiency, and protection from extreme weather events will reduce heat and cold exposure, disease risks from mould and allergy, and from infectious and vector-borne diseases. ${ }^{29}$

Many other co-benefits exist across different sectors, from agriculture to the formal health system. The cost savings of the health co-benefits achieved by policies to cut GHG emissions are potentially large. This is particularly important in a context where health-care expenditure is growing relative to total government expenditure globally. The health dividend on savings must be factored into any economic assessment of the costs of mitigation and adaptation. The poorest people are also most vulnerable to climate change, meaning that the costs of global development will rise if we do nothing, and poverty alleviation and sustainable development goals will not be achieved.

\section{This Commission}

5 years ago, the first Lancet Commission called climate change "the biggest global health threat of the 21 st century". ${ }^{1}$ Since then, climate threats continue to become a reality, GHG emissions have risen beyond worst-case projections, and no international agreement on effective action has been reached. The uncertainty around thresholds, interactions and tipping points in climate change and its health impacts are serious enough to mandate an immediate, sustained, and globally meaningful response.

This report further examines the evidence of threat, before tabling a prescription for both prevention and symptom management. We begin in section 1 by re-examining the causal pathways between climate change and human health, before offering new estimates of exposure to climate health risks in the coming decades. The changes in the spatial distribution of populations, and their demographic structure over the coming century, will put more people in harm's way.

Given that the world is already locked in to a significant rise in global temperatures (even with meaningful action to reduce GHG emissions), section 2 considers measures that must be put in place to help lessen their unavoidable health impacts. Adaptation strategies are those that reduce vulnerability and enhance resilience — ie, the capacity of a system to absorb disturbance and re-organise—so as to retain function, structure, identity, and feedbacks. ${ }^{30}$ We identify institutional and decision-making challenges related to uncertainty, multicausal pathways, and complex interactions between social, ecological, and economic factors. We also show tangible ways ahead with adaptations that provide clear no-regret options and co-benefits for food security, human migration and displacement, and dynamic infectious disease risks.

Symptomatic intervention and palliation must, however, be accompanied by immediate action to address the cause of those symptoms: the epidemiology and options for scaling up low-carbon technologies and technical responses are discussed in section 3, in addition to the necessary measures required to facilitate their deployment. This section also explores the health implications of various mitigation options, with particular attention to those which both promote public health and mitigate climate change.

Transformation to a global low-carbon economy requires political will, a feasible plan, and the requisite finance. Section 4 examines the financial, economic, and policy options for decarbonisation. The goal of mitigation policy should be to reduce cumulative and annual GHG emissions. Early emissions reduction will delay climate disruption and reduce the overall cost of abatement by avoiding drastic and expensive last-minute action. Immediate action offers a wider range of technological options, allows economies of scale and prospects for learning, and will reduce costs over time. The window of opportunity for evolutionary and revolutionary new technologies to develop, commercialise, and deploy is also held open for longer.

In section 5, we examine the political processes and mechanisms that might play a part in delivering a low-carbon economy. Multiple levels are considered, including the global response (the UN Framework Convention on Climate Change), national and subnational (cities, states, and provinces) policy, and the role of individuals. The interaction between these different levels, and the lessons learnt from public health are given particular attention.

Finally, in section 6 we propose the formation of an international Countdown to 2030: Global Health and Climate Action. We outline how an international, multidisciplinary coalition of experts should monitor and report on: the health impacts of climate change; progress in policy to reduce GHG emissions, and synergies used to promote and protect health; and progress in health adaptation action to reduce population vulnerability to build climate resilience and to implement climate-ready low-carbon health systems. A Countdown process would complement rather than replace existing IPCC reports, and would bring the full weight and voice of the health and scientific communities to this critical population health challenge.

\section{Section 1: climate change and exposure to health risks}

No region is immune from the negative impacts of climate change, which will affect the natural world, economic activities, and human health and wellbeing in every part of the world. ${ }^{31}$ There are already observed impacts of climate change on health, directly through extreme weather and hazards and indirectly through changes in land use and nutrition. Lags in the response of the climate system to historical emissions means the world is committed to significant warming over coming decades. 
All plausible futures resulting from realistic anticipated emissions trajectories expose the global population to worsening health consequences. In 2014, WHO estimated an additional 250000 potential deaths annually between 2030 and 2050 for well understood impacts of climate change. WHO suggest their estimates represent lower bound figures because they omit important causal pathways. The effects of economic damage, major heatwave events, river flooding, water scarcity, or the impacts of climate change on human security and conflict, for example, are not accounted for in their global burden estimates. ${ }^{32}$ Without action to address continued and rising emissions, the risks, and the number of people exposed to those risks, will likely increase significantly. WHO emphasises that the importance of the interactions between climate change and many other trends affecting public health, stressing the need for interventions designed to address climate change and poverty-two key drivers of ill health. ${ }^{32}$ Similarly, the authors of the IPCC assessment of climate change on health emphasise that the health impacts become amplified over time. ${ }^{21}$

This report provides new insights into the potential exposure of populations, showing that when demographic trends are accounted for, such as ageing, migration, and aggregate population growth, the populations exposed to climate change that negatively affect health risk are more seriously affected than suggested in many global assessments. It involves new analysis on specific and direct climate risks of heat, drought and heavy precipitation that directly link climate change and wellbeing. The number of people exposed to such risk is amplified by social factors: the distribution of population density resulting from urbanisation, and changes in population demographics relating to ageing.

Thus, human populations are likely to be growing, ageing, and migrating towards greater vulnerability to climate risks. Such data emphasise the need for action to avoid scenarios where thresholds in climate greatly increase exposure, as well as adaptation to protect populations from consequent impacts.

\section{How climate affects human health}

\section{Mechanisms linking climate and health}

The principal pathways linking climate change with health outcomes are shown in figure 2, categorised as direct and indirect mechanisms that interact with social dynamics to produce health outcomes. All these risks have social and geographical dimensions, are unevenly distributed across the world, and are influenced by social and economic development, technology, and health service provision. The IPCC report documents in expansive detail the scientific knowledge on many individual risks. ${ }^{31}$ Here, we discuss how these risks could change globally as a result of a changing climate and of evolving societal and demographic factors.

Changes in extreme weather and resultant storm, flood, drought, or heatwave are direct risks. Indirect risks are mediated through changes in the biosphere (eg, in the burden of disease and distribution of disease vectors, or food availability), and others through social processes (leading, for instance, to migration and conflict). These three pillars, shown in figure 2, interact with one another, and with changes in land use, crop yield, and ecosystems that are being driven by global development and demographic processes. Climate change will limit development aspirations, including the provision of health and other services through impacts on national economies and infrastructure. It will affect wellbeing in material and other ways. Climate change will, for example, exacerbate perceptions of insecurity and influence aspects of cultural identity in places directly affected. ${ }^{33}$

Thus, in figure 2, climate risks might be both amplified and modified by social factors. The links between food production and food security in any country, for instance, are strongly determined by policies, regulations and subsidies to ensure adequate food availability and affordable prices. ${ }^{34}$ Vulnerabilities thus arise from the interaction of climatic and social processes. The underpinning science shows that impacts are unevenly distributed, with greater risks in less developed countries, and with specific subpopulations such as poor and marginalised groups, people with disabilities, the elderly, women, and young children bearing the greatest burden of risk in all regions. ${ }^{31}$

In many regions, the consequences of lower socio-economic status and cultural gender roles combine to increase the health risks that women and girls face as a result of climate change relative to men and boys in the same places, although the converse might apply in some instances. Whilst in developed countries, males comprise approximately $70 \%$ of flood disaster fatalities (across studies in which sex was reported), the converse is generally true for disaster-related health risks in developing country settings, in which the overall impacts are much greater. ${ }^{35,36}$ For example, in some cultures women may be forbidden from leaving home unaccompanied, are less likely to have learnt how to swim, and may have less political representation and access to public services. Additionally, women's and girls' nutrition tends to suffer more during periods of climate-related food scarcity than that of their male counterparts, as well as starting from a lower baseline, because they are often last in household food hierarchies. ${ }^{37}$

\section{Direct mechanisms and risks: exposure to warming and heatwaves}

While societies are adapted to local climates across the world, heatwaves represent a real risk to vulnerable populations and significant increases in the risks of extreme heat are projected under all scenarios of climate change. ${ }^{38}$ On an individual basis, tolerance to any change is diminished in those whose capacity for temperature homoeostasis is limited by, for example, extremes of age or dehydration. There is a well-established relationship between extreme high temperatures and human morbidity and mortality. ${ }^{39}$ There is also now strong evidence that such heat-related mortality is rising as a result of climate change impacts across a range of localities. ${ }^{31}$

Evidence from previous heatwave events suggests that the key parameters of mortality risk include the magnitude and duration of the temperature anomaly and the speed of temperature rise. The risks are culturally defined, even temperate cities experience such mortality as it is deviation from expectations that drives weather-related risks. This is especially true when hot periods occur at the beginning of summer, before people have acclimatised to hotter weather. ${ }^{38}$ The incidence of heatwaves has increased in the past few decades, as has the area affected by them..$^{40,41}$

The most severe heatwave, measured with the Heat Wave Magnitude Index, was the summer 2010 heatwave in Russia. ${ }^{40}$ More than 25000 fires over an area of 1.1 million hectares ${ }^{42}$ raised concentrations of carbon monoxide, nitrogen oxides, aerosols, and particulates $\left(\mathrm{PM}_{10}\right)$ in European Russia. The concentration of particulate matter doubled from its normal level in the Moscow region in August, 2010, when a large smoke plume covered the entire capital. ${ }^{43}$ In combination with the heat wave, the air pollution increased mortality between July and August, 2010, in Moscow, resulting in more than 11000 additional deaths compared with July to August, 2009.44 Projections under climate scenarios show that events with the magnitude of the Russian heatwave of 2010 could have become much more common and with high-end climate scenarios could become almost the summer norm for many regions. ${ }^{40,45}$

Rising mean temperatures mean that the incidence of cold events is likely to diminish. The analysis here focuses on the heat-related element because the health benefits of reductions in cold are not established. Whilst there is an increase in deaths during winter periods in many climates, the mechanisms responsible for this increase are not easily delineated. Most winter-related deaths are cardiovascular, yet the link between temperature and cardiovascular mortality rates is weak. There is a stronger link between respiratory deaths and colder temperatures but these account for a smaller percentage of winter deaths. ${ }^{46}$

The impact of cold temperatures can be measured considering seasonal means, extreme cold spells, and relative temperature changes. Seasonal means and extreme cold spells (or absolute temperature) have relatively small or ambiguous relationships with numbers of winter deaths, however temperature cooling relative to an area's average temperature does more clearly correlate with mortality rates. ${ }^{46,47}$ There may be modest reductions in cold-related deaths; however, these reductions will be largely outweighed at the global scale by heat-related mortality. ${ }^{46}$ Whilst 
climate change will have an impact on cold-related deaths, particularly in some countries with milder climates, the overall impact is uncertain. ${ }^{48,49}$

Population growth, urbanisation trends, and migration patterns mean that the numbers exposed to hot temperature extremes, in particular, will increase, with major implications for public health planning. Urban areas will expand: urban land cover is projected to triple by 2030 from year 2000 levels. ${ }^{50}$ Many assessments of climate risks, including those for heat, do not consider the detail of demographic shifts, in effect, overlooking the location of vulnerable populations as a part of the calculus. We have produced models that consider both climate and population projections. We use Shared Socioeconomic Pathway (SSP) population projections to calculate future demographic trends alongside Coupled Model Intercomparison Project Phase 5 (CMIP5) climate models (as used in the IPCC 5th Assessment report) and projected emission pathways (so-called Representative Concentration Pathways [RCPs]). ${ }^{51-54}$ Appendix 1 outlines assumptions, together with the data and the climate and population scenarios used to estimate the scale of various health risks for the 21st century, shown in figures 3-6.

The projected global distribution of changes in heat in the coming decades is shown in figure 3A using the high-emission projections of RCP8.5, as explained in appendix 1. This focuses on summer temperatures, hence the graph represents the summer months for both the northern (June to August) and southern (December to February) hemispheres. Climatic impact will not be experienced uniformly across the globe. At such levels of warming, the return period of extreme heat events, such as those experienced in 2003 in western Europe, is significantly shortened. Figure 3B makes clear that future health risks arising from exposure to warming (measured as the mean temperature increase experienced by a person) might also be extensively driven by demographics, shown as the divergence between red and blue lines driven by different warming and population scenarios across the incoming decades. In other words, population change in areas of the world where population growth is significant, fundamentally affects the increase in numbers of people exposed to the impacts of climate change.

Whilst hotter summers increase vulnerability to heat-related morbidity, heatwaves in particular have a negative impact on health. Figure 4 reanalyses projections from the latest climate models (the CMIP5 models as used in the IPCC 5th Assessment report) in terms of the number of exposure events per year for heatwaves. Heatwaves here are defined as 5 consecutive days of daily minimum night-time temperatures more than $5^{\circ} \mathrm{C}$ greater than the presently observed patterns of daily minimums. Although heatwaves have different characteristics, this definition focuses on health impacts based on deviation from normal temperature, duration, and extent.

Elderly populations are especially vulnerable to heatwaves, and demographic and climatic changes will combine to shape population heatwave vulnerability in coming decades (figure 4). ${ }^{55}$ We use populations projected over 65 years of age rather than a frailty index, recognising the underlying health of elderly populations and the cultural context of ageing are both likely to change over time. ${ }^{56}$ Educational levels and other demographic factors are also important in the ability of societies to cope with extreme events. ${ }^{57}$ Allowing for these caveats, figure 4D shows growing exposure in global projections of the number of people older than 65 years exposed to heatwave risks. The numbers of events of elderly people experiencing high temperatures reaches more than 3 billion towards the end of the century. A key message is that demographic change added to climate changes will expose increasing numbers of elderly people to increasing numbers of heat waves, especially in the developed and transition economies.

Heat also poses significant risks to occupational health and labour productivity in areas where people work outdoors for long hours in hot regions. ${ }^{58}$ Heavy labour in hot humid environments is a particular health and economic risk to millions of working people and their families in hot tropical and sub-tropical parts of the world. ${ }^{59}$ These have been documented in young and middle-aged men in France 2003 , ${ }^{60}$ agricultural workers in the USA, ${ }^{61}$ and sugar-cane harvesters in Central America ${ }^{62}$ The Climate Vulnerability Monitor 2012 estimated the annual costs in China and India at US $\$ 450$ billion in $2030 .{ }^{63}$ The percentage of GDP losses due to increasing workplace heat is greater than the current spending on health systems in many low-income and middle-income countries. ${ }^{64}$

Impacts of heat on labour productivity will be compounded in cities by increased urbanisation and the corresponding heat island effect, but will also be offset by reductions in populations working outdoors in sectors (eg, construction and agriculture). ${ }^{38}$ Tolerance to any given temperature will be influenced by humidity, which alters the capacity for thermoregulation through the evaporation of sweat. These measures are combined in an index known as wet-bulb globe temperature (WBGT), used to determine how long an individual can work before a break, with work capacity falling substantially after WBGT $26-30^{\circ} \mathrm{C} . .^{58}$

Using projections from RCP8.5 and SSP2, figure 5 estimates the extent of lost labour productivity (on the basis of the response function between temperature and productivity used by Dunne et al, $2012^{65}$ ) across the coming decades, focusing on proportion of the labour force in rural and urban areas. Again the impact of climate change is greater in regions such as sub-Saharan Africa and India. But some trends offset the potential impact, including the trend towards employment in service and other sectors where exposure is reduced (assumed in the SSP2 used here; figure 5C, D). As demographic trends towards urban settlement and secondary and tertiary sector employment progress, increasing urbanisation may reduce the negative impacts of warming on total outdoor labour productivity, depending on the population scenario (SSP2 in figure 5D).

Loss of agricultural productivity through impaired labour will be amplified by direct climate change impacts on crop and livestock production. ${ }^{66}$ The impact of increasing temperatures on labour productivity can be mitigated-eg, by use of air conditioning or by altering working hours. However, these actions are predicated on affordability, infrastructure, the suitability of a job to night labour, and energy availability. ${ }^{67}$

\section{Indirect and complex mechanisms linking climate change and health}

Most climate-related health impacts are mediated through complex ecological and social processes. For risks associated with transmission vectors and water, for example, rising temperatures and changes in precipitation pattern alter the viable distribution of disease vectors such as mosquitoes carrying dengue or malaria. Climate conditions affect the range and reproductive rates of malarial mosquitoes and also affect the lifecycle of the parasitic protozoa responsible for malaria. The links between climate change, vector populations and hence malarial range and incidence may become significant in areas where the temperature is currently the limiting factor, possibly increasing the incidence of a disease that causes 660 000 deaths per year. ${ }^{68}$ In some highland regions, malaria incidence has already been linked to warmer air temperatures although successful control measures in Africa have cut the incidence of malaria in recent decades, and there are long established successes of managing malaria risk in temperate countries including in southern USA and in Europe. ${ }^{69,70}$ There are equally complex relationships and important climate-related risks associated with dengue fever, cholera and food safety. ${ }^{54,71,72}$ Dengue fever for example has 390 million recorded infections each year, and the number is rising..$^{54,73}$

Changing weather patterns are also likely to affect the incidence of diseases transmitted through infected water sources, either through contamination of drinking water or by providing the conditions needed for bacterial growth. ${ }^{74}$ Cholera is transmitted through infected water sources and often occurs in association with seasonal algal blooms with outbreaks sometimes experienced following extreme weather events such as hurricanes that result in the mixing of wastewater and drinking water, and in association with El Niño events. ${ }^{72}$ Such extreme weather events are likely to increase in frequency in the coming decades and waterborne epidemics need to be planned for and monitored carefully. 
In effect, all health outcomes linked to climate variables are shaped by economic, technological, demographic, and governance structures. Institutions and social norms of behaviour and expectation will play a significant part in how new weather patterns impact health. ${ }^{38,71}$ Changes in temperature, precipitation frequency, and air stagnation also affect air pollution levels with significant risks to health. Climate affects pollution levels through pollutant formation, transport, dispersion, and deposition. In total, fine particulate air pollution is estimated to be responsible for 7 million additional deaths globally in 2012, mainly due to respiratory and cardiovascular disease. ${ }^{75}$ Its effect is amplified by changes in ambient temperature, precipitation frequency, and air stagnation - all crucial for air pollutant formation, transport, dispersion and deposition.

Ground-level ozone (GLO) and particulate air pollutants are elements that will be most affected by climate change. Whilst the net global effect is unclear, regional variation will see significant differences in local exposure. ${ }^{31,76} \mathrm{GLO}$ is more readily created and sustained in an environment with reduced cloudiness and decreased precipitation frequency, but especially by rising temperatures. ${ }^{77}$ Thus, ozone levels were substantially elevated during the European heatwave of summer 2003.76,78 Climate change is predicted to elevate GLO levels over large areas in the USA and Europe, especially in the summer, although the background of GLO in the remote areas shows a decreased trend. ${ }^{77,79-82}$ In the USA, the main impact of future climate change on GLO is centred over the northeast and mid-west where the future GLO are expected to increase by 2-5 ppbv (about 3$7 \%$ ) in the next 50-90 years under the IPCC A1 scenario. ${ }^{79,81}$ Knowlton and colleagues estimated that ozone-related acute morality in the USA would rise by $4.5 \%$ from 1990 to 2050 , through climate change alone. ${ }^{83}$ Likewise, climate change is predicted to increase concentrations of fine particulate matter $\left(2 \cdot 5\right.$ micron particles $\left.\left[\mathrm{PM}_{2.5}\right]\right)$ in some areas. ${ }^{80,84}$

The interactions between air pollution and climate are highly differentiated by region. In China, for example, the interactions between climate and a range of pollutants is especially acute. While action on carbon emissions dominate energy policy in China, climatic changes will have a significant impact on air pollutants in all regions of the country. ${ }^{84,85}$ Chinese ozone concentrations in 2050 have been projected to likely increase beyond present levels under many climate scenarios through the combined effects of emissions and climate change. The greatest rises will be in eastern and northern China. ${ }^{85}$ Compared with ozone, $\mathrm{PM}_{2.5}$ levels rely more on changes in emissions than temperature. The concentrations of $\mathrm{SO}_{4}{ }^{2}$, black carbon and organic carbon are projected to fall, but those of $\mathrm{NO}_{3}{ }^{-}$to rise, across China under many possible climate futures ${ }^{84}$ Levels of aerosols (especially $\mathrm{NO}_{3}{ }^{-}$) in the eastern Chinese spring will be especially affected by 2030. Falling emissions would reduce overall $\mathrm{PM}_{2.5}$ concentrations by $1-8 \mu \mathrm{g} / \mathrm{m}^{3}$ in 2050 compared with those in 2000 despite a small increase $(10-20 \%)$ driven by climate change alone. ${ }^{84}$ Although emission changes play a key part in projections, climate-driven change should not be ignored if warming exceeds $2^{\circ} \mathrm{C}$. $\mathrm{PM}_{2.5}$ is sensitive to precipitation and monsoon changes and global warming will alter Chinese precipitation seasonally and regionally, thereby changing the regional concentration of $\mathrm{PM}_{2.5} .^{76,86}$ Independent of climate change, China's air pollution has already come at great cost, with an annual pollution-related mortality of 1.21 million in $2010 .^{87}$

Climate change has important implications for livelihoods, food security, and poverty levels, and on the capacity of governments and health systems to manage emerging health risks. Crops and livestock have physiological limits to their health, productivity, and survival, which include those related to temperature. For every degree greater than $30^{\circ} \mathrm{C}$, the productivity of maize production in Africa might be reduced by $1 \%$ in optimum conditions and $1.7 \%$ in drought, with a $95 \%$ chance of climate change-related harm to the production of South African maize and wheat in the absence of adaptation. ${ }^{88,89}$

Sensitivity of crops and livestock to weather variation has a substantial impact on food security in regions that are already food insecure, pushing up food prices and ultimately affecting food availability and affordability to poor populations and contributing to malnutrition..$^{90}$ This effect is amplified by polices on food stocks, reactions to food prices by producer countries, and by the global demand for land to hedge against climate shifts. The increased volatility of the global food system under climate change has impacts on labour, on farmer livelihoods and on consumers of food, with attendant health outcomes for all these groups. ${ }^{66}$

Within this complex relationship between climate and food security, the availability of water for agricultural production is a key parameter. Figure 6 shows very significant changes in exposure to drought-like meteorological conditions over the coming decades. The analysis shows that the population changes (from SSP2) alongside climate change could lead to 1.4 billion additional person drought exposure events per year by the end of the century. Importantly, the geographical distribution of this exposure is highly localised and variable (eg, across Asia and Europe), acutely degrading water supply and potentially quality. But all such estimates focus on availability of surface water, whereby both long-term water availability and supply for specific regions are also affected by groundwater resources, which have been shown to be in a critical state in many regions. ${ }^{91,92}$

Increased frequency of floods, storm surges, and hurricanes will have a substantial effect on health. Extreme events have immediate risks, exemplified by more than 6000 fatalities as a result of typhoon Haiyan in the Philippines in late 2013. Floods also have long-term and short-term effects on wellbeing through disease outbreaks, mental health burdens, and dislocation. ${ }^{93}$

Risks related to water shortages, flood, and other mechanisms involve large populations. Projections suggest, for example, that an additional 50 million people and $30000 \mathrm{~km}^{2}$ of land could be affected by coastal storm surges in 2100 , with attendant risks of direct deaths and of infectious diseases. ${ }^{94,95}$ Involuntary displacement of populations as a result of extreme events has major public health and policy consequences. In the longer term, flooding affects perceptions of security and safety, and can cause depression, anxiety, and post-traumatic stress disorder. ${ }^{93,96}$

Figure 7 shows estimates of extreme precipitation events (events exceeding 10 year return period) under the RCP8.5 (high-emission) scenario. We estimate that there would be around 2 billion additional extreme rainfall exposure events annually (individuals exposed once or multiple times during any year), partly due to population growth in exposed areas and partly due to the changing incidence of extreme events associated with climate change. Whilst not all extreme rainfall events translate into floods, such extreme precipitation will inevitably increase flood risk. Regions of large population growth dominate changes in the number exposed to flood risk (especially in sub-Saharan Africa and South Asia). ${ }^{97}$

All these climate-related impacts are detrimental to the security and wellbeing of populations around the world. Whilst there is, as yet, no definitive evidence that climate change has increased the risk of violent civil conflict or war between states, there are reasons for concern. The IPCC concludes that climate change will directly affect poverty, resource uncertainty and volatility, and the ability of governments to fulfil their obligations to protect settlements and people from weather extremes. ${ }^{33,98}$ These factors are important correlates of violent conflict within states, suggesting that climate change is detrimental to peaceful and secure development, even if they do not directly enhance conflict risks. ${ }^{99}$ Similarly, migration has significant complex consequences for human security. The continued movement of migrant populations into cities, the potential for climate hazards in high-density coastal mega-cities, and impaired air quality create significant public health challenges, not least for migrants themselves. ${ }^{100,101}$

The direct and indirect effects of climate change outlined here represent significant risks for human health. The precautionary case for action is amplified with three additional dimensions: (1) interventions to adapt to evolving climate risks as discussed in section 2 might not be as effective as required; (2) unforeseen interactions and amplifications of climate risks are possible (eg, emerging zoonotic and other diseases being affected through complex ecological changes, covered in more detail in the Lancet Commission on Planetary Health); (3) the risk that tipping elements in 
the climate system could rapidly accelerate climate change at regional or global scale. Lags in warming and climate impacts mean that irrespective of the mitigation pathway taken, many impacts and risks will increase in the coming decades.

\section{Section 2: action for resilience and adaptation}

Adaptation measures are already required to adapt to the effects of climate change being experienced today. As shown in section 1, these risks will increase as worsening climate change affects more people, especially in highly exposed geographical regions and for the most vulnerable members of society.

This section outlines possible and necessary actions to limit the negative impacts and burden on human health, including direct and indirect impacts within and beyond the formal health system. Responses aim to reduce the underlying vulnerability of populations; empower actors to cope or adapt to the impacts; and whenever possible support longer-term development. The health sector has a central part to play in leading climate change adaptation and resilience efforts. ${ }^{102,103}$ However, effective adaptation measures must cross multiple societal sectors, identify ways to overcome barriers to achieve co-benefits, and target vulnerable groups and regions.

Early action to address vulnerability allows for more options and flexibility before we face indispensable and involuntary adaptation. ${ }^{104,105}$ Panel 2 provides definitions of vulnerability, adaptation, and resilience.

\section{Adaptation to the direct health impacts of climate change}

The direct health impacts result from extreme weather events such as storms, floods, droughts, and heatwaves. Many responses centre on the importance of health system strengthening; however, actions in other sectors are also needed.

\section{Early warning systems for extreme events}

Approaches to the health management of extreme weather events involve improved early warning systems (EWS), effective contingency planning, and identification of the most vulnerable and exposed communities. ${ }^{111}$ They include forecasting, predicting possible health outcomes, triggering effective and timely response plans, targeting vulnerable populations, and communicating prevention responses. Public health authorities need to upgrade existing emergency programmes and conduct exercises to enhance preparedness for anticipated health risks due to new extreme events such as sea level rise, saline water intrusion into drinking water courses, and severe flooding from storm surges. These efforts to improve disaster preparedness must also run in parallel with efforts to strengthen local community resilience.

\section{Actions to reduce burdens of heatwaves}

The frequency, intensity, and duration of extreme heat days and heatwaves will increase with climate change, leading to heat stress and increased death rates (see section 1). The effects are worsened by the so-called urban heat island effect, which results from greater heat retention of buildings and paved surfaces, compared with reflective, transpiring, shading, and air-flow-promoting vegetation-covered surfaces. Evidence suggests that effective adaptation measures would reduce the death rates associated with these heat waves. The 2003 European heatwave, which killed up to 70000 people led France to introduce a heatwave warning system and a national action plan. ${ }^{111}$ Health worker training was modified, urban planning altered, and new public health infrastructure developed. The 2006 heatwave suggested that these measures had been effective, with 4400 fewer anticipated deaths. ${ }^{112}$

Adaptation options within health care include training of health-care workers and integrated heatwave early warning systems (HEWS), especially for the most vulnerable populations. ${ }^{111,113}$ Adaptation measures also include increasing green infrastructures and urban green spaces, improving the design of social care facilities, schools, other public spaces, and public transport to be more climate-responsive. ${ }^{113,114}$ This also entails mitigating effort to reduce air pollutants, which in turn reduces air quality related morbidity and mortality. ${ }^{115}$

\section{Floods and storms}

In general, adaptive measures to floods can be classified as structural or non-structural. Infrastructure such as reservoirs, dams, dykes, and floodways can be used to keep flooding away from people and property. In some areas there is also the possibility to incorporate floodable lowlying areas into the urban design that can be temporarily under water during an extreme event. Structural programmes are considered by many flood managers as a priority and are also the principal source of funds for efforts to control floods. However, the construction of flood control works may have a maladaptive effect, encouraging more rapid economic development of the flood plains, and hence ultimately increasing flood losses. ${ }^{116}$

Adaptation to flood risk requires comprehensive approaches (panel 3). Non-structural measures include flood insurance, development policies, zoning laws, flood-plain regulations, building codes, flood proofing, tax incentives, emergency preparedness, flood fore-casting, and post-flood recovery. ${ }^{16,121}$ Non-structural flood adaptation options aim to reduce flood damages and enhance the ecological functions of flood plains. Many opportunities to increase resilience to extreme weather events are found in improved planning, zoning, and the management of land use. These have the additional advantage of providing multiple co-benefits (see ecosystem-based adaptation below).

\section{Action for resilience to indirect impacts}

Adaptation to indirect effects poses difficult challenges to policy making due to complex causal chains and limited predictibility. ${ }^{122}$ These complex interactions can result in "surprises"- situations in which the behaviour in a system, or across systems, differs qualitatively from expectations or previous experiences. These indirect impacts pose serious obstacles for climate adaptation, especially where health responses require integrated and cross-sectoral interventions. ${ }^{123}$

\section{Food insecurity}

Food insecurity and its health impacts play out at the local level, but have clear links to drivers and changes at the national and international level. The compounded impacts of climate change and ocean acidification will affect both agricultural production and fisheries, including food availability and prices. ${ }^{124-126}$ Adaptation policies should consider agro-food systems and fisheries and aquaculture alike.

Resilience to increased food insecurity and price volatility is of great importance to human health. Food security could be enhanced while simultaneously ensuring the long-term ability of ecosystems to produce multiple benefits for human wellbeing (panel 4). Issues such as improved local ecosystem stewardship (see section on ecosystem-based adaptation), good governance, and international mechanisms to enhance food security in vulnerable regions are of essence. ${ }^{130,131}$ Even though the drivers of increased food prices and price volatilities are contested, investment in improved food security could provide multiple co-benefits and no-regret options. ${ }^{132,133}$

\section{Important adaptation options for food security action include:}

- Enhancement of food security through improved ecosystem based management and ecosystem restoration. Case studies show the benefits of implementing strategies to improve ecosystem management as a means to increase not only food security, but also to achieve other social goals. Examples include collaborative management of mangrove forests to promote conservation, mitigation of climate change and alleviation of poverty among people dependent on the mangroves and adjacent marine ecosystems. ${ }^{125}$ Such strategies require supportive institutions, 
partnerships, collaboration with farmers' innovation networks, and connections from sustainable farms to markets. ${ }^{129,131}$ Similar strategies have recently been explored for fisheries and aquaculture. ${ }^{134}$

- Increased investments in agricultural research and human capital are often raised as an important strategy to improve yields and long-term food security. ${ }^{131}$ Agricultural research and development (R\&D) has proven to have high economic rates of return. ${ }^{135}$ Innovative crop insurance mechanisms, new uses of information technology, and improved weather data also hold promise for increased agricultural production. ${ }^{136}$ Education in agricultural areas is critical to enhance the diffusion of technologies and crop management, and as a means to increase household incomes and promote gender equality. ${ }^{131,137}$

- Increased investments in rural and water infrastructure. Investment is essential for situations in which underdeveloped infrastructure results in poor supply chains and large food losses. Investments could boost agricultural production, reduce price volatilities, and enhance food security in the long term. The investments required in developing countries to support this expansion in agricultural output have been estimated to be an average annual net investment of US $\$ 83$ billion (not including public goods such as roads, large scale irrigation projects, and electrification). ${ }^{131}$

- Enhanced international collaboration. International collaboration is critical for food security in food insecure regions. Early warning systems, financial support, emergency food and grain reserves, the ability to scale up safety nets such as child nutrition schemes, and capacity building play a key part in emergency responses to food crises, and can be supported by international organisations. ${ }^{131,138}$

\section{Environmental migration}

Changes in human mobility patterns have multiple drivers, ${ }^{139}$ and range from large-scale displacement (often in emergency situations), to slow-onset migration (in which people seek new homes and livelihoods over a lengthy period of time as conditions in their home communities worsen). ${ }^{140}$ The efficacy of national and international policies, institutions, and humanitarian responses also influence whether people are able to cope with the after-effects of natural hazard in a manner that allows them to recover their homes and livelihoods. ${ }^{141}$

Displacement occurs when choices are limited and movement is more or less forced by land loss, for example due to extreme events. ${ }^{142}$ Population displacement can further affect health through increased spread of communicable diseases and malnutrition, resulting from overcrowding and lack of safe water, food, and shelter. ${ }^{143}$ Additional impacts on economic development and political instability could develop, generating poverty and civil unrest that will exacerbate the population burden of disease. ${ }^{1,143}$

Existing vulnerabilities will determine the degree to which people are forced to migrate. ${ }^{144}$ The availability of alternative livelihoods or other coping capacities in the affected area generally determines the scale and form of migration that may take place. Conflict undermines the capacity of populations to cope with climate change, leading to greater displacement than might have been the case in a more stable environment. Conflicts have also been shown to reduce mobility and trap populations in vulnerable areas, exposing politically marginalised populations to greater environmental risks. ${ }^{145}$

Migration from both slow and rapid-onset crises is likely to be immediately across borders from one poor country into another. Receiving countries could have few resources and poor legal structures or institutional capacity to respond to the needs of the migrants. Destination areas may face similar environmental challenges (eg, drought or desertification) and may offer little respite. In rural areas, drought particularly affects rural to urban migration. ${ }^{143}$ Urbanisation can be beneficial for health and livelihood, but also entails many risks. ${ }^{121,142}$ The social disruption provoked by migration can lead to a breakdown in traditional institutions and associated coping mechanisms. ${ }^{146}$ Furthermore, the lack of mobility and risks entailed by those migrating into areas of direct climate-related risk, such as low-lying coastal deltas, presents a further hazard. ${ }^{121}$ The mental health implications of involuntary migration are often down-stream effects, seen as a result of multiple interacting social factors (panel 5).

\section{No or low-regret policies to reduce environmental migration}

Effective public health and adaptation strategies to reduce environmental migration or reduce the negative impact of environmental migration should entail the coordinated efforts of local institutions, national and international governments and agencies. ${ }^{100}$ There are several no or lowregret practices that generate both short-term and long-term benefits if integrated with existing national development, public health and poverty reduction strategies.

1 Slowing down the rate of environmental change, including mitigation policies and reducing land degradation. ${ }^{121,154}$

2 Reducing the impact of environmental change through early warning systems, integrated water management, rehabilitation of degraded coastal and terrestrial ecosystems, and robust building standards. ${ }^{154,155}$

3 Promoting long-term resilience through enhanced livelihoods, increased social protection, and provision of services. These include ecosystem-based invest-ments, and processes that decrease marginalisation of vulnerable groups — eg, by increased access to health services.

\section{Limitations of migration as a means of adaptation}

Migration has been proposed as a transformational adaptive strategy or response to climate change. The policy response is often referred to as "managed retreat". ${ }^{121,156}$ With changes in climate, resource productivity, population growth, and risks various governments have now, as part of their adaptation strategies, engaged in planning to move settlement. ${ }^{33}$ As an example, five indigenous communities in Alaska have planned for relocation with government funding support. Research on experience of migration policy concludes that a greater emphasis on mobility within adaptation policies could be effective. ${ }^{100,156}$

Using migration as a strategy to cope with environmental stress might however create conditions of increased (rather than reduced) vulnerability. ${ }^{100,144,156}$ Even though migration is used as a strategy to deal with imminent risks to livelihoods and food security, many vulnerable lowincome groups do not have the resources to migrate in order to avoid floods, storms, and droughts. ${ }^{157}$ In addition, studies of resettlement programmes demonstrate negative social outcomes, often analysed as breaches in individual human rights. ${ }^{154}$ There are significant perceptions of cultural loss and the legitimacy, and success depends on incorporating cultural and psychological factors in the planning processes. ${ }^{158}$

\section{Dynamic infectious disease risks}

Interactions and changes in demographics, human connectivity, climate, land use, and biodiversity will substantially alter disease risks at local, national and international scales. ${ }^{159}$ For example, vector-borne infectious disease risks are affected by not only changing temperatures, but also sea level rise. ${ }^{160}$ The geographical distribution of African trypanosomiasis is predicted to shift due to temperature changes induced by climate change. ${ }^{161}$ Biodiversity loss may to lead to an increase in the transmission of infectious diseases such as Lyme disease, schistosomiasis, Hantavirus and West Nile virus. ${ }^{162}$ Infectious disease risks are dynamic and subject to multiple and complex drivers. Adaptation responses therefore must consider multiple uncertainties associated with dynamic disease risks, which include a focus on co-benefits, no regrets and resilience. ${ }^{113,163-165}$ 
Determinants of health, such as education, health care, public health prevention efforts, and infrastructure play a major part in vulnerability and resilience. ${ }^{166}$ Adapting to climate change will not only be beneficial in reducing climate change impacts, but also have positive effects on public health capacity. ${ }^{163}$ Furthermore, health improvements account for $11 \%$ of economic growth in low-income and middle-income countries. ${ }^{167}$ The UN Framework Convention on Climate Change (UNFCCC) estimates the costs of health-sector adaptation in developing countries to be US\$4-12 billion in 2030. However, the health consequences of not investing would be more expensive, and it is clear that there are several health impacts that we will not be able to adapt to. ${ }^{168}$

\section{One-health approaches}

These approaches involve collaboration across multiple disciplines and geographical territories to protect the health for people, animals and the environment. $70 \%$ of emerging infectious diseases are zoonotic ${ }^{169}$ and have multiple well-established links to poverty. ${ }^{170}$ They also pose considerable global risks (eg, avian influenza, Ebola). Effective responses to emerging infectious diseases require well-functioning national animal and public health systems, reliable diagnostic capacities, and robust long-term funding. Critical gaps are present in existing health systems, including poor reporting, severe institutional fragmentation, and deficient early response capacities. ${ }^{171,172}$

Zoonosis outbreaks are costly: the economic losses from six major outbreaks of highly fatal zoonoses between 1997 and 2009 cost at least US $\$ 80$ billion. ${ }^{173}$ Implementing a one-health approach is, by contrast, economically sensible: the World Bank values its global benefits at $\$ 6 \cdot 7$ billion per year. ${ }^{173}$ It provides no-regret options because investments will contribute to reduced vulnerability applicable across climate futures, and it enhances resilience by linking government and civil society partners, facilitating early warning and building capacities to respond to multiple disease risks.

\section{Surveillance and monitoring}

Strengthening the capacity of countries to monitor and respond to disease outbreaks is vital, as shown by the ongoing Ebola epidemic in West Africa. Climate-change adaptation for human health requires a range of data, including on health climate risks or vulnerabilities, and specific diseases related to climate change impacts. Information and data collected from public health surveillance or monitoring systems can be used to determine disease burdens and trends, identify vulnerable people and communities, understand disease patterns, and prepare response plans and public health interventions. ${ }^{174,175}$

\section{Health co-benefits from climate adaptation}

Even though many climate-related health effects are beset by uncertainties, policy makers and communities can prepare if they focus on measures that: 1) create multiple societal and environmental benefits; 2) are robust to multiple alternative developments, and 3) enable social actors to respond, adapt and innovate as a response to change. ${ }^{164,165}$

\section{Ecosystem-based adaptation (EbA)-co-benefits for indirect effects}

Ecosystem services contribute to human health in multiple ways and can act as buffers, increasing the resilience of natural and human systems to climate change impacts and disasters. ${ }^{155}$

Ecosystem-based Adaptation (EbA) utilises ecosystem services, biodiversity, and sustainable resource management as an adaptation strategy to enhance natural resilience and reduce vulnerability (covered in more detail in a forthcoming Lancet Commission on Planetary Health). ${ }^{176,177}$ Natural barriers can act as a defence against climatic and non-climatic events - eg, restoration of mangroves for protecting coastal settlements and conservation of forests to regulate water flow for vulnerable communities. ${ }^{17,179} \mathrm{EbA}$ is considered to be more cost effective than many hardengineered solutions, and thought to minimise the scope for maladaptation. ${ }^{155,180}$ It can be combined with engineered infrastructure or other technological approaches. EbA interventions can be effective in reducing certain climate change vulnerability as it provides both disaster risk reduction functions, and enables improvements in livelihoods and food security, especially in poor and vulnerable settings. ${ }^{181}$ However, the scientific evidence about their role in reducing vulnerabilities to disasters is developing, and the limits and timescales of EbA interventions need further evaluation. Drawbacks can include the amount of land they require, uncertainty regarding costs, the long time needed before they become effective, and the cooperation required across institutions and sectors. ${ }^{180}$

\section{Ecosystem-based adaptation in urban areas}

$\mathrm{EbA}$ also has the potential to yield benefits for highly urban areas, through the development of green infrastructure. ${ }^{180}$ The evidence comes mainly from the northern hemisphere, in high-income settings with a dense city core. In many cases enhancement of urban ecosystems provides multiple co-benefits for health such as clean air and temperature regulation. ${ }^{182} \mathrm{EbA}$ can further create synergies between adaptation and climatechange mitigating measures by assisting in carbon sequestration and storage, and enhancing various ecosystem services considered beneficial for human health. ${ }^{176,183}$ Trees are particularly considered to be efficient in reducing concentrations of pollutants, although the capacity can vary by up to 15 times between species. ${ }^{184}$

Green urban design can reduce obesity and improve mental health through increased physical activity and social connectivity. ${ }^{164}$ Increased neighbourhood green spaces reduces both morbidity and mortality from many cardiovascular and respiratory diseases and stress-related illnesses. ${ }^{31}$ Tree canopies have a higher albedo effect than other hard surfaces and can work to reduce the urban heat island effect, lowering heat mortality by $40-99 \% .{ }^{185}$ Whilst resulting in improved public health and community resilience, many of these measures will also act to mitigate climate change.

\section{Overcoming adaptation barriers}

Globally, relatively few national strategies bring climate change into public health decision-making processes. The health impacts of climate change are often poorly communicated and poorly understood by the public and policy makers. Barriers to health climate adaptation include competing spending priorities, widespread poverty, lack of data to inform adaptation policies, weak institutions, a lack of capital, distorted economic incentives, and poor governance. Here, we elaborate these barriers and discuss some ways to overcome them.

\section{Institutional collaboration}

Health-adaptation policies and programmes require engagement of numerous agencies and organisations, including government agencies, nongovernmental organisations (NGOs), informal associations, kinship networks, and traditional institutions. ${ }^{186}$ At the same time, institutional fragmentation, lack of coordination and communication across levels of government, and conflicts of interest between ministries are overly common. ${ }^{186,187}$ Strengthening institutions at multiple levels is vital, and institutional capacity needs-assessment and collaboration are critical for health adaptation to climate change. ${ }^{188}$ The support of bridging organisations, as well as partnerships through networks, are critical as a means to overcome fragmentation and improve collaboration, information flows, and learning. ${ }^{189}$

\section{Finance}

Lack of finance is commonly cited as a major obstacle to adaptation, especially in the poorest regions and communities. This might result in economic incentives for investment in adaptation appearing small, individuals or firms lowering initial costs by avoiding expensive adaptation 
technologies or options, and the fact that the long-term benefits of health risk reduction, health improvements, and other societal benefits (reduced public health care costs) are heavily discounted.

Community and informal networks may provide financial support, but regional, national, and international funds as well as private sector funding will be required for adaptation responses at a larger scale. ${ }^{190}$ To date, adaptation funding is inadequate compared to the risks and hazards faced. This is covered in more detail, in section 4 of the Commission.

\section{Communication}

Public awareness of the health risks of climate change, even from heatwaves and other extreme weather events, is currently low. ${ }^{191}$ Innovative media strategies are needed to enhance awareness of such risks and improve public adaptive skills and effectiveness. ${ }^{192}$ health professionals, being knowledgeable and trusted, are in a strong position to communicate the risks posed by climate change and the benefits of adaptation. ${ }^{102}$

\section{Monitoring indicators for adaptation to indirect impacts}

Several indicators can serve as proxies for investments in adaptation and resilience to the indirect health effects of climate change.

\section{National adaptation programmes of action}

National adaptation programmes of action (NAPAs) are designed for low-resource countries to communicate their most urgent adaptation needs to the UNFCCC for funding. ${ }^{193}$ Health projects are more often included in the NAPAs and they typically address current disease (eg, malaria) control issues. ${ }^{168}$ To this end, there is a need to provide ongoing assessment of the number of countries that integrate health aspects in their NAPA, as well as the extent to which health is integrated. This indicator should assess adaptation for both direct and indirect health impacts.

\section{Early warning systems}

This indicator should include the number of countries that have upgraded early warning systems for extreme weather events, climate-changesensitive diseases, food security, and migration movements. Early warning systems have proved to be a critical and co-beneficial investment and, if matched with response capacities, could help societies adapt more promptly to changing circumstances that affect human health.

\section{Ecosystem-based adaptation}

Investments in ecosystem based adaptation for both direct (eg, flood risk) and indirect (eg, food security, disease mitigation) health impacts could create multiple co-benefits and provide no-regret options for several of the indirect effects discussed above.

\section{Conclusion}

This section has outlined interventions available to enhance community resilience and adapt to the health effects of climate change. Many of these are no-regret options that could provide co-benefits across several dimensions including food security, disease prevention, and sustainability in general. Adaptation will provide both short-term and long-term benefits beyond human health. Effective adaptation requires institutional collaboration across levels, integrated approaches, appropriate long term funding, and institutions flexible enough to cope with changing circumstances and surprise. Urgent mitigation efforts must accompany the recommendations provided in section 2, a subject covered in section 3 of this Commission.

\section{Section 3: transition to a low-carbon energy infrastructure}

It is technically feasible to transition to a low-carbon infrastructure with new technologies, the use of alternate materials, changing patterns of demand, and by creating additional sinks for GHGs. This requires challenging the deeply entrenched use of fossil fuels. Any significant deployment to meet demanding $\mathrm{CO}_{2}$ targets will require the reduction of costs of mitigation options, carbon pricing, improvement in the research and development process and the implementation of policies and regulations to act as enabling mechanisms, as well as recognition of the strong nearterm and long-term co-benefits to health.

The technologies for reducing GHG emissions related to energy and many energy-related end-uses have been in existence for at least 40 years (table 2), and several key technologies have their roots deep in the 19th century. The technologies are available now. We have a reasonable grasp of their performance, economics and side-effects (unintended impacts). They treat the causes of the problem (fossil fuel GHG emissions) rather than the symptoms (climate change). Other technologies, such as those described under geo-engineering have a high degree of uncertainty as to their effectiveness and also their side effects. We view these technologies as being highly risky but also (at this time) unnecessary, as we have the tools needed to achieve emission targets to avoid catastrophic climate change. Geo-engineering is analogous to using unlicensed drugs to treat Ebola when public health and hygiene could have prevented the problem in the first place. It is also important to recognise that for an energy source to be renewable, it must satisfy a low-carbon requirement, and consider the use of scarce resources such as copper, silicon, and rare earth metals.

Public health has much to gain from the mitigation of short lived climate pollutants (SLCPs) such as methane, black carbon, hydrofluorocarbons, and tropospheric ozone. The benefits for health, climate change, and crop yields are covered in great detail in a report by WHO and the Climate and Clean Air Coalition. ${ }^{200}$

\section{Main sources of GHG emissions}

In 2010, annual global GHG emissions were estimated at $49 \mathrm{GtCO}_{2} \mathrm{e} \cdot{ }^{201}$ The majority (about 70\%) of all GHG emissions can be linked back to the burning of fossil fuel for the production of energy services, goods or energy extraction (figure 8). ${ }^{202}$ Global emissions from heat and electricity production and transport have tripled and doubled respectively since 1970, whereas the contribution from agriculture and land-use change has slightly reduced from 1990 levels. ${ }^{203}$

When upstream and electricity sector emissions are allocated on an end-use basis, most emissions (about 61\%) are related to the built environment (ie, buildings, transport, and industry). These emissions are related to providing services such as cooling and heat in buildings, power for lights, appliances, electronics and computing, and motive power for moving to and within largely urbanised places, while industrial manufacturing of products feeds into the built environment system through movement of goods, economic activity and employment.

\section{The global energy system}

We know that the global energy system is heavily dependent on the extraction, availability, movement, and consumption of fossil fuels, and this system shows vulnerabilities when stressed. For example, the 1972 Organization of the Petroleum Exporting Countries (OPEC) oil embargo (which resulted in a cut of global production by $6.5 \%$ over 2 months) or the first Persian Gulf War (which caused a doubling of global oil prices over 3-4 months) each caused major pressure on the access and security of global energy supplies. ${ }^{204}$ Furthermore, many of the world's largest actual and potential conventional oil reserves are in areas of historic volatility and civil unrest. ${ }^{205}$

Climate change poses a risk to the existing energy system. Under a changing climate, these vulnerabilities could result in disruption in both supply and production of power under extreme weather events, operations (eg, water availability for cooling towers), viability of infrastructure (eg, location of power lines or hydroelectric systems), impact on transmission (eg, high temperatures or wind damage), and higher demand for cooling and building system performance. ${ }^{206,207}$ 
The usefulness of fossil fuels relates to their power and energy density, portability, and relative cost compared with other forms of energy. These attributes have acted as challenges to the transition to low-carbon energy sources and vectors, such as renewable and nuclear electricity and hydrogen. Maintaining power supply based on intermittent electricity sources such as wind power is a complex system integration problem. ${ }^{208}$ Practical solutions will involve combinations of energy stores (hydroelectric, thermochemical), demand-side management, and the harnessing of geographical diversity with respect to demand and supply. Cross-continental power grids can play a significant part in reducing low-carbon systems costs because greater diversity of demand and supply reduces the need for expensive energy storage.

\section{The growth in energy demand}

Global energy demand has grown by 27\% from 2001-10, largely concentrated in Asia (79\%), the Middle East and Africa (32\%), and Latin America (32\%), but with near stable but high demand (on a territorial accounting basis) in the 1990 Organisation for Economic cooperation and Development (OECD) group of countries. ${ }^{203}$ China doubled its energy demand during this period and represented the single largest proportion of the global increase (44\%). ${ }^{209}$ Most global growth in energy was in coal (44\%) for use in electricity production, a dangerous reality for human health. ${ }^{210}$

Economic productivity has risen alongside global energy demand. Whilst fossil fuel-based energy demand has grown slowly in OECD countries since 1970, gains were made in GDP terms that were largely a result of de-industrialisation of the economy (largely exported to Asia). As a result, Asia has made a significant leap in energy consumption, emissions and GDP. The energy intensity of large global economies (ie, the USA, China, EU, India) have fallen progressively over the period of industrialisation. ${ }^{211}$ Figure 9 shows that economic gains need not be strongly coupled to $\mathrm{CO}_{2}$ emissions, though the association is partly obscured by the export of $\mathrm{CO}_{2}$ emissions. Moving energy-intensive industries offshore (most of which remain fossil-fuel powered) allows for territorial emissions to fall, but at the cost of increased emissions elsewhere.

Growth in demand for energy will probably continue over the coming 25 years, particularly in lower-middle and low-income economic regions, where most citizens lack access to safe and affordable energy. The growth in global per capita energy demand is linked to improvements in the standard of living in developing regions and directly supports development goals. Expected energy demand in non-OECD countries may double by 2035 (107\%) from 2010, while OECD countries may increase by $14 \%$ over the same period. ${ }^{209}$ However, this growth in demand will continue to directly benefit high-income regions through exported production of goods.

\section{Meeting our future energy needs}

Access to energy is a key enabler of economic development and social wellbeing. In recognition of energy being a key determinant of economic and social development, and of health and wellbeing, the UN has declared that 2014-24 is the UN Decade of Sustainable Energy for All. The world's population must be able to access clean forms of energy that can provide these basic needs, which can minimise the health burden from both direct exposure and indirect from future climate change risks. The Sustainable Development Goals (SDGs) have emphasised the role that energy plays in securing a sustainable future for a global 9 billion population by 2050, and has outlined four targets to support, which could act as progress metrics. The indicators measuring progress on the proposed SDGs for securing sustainable energy for all by 2030 include: ensuring universal access to affordable, sustainable, reliable energy services; doubling the share of renewable energy in the global energy mix; doubling the global rate of improvement in energy efficiency; phasing out fossil-fuel production and consumption subsidies that encourage wasteful use, while ensuring secure affordable energy for the poor. ${ }^{214}$

\section{The health burden of the current energy system}

Although linked to a historical transformation in health, a fossil-fuel-based energy system also imposes significant health burdens (figure 10). The direct burden occurs through emissions of particulates and solid wastes (coal, oil, gas, biomass), risk of flooding (hydroelectricity), accidents and injuries (all), and emission of radioactive materials (coal, nuclear). But as the main driver of anthropogenic climate change, an energy system based on fossil fuels will also have indirect effects through climate change and the increase in temperatures, extreme weather, heatwaves, and variable precipitation (see section 1).

The immediacy of this burden varies with the inertia built into the emission to exposure pathways and exposure to health-effect pathways. Compared with climate change, the locality and visibility of fossil fuel emissions are more apparent today as poor air quality and toxic discharges, such as smog in Beijing or Delhi. A coal-fired power plant will emit particulates that result in immediate exposure for the local population with consequent increased risk of developing respiratory disease and lung cancer. The exposure to emissions can result in immediate health effects for the local population, such as respiratory tract infections, or take many years or decades to have an effect. A coal-fired station will produce immediate $\mathrm{CO}_{2}$ emissions, but these emissions do not result in immediate health impact. Instead, GHG emissions that accumulate in the atmosphere over the long term will result in global climate change. The long-term nature of climate change means that these exposures build towards a more dangerous level. Another dimension is locality of the emissions-exposure, exposure-health effect pathways. Locally generated emissions will affect both the population surrounding the point of discharge and in some cases more widely, as in burning coal in north Asia. Climate change, however, will affect all areas to varying degrees.

The global increased use of energy per capita is highly related to considerable improvements in quality of life across much of the world. The majority of this energy use is derived from fossil-fuel use, but mainly coal. Coal's wide availability and economic attractiveness has made it the fuel of choice for use in power generation. The recent expansion of coal use, mainly in the newly industrialising countries, effectively reverses the global pattern through most of the 20th century towards less carbon intensive and less polluting fossil fuels-the progressive displacement of coal by oil, and of both by natural gas. However, the time when fuel switching could decarbonise the global economy sufficiently quickly to avoid dangerous climate change has almost certainly passed. It is increasingly difficult to justify large-scale investment in unabated gas-fired infrastructure. The dangerous impacts of coal on health from exposure to air pollution in the form of noxious particulates and heavy metals, the environmental degradation (eg, contaminating water courses and habitat loss) from the extraction and processing of coal, and the major contribution that burning coal and the release of GHGs has in changing the long-term climate almost certainly undermines the use of coal as a long-term fuel. Although the use of coal as a fuel source for power generation will be linked to economic growth and (sometimes precarious) improvements in quality of life, the risk that coal has on our global health through climate change and habitat loss means that moving to low-emission fuels in areas of high coal demand is a major part of the global low-carbon energy transition. Whilst the use of technologies such as carbon capture and storage (CCS) are consistently cited in reducing the impact of coal-based power generation, at present, these technologies have many major unknowns and are without substantial government investment or the use of carbon pricing.

One important strategy to protect against the health burdens of local and national energy choices, is to ensure that health impact assessments are built in to the planning, costing, and approval phases of a new project. By developing the tools and capacity to enforce this, policy makers can better understand the broader consequences of their decisions.

Actions, technologies, and health outcomes 
Actions that seek to mitigate climate change have the potential to be beneficial to health, both directly and indirectly. ${ }^{1,29}$ Across a number of sectors, the potential health benefits of switching to low-carbon technologies include a reduction in carbon emissions from power generation, ${ }^{215,216}$ improved indoor air quality through clean household cooking technologies in low-income settings and housing thermal efficiency in high-income settings, and lowered particulate-matter exposure from low-emission transport. ${ }^{217,218}$

Decarbonising the power supply sector holds both risks and benefits for health. The direct benefits centre on reducing exposu re to air pollutants from fossil-fuel burning. ${ }^{216}$ In the UK, the associated burden of air pollution from the power sector is estimated to account for 3800 respiratory related deaths per year. ${ }^{216}$ In China, air pollution is thought to result in 7.4 times more premature deaths from PM2.5 than in the EU. ${ }^{215}$ It has been estimated that current ambient concentrations of particulate matter led to the loss of about 40 months from the a verage life expectancy in China, but that this loss could be cut by half by 2050 if climate mitigation strategies were implemented. The risks to health from decarbonisation are more likely to be indirect; if the deployment and adoption of technologies that aim to reduce carbon emissions, reduce energy demand, or switch fuels are not undertaken with care, there are risks of unintended consequences through, for example, poor housing ventilation. ${ }^{219}$ Besides air quality, several links between climate mitigation practices and technologies and potential health benefits have been established (figure 11). ${ }^{220,221}$ Using active transport as an example, the shift from car driving to walking and cycling not only reduces the air pollutant emissions, but also increases levels of exercise, which in turn can lead to reduced risks of several health outcomes, including cardiovascular diseases, diabetes, and some cancers. ${ }^{218}$

The formal health sector itself also has a role to play in reducing its emissions. Hospitals and health systems, particularly in more industrialised settings, account for around 10\% of GDP and have a significant carbon footprint. While the full extent of health care's climate impacts is not known, emerging data confirms its significance and the need for mitigation strategies. For instance, the NHS in England calculated its carbon footprint at more than 18 million tonnes of $\mathrm{CO}_{2}$ each year- $25 \%$ of total public sector emissions. ${ }^{222} 72 \%$ of the NHS's carbon footprint is related to procurement and the remaining split between travel and energy use in buildings. ${ }^{223}$ In the USA, the health-care sector is responsible for $8 \%$ of the country's total GHG emissions. ${ }^{224}$ With among the largest sectoral purchasing power globally, the health sector could reduce its impact through the products it purchases and through investment in its infrastructure (ie, hospitals, ambulatory services, and clinics).

By moving toward low-carbon health systems, health care can mitigate its own climate impact, become more resilient to the impacts of climate change, save money, and lead by example. For instance, in South Korea, Yonsei University Health System is targeting reducing GHG emissions by $30 \%$ by 2020 . Energy efficiency measures saved the system $\$ 1.7$ million and reduced GHG emissions by 5316 tonnes of $\mathrm{CO}_{2}$ in 2011 alone. ${ }^{225}$ In the USA, Gunderson Health has increased efficiency by $40 \%$, saving $\$ 2$ million annually, while deploying solar, wind, geothermal, and biomass to significantly reduce its carbon footprint and end its dependence on fossil fuels. ${ }^{226}$ In England, the NHS Public Health and Social Care System has similarly committed to reducing their carbon footprint by at least $34 \%$ by 2020.227

Conversely, accounting for the health co-benefits of climate change mitigation, can help to bring down the overall cost of greenhouse gas mitigation. Jensen and colleagues have shown that the incorporation of health co-benefits of cleaner vehicles and active travel can make those mitigation practices cost effective. ${ }^{228}$ The health benefits of reducing methane emission in industrialised nations could exceed costs even under the least aggressive mitigation scenario between 2005 and 2030. ${ }^{229}$ For example, in the UK, retrofits aimed at improving energy performance of English dwellings have the potential to offer substantial health benefit over the long-term, providing ventilation to control indoor pollutants is installed (see appendix 2).

\section{Pathways to (GHG emissions reduction) pathways}

Over the last two centuries, the prevailing pattern of national development has involved dramatic increases in productive capacity, supporting transformations in nutrition and housing, underpinned by development of fossil-fired energy supply, conversion, and distribution systems. Three overlapping stages of development can be identified:

- Stage 1: typically low technology, relatively inefficient and with little regard for damage due to pollution and other externalities.

- Stage 2: locally clean. As countries become wealthier, they can afford to invest in the longer term and deal with the local health problems associated with burning fossil fuels.

- Stage 3: regionally and globally clean. This involves the development of energy systems that address transboundary pollution problems including that of anthropogenic climate change. Stage 3 is generally associated with high GDP and indices of public health.

Importantly, improvements in technology and efficiency have historically accompanied and assisted, but have not been primarily driven by the goal of pollution control. The patterns of development associated with stages 1 and 2 are complex and multi-dimensional, and stage 3 is unlikely to be different. Stages 1 and 2 have historically been associated with increasing income and health.

This pattern of development has resulted in emission of about $1600 \mathrm{GtCO}_{2}$ since 1870 , with a consequent rise in global mean temperature anomaly of $+0.85^{\circ} \mathrm{C}(1870-2010)$. To have a better than $66 \%$ probability of keeping the rise in global temperatures to below $2{ }^{\circ} \mathrm{C}$, cumulative greenhouse gas emissions from 2011 on would need to be limited to around $630-1180 \mathrm{GtCO}_{2}$,eq. ${ }^{201,230,231}$ At the current global emission rate, this budget would be used up in between 13 and 24 years.

The last 30 years of OECD data have shown that significant changes to global energy systems are possible. Indeed, the whole of the 20th century has been characterised by a succession of transitions in energy technologies. However, this process has not been inevitable and decisions on energy systems have been aligned with other national objectives - eg, enhanced security of supply or reduced air pollution. This suggests that the transition to low-carbon energy will need to be predicated on achieving multiple objectives, including climate change, health, equity, and economic prosperity.

Many trajectories that are consistent with such a budget (panel 6 shows those of the UK and China) are in principle possible. Such trajectories necessarily involve emissions in the second half of the century in the region of $90 \%$ lower than emissions between 2011-50.232 All would require an unprecedented global commitment to change, and none appears easy. To stabilise $\mathrm{CO}_{2}{ }^{-}$equivalent concentrations in the range $450-650$ ppm (consistent with $2-4^{\circ} \mathrm{C}$ of warming) will require the global emission rate to fall by between $3-6 \%$ per year, a rate that so far has only been associated with major social upheaval and economic crisis. ${ }^{25}$ Postponing deep cuts in emissions may allow for new policies and technologies, but at the cost of significant impacts (eg, for land use and food production) in the second half of the century.

\section{Achieving a $2^{\circ} \mathrm{C}$ warming target}

Many technologies exist or have been proposed to mitigate climate change. But they vary in their potential mitigation impacts, stages of development, costs, and potential risks. Table 2 summarises mitigation technologies. Among them are climate engineering approaches such as land and sea sequestration. Although these have significant potential, they carry significant risks, including the possibility of damage to ecosystems. It is currently uncertain that the necessary international consensus to allow the deployment of such technologies could be achieved. Energy efficiency improvement is considered as the least risky of the options, although on its own it is insufficient to achieve the necessary decarbonisation. ${ }^{233}$ 
Individual behaviour is an important factor that affects the end-user energy efficiency-eg, using high-efficiency heating and cooling systems, adopting more efficient driving practices, routine maintenance of vehicles and building systems, managing temperatures for heating, and hot water for washing. ${ }^{234,235}$ But behavioural changes are not so easily achieved and pose considerable risk as a mitigation strategy. The medical professions have decades of experience with attempts to induce mass changes of behaviour through health promotion. The most prominent campaigns have been targeted at alcohol consumption, smoking, diabetes, and obesity. The overarching lesson is that even when behaviour change yields direct personal benefits, amounting in some cases to a decade or more of life expectancy, it is extraordinarily difficult to achieve through persuasion. In practice, different societies favour divergent approaches to influencing behaviour, ranging from the economic, through the physical to the psychological. ${ }^{236}$

Technologies that have the greatest decarbonisation potential include nuclear power, offshore wind, concentrated solar power (CSP), and CCS. ${ }^{237,238}$ Solar photovoltaic (PV) and wind systems have been growing exponentially for decades (wind about $12 \%$ per year, PV about $35 \%$ ), with consequent reductions in costs due to learning and increasing scale of production and deployment, while both CSP and CCS have not yet been deployed at any significant scale and so cannot capture significant learning effects. CCS suffers from similar problems to nuclear-ie, large unit sizes, potential regulatory concerns, and long lead times, which means weak and delayed learning once deployment has begun. But CCS's additional disadvantage compared with nuclear and renewables is that while the latter decouple economies from the threat of future rising and volatile fossil fuel costs, CCS magnifies these threats. Even in the absence of carbon pricing, renewables and nuclear can be justified as a hedge against future increases in fossil fuel prices, whereas CCS cannot.

Attempts to understand the adaptation of the whole energy system in the context of rapid transitions to low- carbon emissions have been predominantly from the discipline of economics. Among these is the Deep Decarbonization Pathways Project (DDPP), which has developed pathways for 15 countries. ${ }^{230}$ Panel 6 provides an example of these technology pathways for the UK and China. Transforming the global economy in anything like the timescale implied by the above discussion requires unprecedented action in both industrialised and developing countries. The former will need to embark more-or-less immediately on $\mathrm{CO}_{2}$ reduction programmes with a high level of ambition. Developing countries will need to move directly from stage 1 to stage 3 (significantly reduced emissions with associated high GDP and indices of public health) probably with both capital and technical support from developed countries. Delayed emission reduction would lower the possibility to control climate change, raise costs and force the uptake of riskier and unproven mitigation technologies with increased risk of unintended consequences for human wellbeing and ecosystems. ${ }^{239}$

The range of unintended consequences when the technologies are administered to different systems is large, complicated, and in some areas poorly understood. Ultimately, rapid mass deployment of low-carbon technologies requires a better understanding of the drivers and barriers to delivery within different economic sectors, the scale and opportunity of deployment, and the setting and its cont ext including the actors and decision makers involved. The application of low-carbon technologies, their impact, deployment, and co-benefits must be maximised by understanding what works, where it works, and why it works. This understanding is particularly important to support emerging technologies that are yet to reach market-scale deployment. Three key drivers are required to support pathways to a low-carbon future: maximising the efficacy of low and zero carbon technologies, maximising the deployment of these technologies, and max imising and internalising the potential health co-benefits of decarbonisation.

\section{Maximising efficacy}

Although significant progress has been made in adopting clean technologies, the resulting impact on energy intensities and carbon emissions has been lower than expected. Barriers to adoption and deployment of mitigation technology include a lack of awareness and access to technical knowledge, segmentation and fragmentation within and amongst sectors, and financial disincentives. These barriers will be particularly acute in developing countries where the benefits of energy efficiency are not necessarily recognised and may be a lower priority compared to many other urgent issues, such as poverty eradication, public health improvement, and crime reduction; this may be further affected by a lack of means of communication. Furthermore, due to a lack of quantitative and reliable measurements of energy performance, many stakeholders are not aware of energy savings potential. We propose three actions to improve efficacy:

1 Understanding the direct and indirect impacts of technologies from an integrated technical, economic, social, health and cultural, and political perspective;

Gathering, evaluating, and reporting real-world evidence to support and guide development and implementation of mitigation strategy;

3 Put in place policies and regulations (such as reporting schemes, inspections, and benchmarks) to make performance visible within the market.

\section{Maximising uptake}

Minimum deployment of low-carbon technologies poses a significant risk to the transition to a low-carbon future. The International Energy Agency (IEA) has stated that nine out of ten low-carbon technologies that are essential for energy efficiency and decarbonisation are failing to meet their deployment objectives. Limited deployment, particularly early in the process, limits learning and constrains subsequent progress.

Inertia in the technology diffusion process within many sectors means that many off-the-shelf technologies today could take 20 years to achieve significant market penetration without incentives to support their uptake. Overcoming such inertia requires clear guidance on technology potential; robust data on technology performance, impact, and costs; detailed information on existing sectors and historic structures; removal of disincentives and perverse incentives; and strong regulations. For certain technologies, regulation can play a major part in accelerating deployment. Criteria for regulations to be effective in this role may be summarised as follows: that the goal of regulation should be unambiguous; that the technical nature of measures which will achieve the goal should be clear, and they should be easy to apply; that the technical nature of these measures should make it easy for the regulator to confirm that they have been implemented; that the total benefits should outweigh costs; and that both benefits and costs should be a small part of some larger economic transaction. ${ }^{240}$ Cities offer opportunities and challenges for technology deployment. For appropriate technologies, economies of scale are quickly achieved with population and economic densities supported by larger tax bases, deployment through existing services and a history of operating large scale infrastructure. Density intensifies local environmental problems (particulates, noise, etc), which can in turn make it politically possible to introduce local regulation favouring low-carbon technologies. Resulting niches and learning can then accelerate the development and wider deployment of key mitigation technologies. ${ }^{241}$

Development status is another important driver of deployment. The bulk of technology transfer occurs between developed countries who dominate the invention of technologies for climate mitigation. ${ }^{242}$ This does nothing to overcome the low availability of mitigation technologies in developing countries. Major barriers to technology transfer from developed to developing countries include insufficient local human capital and technology support capabilities, lack of capital, trade and policy barriers, lax intellectual property regimes in developing countries, and the potential lack of commercial viability of the technology itself. ${ }^{243}$ These barriers need to be overcome to enable countries seeking to achieve a high quality of life to tunnel from stage 1 to stage 3 . 
Mechanisms to support low-carbon technology uptake should include:

- Enacting policy regulations to improve deployment of technologies (such as incremental minimum performance standards or delivery obligations)

- Developing strong national-level commitments and sources of funds for investment in low-carbon infrastructure that is accessible to local delivery agents.

- Targeting decision makers who can achieve maximum on-the-ground change and uptake of technologies and changes in practices (ie, sector heads, mayors, and councils).

\section{Maximising co-benefits and avoiding unintended consequences}

Many low-carbon technologies provide benefits other than reducing greenhouse gas emissions—eg, increased energy security, improved asset values, improved air quality, greater disposable income, and improved health and comfort. Some low-carbon technologies are primarily deployed because of their co-benefits.

Low-carbon technologies inappropriately deployed can hurt the economic and social development of developing countries. The increased use of expensive low-carbon energy sources could delay essential structural changes and slow down the construction of much needed infrastructure. Higher energy prices can affect economic growth and exacerbate poverty and inequality. However, abstaining from mitigation technologies in developing countries carries the risk of lock-in into a high-carbon-intensity economy. ${ }^{244}$ In order to avoid such unintended consequences, a balanced strategy focusing on both human development and climate mitigation in developing countries is needed.

Mechanisms to maximise co-benefits should include:

- Developing compelling arguments for action that emphasise co-benefits (ie, health, quality of life, air quality, a creative and resilient economy).

- Putting in place national and international level mechanisms to support and encourage technology adoption (ie, carbon pricing).

- Putting in place policies and economic tools that can facilitate the technology transfer from developed countries to developing countries (ie, the importance of the Green Climate Fund).

\section{Conclusions}

Energy systems comprise some of the largest, most complex and enduring capital structures in modern economies. Decarbonisation and reducing energy demand is not a simple challenge of cleaning up pollutants or installing new equipment, it requires systemic transformations of energy infrastructures and associated systems. We need to put in place mechanisms that support the uptake of technologies in an effective manner (ie, support pathways to impact pathways or pathways to pathways). Finally, it should be noted that the full potential of mitigation technologies will only be achieved if the social and political systems around these technologies co-evolve to deliver carbon targets.

There is a clear and compelling need for the industrialised world to achieve faster and much deeper emission reductions than anything delivered to date. At the same time, industrialisation historically has been accompanied by rising greenhouse gas emissions (particularly $\mathrm{CO}_{2}$ ) up to income levels of \$10-15000 per capita. Some of the major emerging economies are already reaching such levels, with concomitant emissions; helping others to avoid doing so, or helping those (like India) still with huge challenges to lift hundreds of millions of people out of extreme poverty, will require international assistance.

Through a multipronged approach that advocates co-benefits, targets decision makers and puts in effective measures that are understood, it might be possible to make real progress towards meeting our emission reduction goals. These mechanisms represent a public health-style approach to developing and implementing mitigation strategies, with the end goal of many co-benefits.

\section{Section 4: financial and economic action \\ The total economic cost of fossil-fuel use}

Past failures to reduce GHG emissions mean that remaining within the required carbon budget is becoming progressively challenging. We are increasingly committed to a certain level of climate disruption, requiring adaptation measures to reduce the impact this is likely to have. Given that the world is already committed to some degree of climate change, and given too that the combustion of fossil fuels also emits a variety of other pollutants, the total external costs of burning fossil fuels (ie, those costs that are not included in the price of fossil fuels) may be expressed as shown in panel 7.

The optimum outcome of this formula is that which minimises $T E C_{\mathrm{ff}}$, computed over the time horizon of interest. Unfortunately, the state of knowledge now, or at any likely point in time in the future, does not permit such a dynamic optimum to be computed. The purpose of this section is to explore the estimates of these different cost categories that appear in the literature to draw conclusions regarding the extent of climate change adaptation and mitigation that should be attempted, and the policies that might be able to deliver it.

The question of what is optimum in economic terms (GDP or welfare per head) for a given level of carbon emissions and discount rate requires the computation of an optimal time path. What is optimum today (without regard for the future) will not be optimal if the future is to be taken into account. And of course the relation between low prevention costs now means very high treatment costs later, compared with high prevention costs now means lower treatment costs later will be subject to very great uncertainty. Higher uncertainty may mean that high prevention costs would be wasted. On the other hand, with higher uncertainty comes the increased probability that high prevention costs are not high enough. However, whatever the answers to these questions, models reviewed in the IPCC's Working Group III Fifth Asse ssment Report (AR5) indicate with sufficient certainty that more needs to be spent earlier rather than later if even a moderate value is given to the intermediate and long term future. ${ }^{201}$

\section{The health and related economic benefits of adaptation}

There are significant research gaps regarding the scientific evaluation of the health benefits of climate-change adaptation due to its highly diffuse and context-specific nature, with only scattered quantitative or semi-quantitative studies on the health costs and benefits of adaptation options. ${ }^{245}$ Monetising these costs and benefits is an even more difficult task. However, the studies that do exist present a strong message. Seven of the eight studies on the effectiveness of heatwave early warning systems reported fewer deaths after the systems were implemented. For example, in the summer of 2006, a heatwave in France produced around 2000 excess deaths - 4000 less than anticipated based on previous events. ${ }^{31}$ A national assessment attributed this to greater public awareness of the health risks of heat, improved health-care facilities, and the introduction of a heatwave early warning system in 2004. ${ }^{112}$ A Climate Forecast Applications Network developed in the USA had successfully forecast three major floods in 2007 and 2008 in Bangladesh 10 days in advance, allowing farmers to harvest crops, shelter animals, store clean water, and secure food before the event. ${ }^{246}$ Webster also strongly advocates the establishment of a network between weather and climate forecasters in the developed world, and research and governmental and non-governmental organisations in the less-developed world. ${ }^{246}$ According to his estimation, such a network could produce 10-15 day forecasts for south and east Asia for a wide range of hydrometeorological hazards (including slow-rise monsoon floods, droughts, and tropical cyclones) at an annual cost of around \$1 million, but 
with prevention of "billions of dollars of damage and protecting thousands of lives". To support assessments such as these, WHO Europe have prepared an economic analysis tool to enable health systems to calculate the health and adaptation costs of climate change, which was in turn tested in their study of seven European countries. ${ }^{247,248}$

\section{The health and related economic benefits of mitigation}

Unmitigated climate change presents serious health risks that could reach potentially catastrophic proportions. Mitigating climate change not only significantly reduces this risk, but can also yield substantial health co-benefits against contemporary circumstances.

Panel 8 illustrates the proportion of national GDP directed to heath care increasing with wealth, along with the proportion accounted for by government expenditures. This suggests that governments of high and increasing income countries should give significant priority to mitigating climate change to prevent detrimental health impacts, which could result in the need for significant extra health expenditures, from both governmental and personal finances. Indeed, the direct and indirect cost of existing pollution-induced illnesses alone is significant. The OECD estimates the cost of ambient air pollution in terms of the value of lives lost and ill health in OECD countries, plus India and China, to be more than $\$ 3 \cdot 5$ trillion annually (about $5 \%$ gross world product [GWP]), with India and China combined accounting for $54 \%$ of this total. ${ }^{251}$ Globally, and with the addition of indoor air pollution, this value is likely to be substantially higher (appendix 3 )

The European Commission has estimated that in the EU alone, reduced air pollution from policies to mitigate climate change could deliver benefits valued at $€ 38$ billion a year by 2050 through reduced mortality. From a broader perspective, the European Commission estimates that moving to a low-carbon economy could reduce the control costs of non- $\mathrm{CO}_{2}$ air pollutants by $€ 50$ billion by $2050 .{ }^{252}$ With an increase to $36 \%$ renewables in global final energy consumption by 2030 (from $18 \%$ in 2010), IRENA calculates up to $\$ 230$ billion of avoided external health costs annually by $2030 .{ }^{253}$ In addition, West and colleagues note that if RCP4.5 is achieved, annual global premature deaths avoided reach 500000 by $2030,1 \cdot 3$ million by 2050 , and $2 \cdot 2$ million by 2100 . Global average marginal benefits of avoided mortality are $\$ 50-380$ per $\mathrm{tCO}_{2}$, exceeding marginal abatement costs in 2030 and 2050. The greatest benefit is projected for east Asia, with 220 000-470 000 premature deaths avoided per annum by 2030 , with marginal benefits of $\$ 70-840 / \mathrm{tCO}_{2}-$ a range $10-70$ times that of the projected marginal $\operatorname{cost}^{254}$ (see appendix 3 for more about the cost of ambient air pollution in China). In the USA, Thompson and colleagues estimate that human health benefits associated with air quality improvements driven by $\mathrm{CO}_{2}$ mitigation policies can offset the cost of the policies by up to ten times. ${ }^{255}$

Mitigation actions have other health-related benefits. Policies in the transport sector that encourage active travel (eg, walking and cycling) produce significant reductions in cardiovascular disease, dementia, diabetes, and several cancers, in addition to reduced duration and severity of depressive episodes - all of which are linked to obesity and are costly to treat. ${ }^{218}$ For example, increased levels of active travel coupled with increased fuel efficiency in the UK's urban areas could lead to a net saving to public funds cumulatively exceeding $£ 15$ billion by 2030 , whilst achieving GHG reductions of over $15 \%$ in the private transport sector by $2030 .{ }^{228}$ Patz and colleagues have comprehensively reviewed the heath, environ-mental, and economic benefits of active travel. ${ }^{256}$

In many countries, climate-change mitigation through increased energy efficiency will have the benefit of reducing fuel poverty (a condition in which low-income households have to spend a high proportion of their income to keep warm or cool), and associated impacts on excess winter mortality, respiratory health of children and infants, and the mental health of adults. ${ }^{257}$ Nicol and colleagues estimated that improved housing in England alone could save the UK NHS more than $€ 700$ million per year in treatment no longer required. ${ }^{258}$ In addition, Copenhagen Economics estimates that improvements in housing energy efficiency in Europe would, alongside the production of direct energy and health-care savings, reduce public subsidies for energy consumption by $€ 9-12$ billion per year. ${ }^{259}$ Various other health and ancillary benefits exist. Appendix 4 provides information about a recently developed framework to quantity key co-benefits.

It is apparent both that societies spend very large sums on health care and that measures to mitigate climate change would directly reduce existing and projected damages to health from the combustion of fossil fuels, and associated costs. In fact, Markandya and colleagues estimated that in India, if the health benefits of reduced $\mathrm{PM}_{2.5}$ emissions alone, resulting from a 50\% reduction in $\mathrm{CO}_{2}$ emissions by 2050 (from 1990 levels) from electricity generation, were valued similarly to the approach used in the EU for air pollution, then they offset the cost of GHG emissions reductions in full. ${ }^{215}$ As such, a significant proportion of expenditures for climate-change mitigation (and adaptation) may legitimately be seen as offsetting health expenditures, existing or anticipated, or even put forward itself as expenditure on the treatment and prevention of ill health. If a large part of the costs of climate-change mitigation and adaptation is offset by improved health of the existing population, and if unabated climate change is itself a major health risk, investment in such actions is clearly an attractive and sensible proposition.

\section{Investment required for mitigation and adaptation}

In industrialised countries, large-scale investment in energy systems is required simply to maintain existing services as infrastructures age and need to be replaced. Emerging and developing economies will require very large energy system investments to meet growing demand as they develop and to provide increasing proportions of their populations with access to modern energy services. It is estimated that such business-asusual investments will total around $\$ 105$ trillion between 2010 and 2050, with average annual investment requirements rising rapidly over time. ${ }^{260}$ However, this value excludes the costs of climate damage to the energy system or resilience measures to reduce it. Such costs could be significant.

The IEA estimates that to achieve a trajectory that produces an $80 \%$ chance of remaining on a $2^{\circ} \mathrm{C}$ stabilisation pathway, additional cumulative investment of $\$ 36$ trillion in the energy system is required by 2050 -roughly $\$ 1$ trillion per year (in the order of $1 \%$ GWP under moderate growth assumptions or about $10 \%$ of existing expenditure on health care), although recent estimates from the New Climate Economy report suggest that this value may be a much reduced $\$ 270$ billion per year. ${ }^{260,261}$ The insurance premium represented by this additional investment is very modest in relation to the potential costs that are being avoided, even without the offsetting health and other co-benefits such as those described above. To achieve both the requisite level of decarbonisation whilst meeting increasing global demand for energy, the IEA estimates that investments in low-carbon technologies and energy efficiency must account for around $90 \%$ of energy system investment by $2035 .{ }^{262}$ Currently, this value is around $23 \%{ }^{262}$

Estimates for the investment required for adaptation measures to protect against climate impacts to which the world is already committed are limited. The most comprehensive global estimate thus far was produced by the World Bank (2010), which estimates the annual global cost of adaptation even on a $2^{\circ} \mathrm{C}$ trajectory to be $\$ 70-100$ billion by $2050 .{ }^{171}$

Estimating existing expenditure on adaptation actions is not much easier than estimating the possible future costs of adaptation. Buchner and colleagues $^{263}$ estimate that in 2012 , about $\$ 22$ billion was invested in activities with an explicit adaptation objective. However, the lack of common agreement on what constitutes an adaptation measure over other investment classifications and objectives mean understanding of existing financial flows to adaptation measures is poor. Even so, whilst the magnitude is difficult to determine, it is reasonable to conclude that existing financial flows for climate change adaptation are not sufficient to match long-term requirements, even for impacts resulting from current and past emissions. 


\section{The macroeconomic impacts of climate change}

Attempts to estimate the marginal social cost of $\mathrm{CO}_{2}$ emissions in the absence of mitigation or adaptation measures have produced an extremely wide range of results, spanning at least three orders of magnitude. ${ }^{264}$ Table 3 illustrates the multifaceted, diverse, and potentially extreme nature of the impacts involved.

The IPCC's AR5 chapter on impacts, adaptation and vulnerability estimates an aggregate loss of up to $2 \%$ GDP if global mean temperatures reach $2 \cdot 5^{\circ} \mathrm{C}$ above pre-industrial levels. ${ }^{266} \mathrm{~A}$ world of unabated $\mathrm{GHG}$ emissions, what might be called a business-as-usual pathway (in which a global mean temperature increase is likely to far exceed $2.5^{\circ} \mathrm{C}$, and in which many of the kinds of impacts in the last row and column of table 3 are likely to be experienced) could produce costs equivalent to reducing annual GDP by $5-20 \%$ now, and forever, compared with a world with no climate change, according to the Stern Review on the Economics of Climate Change. ${ }^{267}$

It may be noted that these costs are the result of a low discount rate, the validity of which has been questioned. ${ }^{268}$ However, the relevant point here is that the physical impacts underlying the upper range of these costs represent a substantial risk to human societies-what Weitzmann ${ }^{269}$ has called the "fat tails" of climate-risk distributions. The costs of mitigation may be seen to represent a premium paid to reduce these risks and, hopefully, avoid the worst climate outcomes entirely. In any case, even these large costs derive from economic models built upon climate science and impact models, which themselves necessarily cannot fully characterise all processes and interactions known to be of importance. ${ }^{270}$

\section{The macroeconomic impacts of responding to climate change}

The theoretical microeconomics position on the balance to be struck between mitigation and adaptation is clear-there should be investment in mitigation up to the point where the marginal cost of further investment is higher than the marginal cost of adaptation plus that of remaining climate damages. In practice, the robust identification of this point is impossible, because of the uncertainty of the costs concerned and how they will develop over time, the difficulties of valuing non-market costs, and the lack of consensus over the appropriate discount rate for such costs, when they are incurred over long and varied time periods. ${ }^{271}$ Given that some climate impacts (such as the phenomena in the bottom-right corner of table 3) cannot be adapted to at any computable cost, mitigation-focused investment would seem to be the prudent priority at a global level. In a globally interdependent world, even regions that might be less negatively affected by climate change itself, could expect considerable economic and social disruption from those regions that were thus affected.

The macroeconomic impacts of reducing $\mathrm{CO}_{2}$ emissions derive from several sources, all of which need to be taken into account if the overall impact is to be properly evaluated. First, there are the impacts of the various kinds of investments discussed above. Investments in energy efficiency measures and technologies are often cost effective at prevailing energy prices, and there is substantial evidence that opportunities for such investments are considerable. ${ }^{272}$ Such investments will themselves tend to increase GDP. Investments in low-carbon energy that are redirected from fossil fuel investments will, where the low-carbon energy is more expensive than fossil fuels and leaving out considerations of avoided climate change and co-benefits, tend to reduce GDP. However, if fossil fuel prices increase from their currently relatively low levels and remain volatile, and the capital costs of renewables (especially solar and wind) continue to fall, then at some point renewable electricity may become economically preferable to fossil-fuel derived power, irrespective of other factors.

Investments in low-carbon energy that are additional- — such as the extra $\$ 1$ trillion required annually as identified above-may increase or reduce GDP depending on whether they employ unutilised resources or, in a situation of full employment, crowd out more productive investment, and whether they can build domestic supply chains and new competitive industries that can substitute for imports. Whilst employment in fossil fuel-related and emission-intensive industries would decline over time, low-carbon technology industries would expand and increase employment. IRENA estimate a net global increase of 900000 jobs in core activities alone (i.e. not including supply chain activities), if the level of renewable energy in global final energy consumption doubles from $18 \%$ in 2010 to $36 \%$ of by $2030 .{ }^{253}$ Advantages may accrue to those countries or industries that begin investment in decarbonisation quickly, by gaining technological leadership through experience and innovation, affording the first mover a competitive edge in a growing market.

For fossil-fuel importing countries, investment in indigenous low-carbon energy sources will reduce the need to import fossil fuels. In the EU, the trade deficit in energy products in 2012 was $€ 421$ billion (3.3\% EU GDP), ${ }^{273}$ and is projected to rise to $€ 600$ billion (in 2010 euros) by 2050 , as the EU's dependence on foreign fossil fuels increases. ${ }^{274}$ Low-carbon investments that reduce the need to import fossil fuels are macroeconomically beneficial, with the value of these trade effects in the future being uncertain and dependent on the price of oil and other fossil fuels. Such uncertainty is itself a cost, which is amplified when allied with price volatility - a common characteristic of fossil-fuel markets.

\section{Possible sources of finance}

In the public sector (aside from the extensive resources to be found in local, regional, national, and supranational government budgets), sovereign wealth funds, as of August 2014, held over $\$ 6 \cdot 7$ trillion in assets. ${ }^{275}$ However, in the private sector, institutional investors held a global total of $\$ 75.9$ trillion in assets under management in 2013 (this includes $\$ 22.8$ trillion with pension funds, $\$ 24.6$ trillion with insurance companies, and $\$ 1.5$ trillion in foundations and endowments). ${ }^{276}$

Institutional investors are likely to be critical sources of finance for mitigation and adaptation due to the scale of resourc es available and the presence of long-term investment obligations. However, only $0 \cdot 1 \%$ of institutional investor assets (excluding sovereign wealth funds) are currently invested in low-carbon energy infrastructure projects ( $\$ 75$ billion). ${ }^{277}$ Commercial banks are also a key source of finance and are one of the main existing sources of renewable investment capital. The resources held by non-financial companies are also extensive, with the largest 1000 such companies estimated to hold $\$ 23$ trillion in cash reserves. ${ }^{278}$

International financial institutions (IFIs) such as the Bretton Woods institutions and other multilateral development banks (MDBs), multilateral finance institutions (MFIs), and regional investment banks (RIBs), whilst not holding collective assets to match those above, are also leaders in existing mitigation and adaptation finance, and are likely to be key in building a low-carbon economy in developing countries; their mandates are explicitly focused on development and poverty reduction promoted through low-interest, long-term loans-suitable for large infrastructure projects. Existing dedicated funds for climate-change mitigation and adaptation under the UNFCCC, such as the Green Climate Fund (GCF), are also important resources. The GCF, established by the UNFCCC in 2010 and launched in 2013, aims to raise $\$ 100$ billion of new and additional funding per annum from industrialised nations, by 2020 (from both public and private finance), to support mitigation and adaptation pathways in developing countries. In 2012, $\$ 125.9$ billion of official development assistance (ODA) was delivered by donor countries, equivalent to $0 \cdot 29 \%$ of their combined gross national income (GNI). Were states to meet their ODA commitments of $0.7 \%$ of GNI, another $\$ 174 \cdot 7$ billion would be mobilised. ${ }^{279}$

\section{Enabling architecture and policy instruments}

The mobilisation of such financial resources requires robust policy-generated incentive frameworks, under-pinned by credible political commitments. By the end of 2013, 66 countries had enacted 487 climate mitigation and adaptation-related laws (or policies of equivalent status), with a rich diversity of approaches. ${ }^{280}$ The Stern Review considered that a policy framework for $\mathrm{CO}_{2}$ abatement should have three elements: carbon pricing, technology policy, and the removal of barriers to behaviour change. ${ }^{267}$ This three-part classification maps closely to three policy 
pillars, which in turn correspond to three different domains of change. ${ }^{265}$ Figure 16 illustrates this framework, which can be applied to develop both mitigation and adaptation policy.

Each of the three domains reflects three distinct spheres of economic decision making and development. The first, satisficing, describes the tendency of individuals and organisations to base decisions on habit, assumptions, and rules of thumb, and, to some extent, the presence of psychological distancing (discussed in section 5). Such occurrences are the subject matter of behavioural and organisational economics, which can explain the significant presence of unutilised opportunities for already cost-effective energy efficiency measures. The first pillar of policy, standards and engagement, seeks to address these issues, resulting in firms and individuals making smarter choices. The second domain, optimising, describes the rational approach that reflects traditional assumptions around market behaviour and corresponding theories of neoclassical and welfare economics. The second pillar of policy, markets and pricing, seeks to harness markets, mainly acting through producers rather than consumers, to deliver cleaner products and processes. The final domain, transformation, uses insights from evolutionary and institutional economics to describe the ways in which complex systems develop over time under the influence of strategic choices made by large entities, particularly governments, multinational corporations and institutional investors. The third pillar of policy arising from such analysis seeks to deliver strategic investment in low-carbon innovation and infrastructure. ${ }^{265}$

Each of the three domains and policy pillars, whilst presented as conceptually distinct, interact through numerous channels. For example, as figure 16 illustrates, whilst the impact of each policy pillar is strongest in one domain, each of the pillars of policy have at least some influence on all three domains. All three pillars of policy have an important role in producing a low-carbon global energy system. ${ }^{265}$

\section{Standards and engagement}

Energy efficiency standards may take many forms. However, all act to push a market, product or process to higher levels of efficiency (or lower levels of emission intensity), through regulation. Such regulations help to overcome market failures such as split incentives, a prominent example of which is the landlord-tenant problem, when the interests of the landlord and tenants are misaligned. The problem arises because, whilst the installation of energy efficiency measures would benefit the energy bill-paying tenant, savings do not accrue to the landlord who therefore has no incentive to bear the cost of installing such measures. Instead, standards can require their installation, or other measures to induce the same effect.

The main typologies of standards relating to mitigation are $\mathrm{CO}_{2}$ intensity standards, energy intensity standards and technology standards. The first two specify a target limit for specific $\mathrm{CO}_{2}$ emissions or energy consumption. Examples are a cap on $\mathrm{CO}_{2}$ emissions from passenger cars per kilometre driven (based on the average rating for all cars sold per manufacturer), or on the annual energy consumption of a new building per unit of floor area. Both such policies (and variants) have been successfully implemented in the EU and around the world, and have proven effective. Technology standards may act in a similar manner to $\mathrm{CO}_{2}$ or energy intensity standards, but may also proscribe the use of certain components in products, or prevent the sale of the least efficient models of a product type. Such standards may be applied with a legal basis, or through the use of voluntary agreements. Standards may also be applied to produce adaptation actions, for example by amending building codes to obligate developers to incorporate resilience measures in new construction.

Processes and mechanisms for targeted communication and engagement between governments, businesses, other organisations, communities and individuals help to overcome issues of psychological distancing, motivational issues, split incentives and information asymmetry, and act to pull the market towards higher efficiency, lower emissions and greater resilience. Such mechanisms can take many forms and include training and education campaigns, but also labelling and certification, public reporting and other information disclosure and transparency measures. All these approaches act to provide consumers and investors with information surrounding environmental performance of a product, service, process or organisation at the point of use, or across the product lifecycle or organisational operations and supply chain, in order to help them to make informed decisions regarding investments and purchases. This encourages organisations to mitigate risks by reducing organisational (and possibly supply chain) emissions and to invest in adaptation measures to improve resilience, ensuring they retain a strong customer base and remain a safe investment. The introduction of these instruments may also reveal opportunities for efficiency measures that have an economic rationale independent of environmental considerations.

\section{Markets and prices}

The Stern Review called the market externality of GHG emissions in the global economy "the greatest and widest-ranging market failure ever seen". ${ }^{267}$ Carbon pricing is the economist's preferred means to address this externality. Such pricing may be achieved through national or regional explicit carbon taxes or cap-and-trade emissions trading systems (ETS), which are increasingly present around the world. A carbon tax sets the carbon price directly, but not the level of abatement, whilst an ETS sets the level of abatement, but the price derives from the carbon market. Regardless of the pricing mechanism, market actors may be expected to factor the existing and expected carbon price into short-term operational and long-term investment decisions. Figure 17 summarises the state of pricing mechanisms around the world. As of June 2014, around 40 national and over 20 subnational jurisdictions were engaged in carbon pricing of varied scope and instrument design, covering about $12 \%$ of annual global GHG emissions (the Australian ETS was discontinued in July 2014). ${ }^{281}$ The largest ETS is the European ETS, established in 2005 , and capping more than $40 \%$ of annual GHG emissions from power generation and energy-intensive and emission-intensive heavy industry across the EU-28 (plus Norway, Iceland, and Lichtenstein). This is followed in scale by the aggregate of the seven ETS pilot schemes in China, described in appendix 5. As of 2014, the total value of all explicit pricing mechanisms was around $\$ 30$ billion. $^{281}$

For sectors of the economy for which explicit carbon pricing is infeasible or administratively burdensome, taxes on energy products (such as transport fuels) could be realigned to reflect their carbon content (producing an implicit carbon price) By implementing Environmental Tax Reform (ETR) principles, in which the burden of taxation increases on environmentally damaging activities and is reduced on desired inputs, such as labour, the increase in energy prices can be neutralised from a macroeconomic perspective. Parry and colleagues estimate that corrective taxation that internalises $\mathrm{CO}_{2}$ emissions, local air pollution, and additional transport-related externalities (such as congestion and accidental injury) arising from coal, natural gas, gasoline, and diesel, could raise additional revenues of $2.6 \%$ GDP globally, whilst simultaneously reducing $\mathrm{CO}_{2}$ emissions by $23 \%$ and pollution-related mortality by $63 \% .{ }^{282}$ If this revenue was used to offset labour taxation (eg, by a reduction in payroll or other corporate taxation), revenue neutrality is achieved whilst producing a double dividend effect of employment, as well as environmental improvement. ${ }^{283}$ Alternatively, carbon pricing mechanisms can be used to finance, subsidise, or otherwise incentivise investments into other mitigation and adaptation measures, as discussed below.

In addition to pricing pollution, distorting subsidies for the extraction and consumption of fossil fuels should be removed. For consumers, such subsidies (aimed at providing energy at below market price, and principally applied in developing countries) total around $\$ 400$ billion annually, ${ }^{284}$ whilst producer subsidies (aimed at sustaining otherwise uncompetitive production, principally applied in industrialised countries), are around $\$ 100$ billion annually. ${ }^{285}$

Both fossil-fuel subsidies and the presence of externalities tend disproportionately to benefit the wealthiest in society (in both national and international contexts), as energy consumption (and associated emissions) increases with prosperity, both directly (eg, via additional travel 
demand, domestic heating and cooling requirements) and indirectly through additional consumption of energy embodied in products and services. Globally, an estimated $80 \%$ of such subsidies actually benefit the wealthiest $40 \%$ of the population. ${ }^{286}$ However, the introduction of carbon pricing and the removal of fossil fuel subsidies may be regressive, as the poorest in society spend a greater proportion of their disposable income on energy. Reduced taxation of the low paid may partly offset this in industrialised economies, although further targeted support, such as the provision of energy efficiency measures for low-income or vulnerable households (funded by carbon price revenues and foregone subsidy), or the introduction of electricity tariffs differentiated by consumption level, is also likely to be required. In developing countries where most consumer fossil-fuel subsidies are provided, and where a greater proportion of the population is not employed in the formal economy or have no access to electricity, more targeted interventions to remove disproportionate effects on low-income households, such as the expansion of social security, health care, and education provision, will be required.

\section{Strategic investment}

Whilst a price on carbon is a key component for mitigation, it is technologically agnostic and mainly encourages the adoption of mature lowcarbon technologies. To encourage deployment, improvement and cost-reduction of less mature technologies, direct investment is also required. Although various options exist, Feed-in tariffs (FiTs), used in the electricity sector to provide a guaranteed rate of return to low-carbon generators, have been the most effective policy instrument used for this purpose, and have been responsible for a significant majority of installed global renewable power capacity (appendix 6). A FiT-style instrument may also be used to encourage the deployment of non-electric renewable technologies, including heating and cooling options.

However, FiTs and comparable instruments only encourage diffusion and incremental improvements for technologies around the end of the innovation chain (market accumulation and diffusion). For technologies in the earlier stages (applied research to demonstration and commercialisation), concerted R\&D efforts are required, comparable to public and private pharma-ceutical research that has been shown to produce innovative new drugs. ${ }^{287}$ Such efforts may be analogous to the Manhattan Project for nuclear technology, or the Apollo Program for space flight, but focused perhaps on energy storage technologies, which are often seen as crucial for the effective decarbonisation of the global energy system.

Public-led strategic investment is also required in urban low-carbon travel infrastructure (eg, segregated cycle lanes), along with investment in electric-car charging points. This also applies to the electricity transmission network, which is under state ownership in most countries. Such investments may be financed in a number of ways, including directly by governments, multilateral organisations, or other public bodies, through the use of carbon pricing revenues or by the issuance of specialised climate bonds (appendix 7).

\section{Institutional reform and support}

Beyond the appropriate selection of policy instruments and timeframes for implementation, investments in decarbonisation and adaptation measures will depend on the existence of effective and supportive governance and well-functioning markets. Good governance requires the well-defined division of responsibilities between govern-ment departments, agencies and hierarchies, enforcement of standards and regulations, transparency at key stages of the regulatory process and subsequent monitoring and reporting, and effective communication and stakeholder engagement. Additionally, governments are often the largest consumer in the market, with public spending accounting for 15-30\% of GDP in any given country. ${ }^{288}$ Sustainable public procurement (SPP) policies act to provide a market for efficient, low-carbon goods and services.

Governments may promote well-functioning markets through the kinds of policies described above, and by reducing institutional barriers to low-carbon investment and innovation. For example, many pension funds across the world are barred from investing in infrastructure, including all in China (except the National Social Security Fund) and many in the EU. Whilst these regulations aim to alleviate legitimate concerns (such as preventing pension funds from becoming an extension of government budgets), they are often excessive and increasingly irrelevant as funds gradually become independent of political interference. ${ }^{276}$ Reform of such rules is essential in mobilising capital from institutional investors, irrespective of the policy and incentive mechanisms in place to encourage investment in developing the low-carbon economy.

\section{Section 5: delivering a healthy low-carbon future}

Central to this Commission's work is the question of whether human societies can deliver a healthy, low-carbon future. Sections 1 and 2 have explained the scientific basis for concern, the potential health dimensions of impacts, and the adaptation responses required. Sections 3 and 4 have demonstrated the technological and economic feasibility of tackling the problem. Yet over the past decade, global emissions have still risen sharply. The evidence to date of humanity's ability to respond effectively is not encouraging. The difficulty, essentially, is ourselves: the tendency of humans to ignore or discount unpleasant facts or difficult choices (something familiar to doctors); the nature of companies and countries to defend their own rather than collective interests (something familiar to those working in global health); and the narrow, short-term horizons of most human institutions, which feed into the difficulties of global negotiations.

Over the past century, the world has made enormous strides in overcoming similar obstacles in the field of health, with international cooperation on health challenges as a shining example. The problem of anthropogenic climate change is more recent, arguably more complex, and the efforts to tackle it more nascent. But there are some promising developments, and a great deal can be learned by examining the history of efforts to date.

One conclusion evident throughout our report is that much of the technical expertise, technology, and finance required to tur $\mathrm{n}$ climate change from a public health threat into an opportunity is readily available, but politically restricted. In essence, whether we respond to "the biggest global health threat of the 21 st century" is no longer a technical or economic question-it is political. This section analyses the politics of climate change and provides suggestions for action. We examine the international regime (under the UN Framework Convention on Climate Change and its Kyoto Protocol); national policy responses; the role of sub-national governance processes, particularly in major cities; and the importance of individuals and public opinion. Importantly, we stress the need for better synergy between top-down and bottom-up approaches. We seek to draw lessons from global health governance mechanisms, and make suggestions for how health-related issues can inform the climate change negotiation process.

\section{Three phases of response-the international regime}

It is almost 30 years since climate change emerged onto political agendas, with three phases of response since then, of roughly a decade each.

\section{First phase: understanding the evidence and establishing institutions and broad goals}

The first phase established the institutional basis for responding to climate change, including for scientific input into policy processes. Building on long-held concerns of the scientific community, a series of international workshops in the mid-1980s, hosted by the World Meteorological Organisation and the UN Environment Programme, led governments to establish the IPCC in 1988, as the official channel of scientific advice to the international community. In 1990, the IPCC's first report expressed enough concern for governments to formally launch international negotiations aimed at tackling the problem, and 2 years later to agree on the UNFCCC. The UNFCCC now enjoys almost universal membership. 
The UNFCCC established the "ultimate objective" of stabilising GHG concentrations at a level that would prevent dangerous human interference in the climate system (UNFCCC, article 2). This objective has been recently interpreted as implying that global temperatures should not rise more than $2^{\circ} \mathrm{C}$ above pre-industrial levels, an aim reiterated in frequent statements under the UNFCCC and other international fora, such as the G8. The $2^{\circ} \mathrm{C}$ goal implies a need to roughly halve global emissions by 2050; stabilising the atmosphere at any level ultimately means bringing net emissions (emissions minus removals from forests, oceans, and other carbon sinks) to zero.

The UNFCCC established that industrialised countries would take the lead in curbing GHG emissions, setting them a non-binding goal of returning their emissions to 1990 levels by 2000. All parties, including developing countries, were given general commitments to address climate change, as well as reporting obligations. The UNFCCC also set up a raft of institutions to monitor implementation and pursue ongoing negotiations, under the auspices of the main decision-making body, the Conference of the Parties (COP).

Health concerns feature, albeit in general terms, in the UNFCCC, which lists impacts on human health and wellbeing as part of the adverse effects of climate change (definitions, article 1). The only other reference requires parties to consider the broader implications of their mitigation and adaptation actions on human health. ${ }^{289}$

\section{Second phase: leading through top-down international commitments}

In 1995, governments accepted the findings of the IPCC's second report and launched negotiations to strengthen the UNFCCC's commitments. The working assumption was that the international response would be led by specific, binding emission targets for industrialised countries, which would then be implemented at a national level. This was the approach adopted in the Kyoto Protocol of 1997, which built mainly on designs proposed by the USA under President Clinton.

However, the fact that developing countries were not subject to any such specific commitments weakened the Protocol's short-term impact and undermined its political viability, particularly in the USA, where strong political forces were opposed to any robust action on climate change. The subsequent US repudiation of the Kyoto Protocol made it clear that the Kyoto-type top-down model was unworkable in these circumstances as the principal way forward.

\section{Third phase: bottom-up initiatives}

Global negotiations continued, but with widely varying objectives and perceptions. Whilst the EU and developing countries continued to support a Kyoto-style approach with specific targets, few others believed that to be feasible, or even appropriate. Academics and commentators increasingly argued that action happens from the bottom up, not in response to binding top-down commitments, and pointed to a wide range of initiatives, including at state level in the USA, to argue that a fundamentally different approach was needed.

These divergent views came to a head at a summit in Copenhagen in 2009, which collapsed in acrimony save for two pages of unofficial outline text hammered out as a fallback compromise, initially between the USA and major emerging economies. The so-called Copenhagen Accord did register some landmark achievements, notably confirming the $2^{\circ} \mathrm{C}$ goal, and a promise to raise $\$ 100$ billion per year of international finance by 2020 to help developing countries deal with climate change. In terms of emission commitments, however, there were no binding targets; instead, the Copenhagen Accord called on countries to declare domestically-generated voluntary pledges of what they might deliver. Since then, almost all major emitters have registered pledges, although based on varying indicators and with very different levels of precision and ambition.

Negotiations in Durban in 2011 saw the launch of a new round of talks aimed at agreeing a universal framework to deal with climate change from 2020. According to the so-called Durban Platform, this new agreement should be applicable to all parties, and "raise the ambition" of the international community.

\section{Patchy progress in the negotiations}

If global emission trends are the only indicator of progress, the results of the negotiations to date have been dismal. The 2014 IPCC report warned that global emissions since 2000 have been rising ever faster at around $2 \%$ every year, powered largely by spectacular growth in China, and other emerging economies. ${ }^{201}$ Viewed more closely, the picture is more nuanced. Taken together, the industrialised countries did meet the UNFCCC's goal of returning their emissions to 1990 levels by 2000 (helped by massive declines in the former Soviet Union and Eastern Bloc). The industrialised countries that accepted targets under the Kyoto Protocol and remained parties to that agreement also all achieved their official goals. There is no question that in the EU, the Protocol provided the legal framework and impetus for strengthening mitigation policies.

The international process has also had successes in other areas. Through the Kyoto Protocol's Clean Development Mechanism (CDM), many developing countries came forward with new projects that generated cheap emission reductions (that could then be sold on to industrialised countries), and by most accounts contributed to the establishment of renewable energy industries and other low-carbon technologies. Through a levy on CDM transactions, the Kyoto Protocol also established a fund to help finance adaptation measures in developing countries.

The UNFCCC also provides a crucial ingredient of transparency. A major achievement has been in establishing a robust system of reporting and review, for both national emissions data and broader policy actions. In 1992, when the UNFCCC was adopted, many countries had very little knowledge of their emissions profile-ie, what GHGs they were emitting and from what sources. The UNFCCC's provisions, building on the IPCC's methodological work, have been crucial in filling that knowledge gap, which lays the foundation for an effective response to climate change.

Despite patchy progress, the global negotiations continue, and indeed are regaining momentum. It is likely that the hybrid course set out in the Copenhagen Accord, and ratified in 2010 by the Cancun Agreements, of domestic aspirations, policies, and objectives will define the primary ingredients of a future global agreement. Perhaps most importantly, it is also now clear that international agreements must run concurrent with (rather than precede) implementation efforts. The future of the international negotiations will inevitably have to combine elements of top-down and bottom-up policies within the global framework.

One indication of both the opportunities and challenges is found in a joint US-China agreement of 2014, in which the US Administration pledged to reduce its emissions by 26-28\% below 2005 levels by 2025, and China offered to cap its emissions growth by 2030 , or sooner if possible. On the positive side, this is the first time that any major emerging economy has stated it is willing to cap its emission growth in absolute terms, and interactions between the USA and China helped each to a new level of commitment.

On the negative side, it illustrates the scale of the gap between science and action: if viewed in terms of per-capita emissions, it means that the USA is planning to come down somewhat below $15 \mathrm{tCO}_{2}$ per capita, whilst China wants headroom to reach potentially $10 \mathrm{tCO} 2$ per capita by 2030, before declining. This is a far cry from the scientific goals - a $2{ }^{\circ} \mathrm{C}$ limit implies the need for a global average close to $2 \mathrm{tCO}$ per capita by mid-century. It emphasises that in isolation, such decentralised policy action also seems unlikely in the aggregate to deliver the necessary global mitigation effort effectively, equitably, and efficiently, and points to the risks of abandoning any collective, science-led direction to the global effort.

There are indeed reasons for concern regarding the international regime's ability to deliver on its promise. ${ }^{290}$ The international relations literature has tended to assume that regimes start off weak, but as scientific evidence hardens and political will increases, parties agree to ratchet up their commitments and the regime strengthens; this was clearly the assumption of the early climate change negotiators. ${ }^{291,292}$ It is 
difficult to say, however, whether the climate change regime is now getting stronger or weaker. On the one hand, the regime's coverage is expanding and deepening among the developing countries parties. The voluntary approach of the Copenhagen Accord and Cancun Agreements has engaged a much wider group of countries, including all major emitters, into national target-setting. At the same time, the Durban Platform mandate implies that all countries, not just the industrialised ones, are expected to raise their ambition in the new post-2020 regime. On the other hand, the engagement of industrialised countries is weakening compared with in the 1990s and early 2000s, with major emitters, such as Canada, Japan, Russia and, of course, the USA, now operating only under the Copenhagen Accord and Cancun Agreements, whose targets are voluntary and not subject to common metrics.

The outlook for future international negotiations is therefore challenging, to say the least. The rest of this section turns to consider reasons why progress on this issue is so difficult (from both a top-down, and bottom-up perspective), and what can be done to change this.

\section{The generic barriers}

The technological, investment, and behavioural changes needed to meet ambitious long-term goals, as illustrated in sections 3 and 4 , are, in principle, entirely feasible. But they need to be accomplished in the face of highly diverse social, cultural, economic, and political contexts. Opposing national (and vested) interests, clashing views of what constitutes fair distribution of effort, and a model of economic growth that is currently tied to fossil fuel use, can make progress fraught. There are several key issues, as outlined by Hulme, 2009:293

- Uncertainty and complexity. The climate is naturally variable and the science that has identified dangerous, anthropogenic climate change to a very high level of probability is complex. This leaves considerable room for public ignorance or misunderstanding of the nature and severity of the issue. Moreover, climate scientists can be ineffective at communicating the issue to the public. ${ }^{294}$

- Climate change is psychologically distant along four dimensions - temporal, social, geographical, and degree of uncertainty-whereas people tend to connect more easily with issues that are close in time, space and social group, and about which there is little uncertainty. These dimensions interact with each other, all tending to dampen concern and willingness to act. ${ }^{295}$

- There is enormous lock-in to current economic patterns. ${ }^{296}$ Fossil-fuel use is at the heart of the industrial economy, often operating through long-lived infrastructure (eg, roads, buildings, and power plants) and enabling valued dimensions of modern lifestyles (eg, travel and temperature control in buildings). It is no exaggeration to say that human societies are addicted to fossil fuels, or at least the services they provide. Providing these valued services through alternative, lower-carbon means requires systemic change over a long period.

- These three factors can all come together in a fourth: the active promotion of misinformation, motivated by either ideology or vested economic interests. Here, parallels can be drawn between public health efforts to reduce tobacco consumption (appendix 8). It is estimated that US industry spent close to \$500 million in its successful campaign against the 2010 House of Representatives proposal to cap US emissions. A major study of the Climate Change Counter Movement in the USA identifies funding of around \$900 million annually. ${ }^{297}$

These obstacles are further compounded by the economic characteristics of responses. Low-carbon technologies are generally more capitalintensive than their fossil-fuel alternatives, albeit with much lower running costs. Their implementation therefore requires more upfront investment and a longer time horizon, resulting initially either in higher energy prices or higher taxes, or some combination of the two. The same is true of most adaptation measures; flood protection defences, for example, are capital-intensive investments with uncertain returns.

A large-scale shift to such technologies will require very large investments over a prolonged period of time. This shift in financial flows will need to be incentivised, in the early periods at least, by strong, consistent, and credible public policies, and a change in financial structures. Such policies are far from easy to introduce and sustain, given other political priorities that may be perceived as more pressing, and the political complexities indicated above.

\section{Cities, states, and provinces: progress at the subnational level}

Despite all these obstacles, action does continue in varied ways, at many levels. Local issues have long been part of the broader agenda of international environmental politics, and local governments have an increasingly well-documented track record in climate action.

In the past two decades, cities have been pivotal in producing multiple policy-making frameworks and advocacy coalitions. This has fostered a thick texture of para-diplomatic links and policy action around climate change and environmental health. ${ }^{298,299}$ The rise and cross-cutting international spread of cities as actors in climate action also evidences a more refined pattern of transnational connections that are not solely bottom up, but rather offer a level of governance from the middle that cuts horizontally across international and national frameworks, involving an expanding variety of public-private structures and offering a distinct variation on civil society models of climate action. ${ }^{300,301}$

The leaders of cities around the world, from major metropolitan hubs like New York and São Paulo, to smaller centres like Rabat or Medellin, are increasingly using the networked reach of their municipal governments to address climate change in ways that are often more flexible and more directly applied than those of the national or international levels. Evermore city leaders have been leveraging their network power through international networks such as the United Cities and Local Governments (UCLG), ICLEI Local Governments for Sustainability, the World Mayors Council on Climate Change and the Climate Leadership Group (or C40). ${ }^{299}$

These groups are now a well-established presence in the international climate change arena, ${ }^{302}$ pointing to the emerging imprint on global environmental governance by city leaders. ${ }^{303}$ Their most crucial contribution to climate action is that of leveraging city diplomacy to implement specific actions on the ground via municipal management and multi-city initiatives. In practice, this governance from the middle is about taking advantage of the pooled networked connections of cities to implement a plethora of initiatives aimed at direct and quick implementation, which then injects urban elements in wider international processes.

Among the networks of larger cities, there is an emerging pattern of their local policy priorities becoming aggregated under a single strategic issue, as seen in integrated planning, climate, and sustainability plans such as Sustainable Sydney 2030. Concurrently, climate action has taken place on municipal purview areas such as energy regulation, transport and mobility, building retrofit, or waste management. Major centres like New York or Tokyo, for instance, have implemented building energy retrofit schemes across their city infra structures.

Taken together, such a two-headed agency can enable cities to collectively attract and therefore release investment capital to execute wideranging policy programmes (such as C40's Energy Efficiency Building Retrofit programme). This ability to leverage global capital by effectively generating a large single market can be highly influential insofar as the cities are able to act quickly, often within the space of a year, and increasingly represent a significant proportion of the world's population and energy generation. This stands by contrast with national governments, where climate policy is often subsumed within other priorities rather than as an organising aim across government.

City-level governance may also provide the flexibility and scope to include health in actions on climate change, with city leaders becoming key actors in recognising and responding to the health co-benefits of doing so. It is important that the UN-led international negotiations process takes account of this dimension of multi-level governance, which operates in both formal and informal ways.

\section{Public opinion and behaviour}

Ultimately, effective actions by local and national governments, and by businesses, are unsustainable without supportive public opinion. Public support for stronger action on climate change is a necessary, albeit far from sufficient, factor, and is essential if behavioural change is to 
contribute to solving the problem. In this respect, the evidence is somewhat mixed. Cross-national studies, such as the 2013 survey presented in figure 18, suggest that most people view climate change as a threat, although with some significant variation within regions. ${ }^{304}$

Public understandings of climate change are shaped by broader knowledge and belief systems, including religious convictions and political beliefs. ${ }^{294}$ There is evidence that the public recognises that climate change is complex, and interconnected with other environmental and social challenges. ${ }^{305}$ Effective communication about climate change requires trust. ${ }^{306}$ The most trusted sources vary across time and place, and can include family and friends, environmental groups, scientists, and the media; local and city-level authorities may provide an important conduit for communicating information from trusted sources. For scientists to engage effectively with the public, however, they need to seek a greater understanding of prior knowledge and belief systems, and communication skills radically different from those of academia. They must move beyond traditional scientific discourse to convey a big picture of climate change with which members of the public can engage; this can then provide a context and framing for the discussion of new scientific results and their consequences. ${ }^{294}$

\section{Public responses to climate change}

The causes of climate change lie ultimately in human behaviour, in particular in the economies and lifestyles of rich societies. ${ }^{307}$ However, it has been science, rather than social science, that has underpinned climate change communication and policy development. ${ }^{308}$ There is as yet little evidence on how to change behaviours that contribute to climate change, ${ }^{309}$ but taking broader evidence on the determinants of behaviour and behavioural change, four themes stand out.

First, knowledge deficits are not the primary barrier to action; knowing about the causes and consequences of climate change does not, on its own, motivate people to change their lifestyles. ${ }^{310}$ Instead, it is emotions - the feelings that accompany thinking-that are central. ${ }^{311}$ Negative emotions, including fear, pessimism, and guilt, can produce passive and defensive responses, and do little to encourage individuals to change their behaviour and to press for wider social action. So-called fear appeals only work if accompanied by equally strong messages about how to address the problem. ${ }^{312}$ Representations of climate change as inexorably heading for catastrophe close off the possibility that individual and collective action can make a difference. ${ }^{294}$

Second, climate change is best represented in ways that anchor it in positive emotions, ${ }^{313}$ by framing action in ways that connect with people's core values and identities. Examples include framing climate change as: an ethical and intergenerational issue; about safeguarding ancestral lands and the sanctity of the natural world; or an appreciation of the global injustice of anthropogenic climate change driven by rich countries but paid for by poorer ones. ${ }^{107,314}$ Aligning climate change to a range of ethical positions and a core set of identities can offer a way of appealing to diverse social groups, and thus securing a broad and inclusive platform of public support for action. This could be facilitated by avoiding the rhetoric of climate catastrophe, and emphasising, instead, human capacity to steer a way to a sustainable future, including lifting the burdens that unmitigated climate change would otherwise impose on future generations. ${ }^{313,315}$

Third, integral to such an ethical framing of climate change is the implied duty on national and international organisations to take action. A recurrent finding is that the public sees the main responsibility for action lying with governments and other powerful institutions, not least because the options open to individuals to take radical action to cut their own GHG emissions are often sorely limited by cost or availability (eg, poor public transport provision). Public willingness to take action is also contingent on those considered responsible for climate change taking action themselves. ${ }^{316}$ The majority of the public in cross-national surveys believe that their country has a responsibility to take action on climate change, and that their government is not doing enough. ${ }^{317}$

Fourth, many climate-affecting behaviours are habitual and resistant to change. Everyday domestic energy use (eg, cooking, heating the home), travel behaviour, and eating patterns are undertaken as part of a daily routine and without conscious thought. Such behaviours are resistant to change, even if alternative options are available, and interventions relying on increasing knowledge have limited effect. ${ }^{318}$

\section{Conclusions}

It is clear that in isolation, a top-down approach (international agreement followed by national legislation with which individuals and business must comply) to managing climate change is no longer a sufficient response. Other actors are already taking steps independent of any agreement to reduce their emissions, and a voluntary transformation to a low-carbon economy may already be underway. At the same time, as indicated throughout this report, these bottom-up initiatives have hardly, as yet, taken us any closer to the scale of global action required to protect human health against the risks of climate change, than has the decade of targets under the Kyoto Protocol.

Section 1 has underlined the way in which the continued acceleration of GHG emissions and atmospheric concentrations, mapped on to changing global demographics, is making climate change an increasingly severe risk to global health. Despite the threat that climate change poses to human development, it remains but one of many factors influencing decision makers, and rarely the most important one. Precautionary adaptation is clearly inadequate and prevailing patterns of energy production and consumption are still driving the world towards a dangerous climatic future. Current economic drivers of growth lock communities into patterns of energy use which no amount of reframing can change unless coordinated realignment of these drivers takes place. And the argument that others should be doing more to tackle climate change, because they are more to blame, remains one of the most politically potent excuses for inadequate action.

Thus the challenge, and the crucial test of the international process, will be finding a synthesis of top-down and bottom-up forces. An effective international agreement will be one that supports stronger efforts everywhere and at every level. The diverse worlds of bottom-up initiatives in cities, companies and many others should in turn help overcome the obstacles that impede the ability or willingness of national governments to commit to stronger national actions. To be truly effective, any future agreement will thus need not only to agree goals and aspirations, but also identify what is necessary at the international and national levels to achieve them. This may also require a mechanism, such as a feedback loop, that will motivate increased national ambitions over time. A system of review will be a crucial component, with regular assessments of the effectiveness of national policies, actions, and targets.

\section{Section 6: bringing the health voice to climate change}

Our studies point to multiple ways in which the health agenda may help accelerate the response to climate change. First are the positive lessons for international cooperation. No-one would suggest that national action to protect health should depend on a global, all-encompassing treaty. Yet few would deny that WHO and numerous other fora of international cooperation are important in accelerating, coordinating, and deepening responses to health challenges-particularly, but not exclusively, those with transboundary dimensions. The health experience neatly illustrates the falsity of the dichotomy between top-down and bottom-up: one measure of success is how each can reinforce the other. Learning from the health experience may illuminate the most effective actions at a particular level or levels of governance, and how the multilevel governance framework and international negotiation process can mutually reinforce actions at different levels.

Second, political lessons from health have particular, and largely encouraging, resonance for a climate dialogue increasingly characterised by pessimism about the ability to control the problem. The denialism of HIV, responsible for perhaps a million deaths, did eventually give way to global acceptance of the science. 50 years of tobacco industry resistance and obfuscation of the science on lung cancer has to a large extent been 
overcome, including with recognition embodied in WHO's Framework Convention on Tobacco Control, that governments have a duty to resist such lobbying forces.

Third, the health implications could and should be more effectively harnessed in efforts to build support for a stronger response to climate change. The health impacts of climate change discussed in this Commission are not well represented in global negotiations, but they are a critical factor to be considered in mitigation and adaptation actions. A better understanding of the health impacts of climate change can help to drive topdown negotiations and bottom-up action in many realms. A sophisticated approach is needed, which draws on the universal desire to tackle threats to health and wellbeing (without any particular philosophical slant), in order to motivate rapid action, and a policy framing that is more human than purely environment, technology, or economy focused. This requires making the impact of climate change on people explicit, rather than implicit. By considering directly how climate change will impact on human health, we are naturally drawn to the human component of climate impacts, rather than the environmental (flooding, forest fires) or more abstract effects (the economy, the climate). This supports a human framing of climate change, putting it in terms that may be more readily understood by the public. Fostering such public resonance can act as a powerful policy driver: public pressure is, of course, a crucial factor motivating both national governments and their negotiators in the international arena.

Fourth, local health benefits could in themselves help to drive key adaptation and mitigation actions. The numerous health co-benefits of many adaptation measures were emphasised in section 2, whilst section 3 noted substantial health co-benefits of many mitigation measures. Examples of the latter include the reduced health risks and costs when populations live in well-insulated buildings, and the reduction in air pollution (and other health) damages associated with fossil fuel use, which, as noted, even in strictly economic terms typically amount to several percent of GDP, as well as adding directly to the strain on limited health-care resources. With the direct costs of deep cuts in emissions estimated at around 10\% of global expenditure on health, both the direct and indirect health dimensions should be a major driver for mitigation efforts. It is also commonly seen that responding to climate change from a public health perspective brings together both mitigation and adaptation interventions, yielding powerful synergies.

Fifth, analogies in health responses can also help to underline that there is rarely a single solution to complex problems: different and complementary measures are required to tackle different dimensions, and pursuing both prevention (mitigation) and treatment (adaptation) is crucial:

With severely ill or vulnerable patients, the first step is to stabilise the patient and tackle the immediate symptoms. Helping poor countries particularly to adapt to the impacts of climate change is similarly a priority. But as noted in section 2, adaptation cannot indefinitely protect human health in the face of continuing and accumulating degrees of climate change, any more than tackling the symptoms will cure a serious underlying disease.

- For infectious diseases, antimicrobials and a functioning health system to produce, distribute, and administer drugs effectively are essential components. The obvious analogy here is with specific greenhouse gas mitigation policies, such as energy efficiency programmes and technology programmes that span the full spectrum from R\&D through to policies to support industrial scale deployment and related infrastructure.

- Deeply-ingrained patterns of behaviour are best addressed by comprehensive approaches and the use of multiple policy levers. Evidence from studies of health behaviour change suggests that, to be sustained, changes in the individual's everyday environments are required. Structural levers are also important for addressing social inequalities in harmful behaviours. Such evidence could be harnessed to inform policies to address climate change - eg, the behaviour change checklists developed to guide policy to reduce tobacco use and tackle harmful alcohol consumption may be particularly useful. Applying lessons from health behaviour change may help to accelerate policy development, building an evidence platform for interventions to promote mitigative and adaptive behaviours.

- As with the evolution of drug-resistant bacteria, the challenges of drug addiction, or the rising health problems of obesity, medical fixes cannot solve all health problems. Similarly, in our energy systems, specific mitigation policies and projects are constantly faced with the ingenuity of the fossil fuel industry in finding and driving down the costs of extracting new fossil fuel resources and marketing them. The long-term antidote is more analogous to programmes of sustained immunisation, education, incentives, and enforcement, all oriented towards supporting healthier lives.

The single most powerful strategic instrument to inoculate human health against the risks of climate change would be for governments to introduce strong and sustained carbon pricing, in ways pledged to strengthen over time until the problem is brought under control. Like tobacco taxation, it would send powerful signals throughout the system, to producers and users, that the time has come to wean our economies off fossil fuels, starting with the most carbon intensive and damaging like coal. In addition to the direct incentives, the revenues could be directed to measures across the spectrum of adaptation, low-carbon innovation, and the global diffusion of better technologies and practices. As outlined in section 4, carbon pricing thus has immense potential, particularly when embedded in comprehensive policy packages. This most powerful antidote, however, still faces many political obstacles.

The crux of the matter is that stabilising the atmosphere at any level ultimately requires reducing net emissions to zero. A healthy patient cannot continue with indefinitely rising levels of a toxin in the blood; even nutrients essential to a healthy body (like salt) can become damaging if not stabilised. The climate-change analogy is obvious and focuses global attention on the need to stabilise atmospheric concentrations, which in climate terms, means getting net emissions (that is, emissions minus removals by forests, oceans, and other sinks) to zero. On most scientific indicators, it means getting to zero during the second half of this century. A unifying goal, therefore may be a commitment to achieve zero emissions based on multiple partnerships involving different actors. If any region can achieve net zero, there is no fundamental reason why that should not become global. Getting to net zero also focuses us on a common task: how to get there, which is potentially harder for the societies that have become more dependent on fossil fuels, whilst in developing countries, it sends a clear signal that the sooner their emissions can peak, the better for their own path towards that common goal. If the goal is net zero, all actors in all societies have a sense of the direction of the international framework for action in order to protect everyone's health against the risks posed by continual increases in the global concentration of heat-trapping gases.

\section{A Countdown to 2030: global health and climate action}

If we are to minimise the health impacts of climate change, we must monitor and hold governments accountable for progress and action on emissions reduction and adaptation. One might argue that action on climate change is already effectively addressed by the IPCC, World Bank, UNFCCC, WHO, and the G20. We believe, however, that the health dimension of the climate change crisis has been neglected. There are four reasons why an independent accountability and review process is warranted:

1 The size of the health threat from climate change is on a scale quite different from localised epidemics or specific diseases. On current emissions trajectories there could be serious population health impacts in every region of the world within the next 50 years.

2 There is a widespread lack of awareness of climate change as a health issue. ${ }^{191}$ 
3 Several independent accountability groups have brought energy, new ideas and advocacy to other global health issues. For example, the Institute of Health Metrics and Evaluation in Seattle have led analyses of the Global Burden of Disease, the Countdown to 2015 child survival group has monitored global progress since 2003, and the Global Health 2035 group have stimulated new ideas about global health financing.

4 Perhaps the paramount reason for an independent review is the authority of health professional voices with policy makers and communities. Doctors and nurses may be trusted more than environmentalists. They also bring experience of collating evidence and conducting advocacy to cut deaths as a result of tobacco, road traffic accidents, infectious disease, and lifestyle-related non-communicable diseases.

We propose the formation of an independent international Countdown to 2030: global health and climate action coalition, along the same lines as other successful global health monitoring groups. We recommend that a broad international coalition of experts across disciplines from health to the environment, energy, economics, and policy, together with lay observers, drawn from every region of the world, should monitor and report every 2 years. The report would provide a summary of evidence on the health impacts of climate change; progress in mitigation policies and the extent to which they consider and take advantage of the health co-benefits; and progress with broader adaptation action to reduce population vulnerability and to build climate resilience and to implement low-carbon, sustainable health systems.

A Countdown process would complement rather than replace existing IPCC and other UN reports. UN reports understandably seek cautious consensus. An in-dependent review of progress would add the full weight and voice of the health community and valuable metrics to this critical population health challenge. A Countdown to 2030: global health and climate action coalition would independently decide the structure of their reports and the sentinel indicators they would choose to monitor progress towards key outcomes, policies and practice. Panel 9 outlines one possible framework for monitoring progress in three critical areas: health impacts; progress with action to reduce GHG emissions; and progress with actions to support adaptation, and the resilience of both populations and health systems, to climate change.

\section{Optimism}

We should draw considerable strength in the face of the challenges of climate change from the way in which the global community has addressed numerous other threats to health in the recent past. Although the threats are great and time is short, we have an opportunity for social transformation that will link solutions to climate change with a progressive green global economy, reductions in social inequalities, the end of poverty, and a reversal of the pandemic of non-communicable disease.

There are huge opportunities for social and technological innovation. We have modern com-munications to share successful local learning. At the highest levels of state, there are opportunities for political leaders to grasp the global challenge with transformative climate initiatives of a scale and ambition to match the Marshall plan, the Apollo and Soyuz space programmes, and the commercial success of mobile telephony. Scalable, low-carbon, and renewable energy technologies require billions of dollars of new investment and ideas. In cities, municipal governments are already bringing energy and innovation to create connected, compact urban communities, better buildings, managed growth, and more efficient transport systems. In local communities transformative action creates greater environmental awareness and facilitates low-carbon transition. And within local government, civil society, and business, many people aim to bring about social and economic transformation. All of us can help cut GHG emissions and reduce the threat of climate change to our environment and health. At every level, health must find its voice. In health systems we can set an example with scale up of renewables, combined heat and power generation in health facilities, decentralisation of care and promotion of active transport, and low-carbon healthy lifestyles. But time is limited. Immediate action is needed. The Countdown to 2030 coalition must begin its work immediately.

\section{Contributors}

The 2015 Lancet Commission on Health and Climate Change is an international collaboration led by University College London, Tsinghua University, the University of Exeter, the Stockholm Resilience Centre, and Umeå University. The Commission undertook its work within five central working groups, which were responsible for the design, drafting, and review of their individual sections. All commissioners contributed to the overall report structure and concepts, and provided input and expertise in facilitating integration between the five core sections.

Members of Working Group 1 (climate change and exposure to health risks): W Neil Adger, Mat Collins, Peter M Cox, Andy Haines, Alasdair Hunter, Xujia Jiang, Mark Maslin, Tara Quinn, Sergey Venevsky, Qiang Zhang. Members of Working Group 2 (action for resilience and adaptation): Victor Galaz, Delia Grace, Moxuan Li, Georgina Mace, My Svensdotter, Koko Warner, Yongyuan Yin, Chaoqing Yu, Bing Xu. Members of Working Group 3 (transition to a low-carbon energy infrastructure): Ian Hamilton, Lu Liang, Robert Lowe, Tadj Oreszczyn, Steve Pye, Jun Yang.

Members of Working Group 4 (financial and economic action): Wenjia Cai, Paul Drummond, Paul Ekins, Paolo Agnolucci, Melissa Lott. Members of Working Group 5 (delivering a healthy low-carbon future): Jason Blackstock, Sarah Chaytor, Adam Cooper, Joanna Depledge, Hilary Graham, Michael Grubb, Yong Luo.

Michael Grubb acted as the integrating editor for mitigation (working across Working Groups 3, 4, and 5), and Maria Nilsson acted as the integrating editor for health (working across all working groups). Peter Byass, Ilan Kelman, and Tim Colbourn provided global health expertise for a number of working groups, and contributed to the Commission's overall direction. Nick Watts, Anthony Costello, Hugh Montgomery, and Peng Gong were responsible for the strategic direction, integration, and editing of the Commission.

\section{Declaration of interests}

Five commissioners (PD, MG, MLo, MS, and NW) were compensated for their time whilst working on the Commission's drafting and development. The Commission also covered meeting and travel costs for each author, helping to facilitate improved integration between working groups. NA has received grants from the Natural Environment Research Council UK during the conduct of the study. HG has received an ESRC grant ES/L003015/1 Health of Populations and Ecosystems (HOPE), outside the submitted work. MM is Executive Director and co-founding shareholder of Rezatec. This company uses remote sensing and ground data to provide companies with data on the state of the environment. It does not engage with global health or health related work. HM is a member of the Executive Committee of the UK Climate and Health Council. NW works as a consultant for WHO's Department of Public Health, Environmental, and Social Determinants of Health, and is the Director of the Global Climate and Health Alliance. The UCL Institute for Sustainable Resources receives funding from BHP Billiton, outside of the Commission's work.

\section{Acknowledgments}

Central funding for the Commission was provided by ClimateWorks Foundation, the European Climate Foundation, Microsoft Research Asia, the Norwegian Agency for Development Cooperation (NORAD), the National Environment Research Council through an Impact Acceleration award to the University of Exeter (NE/L012782/1), Martin Rushton-Turner, the Stordalen Foundation, and University College London's Grand Challenge for Global Health. In-kind support was also provided from Tsinghua University, University College London (UCL), and the Stockholm Resilience Centre through the Dynamic Drivers of Disease in Africa Consortium (DDDAC). The contributions of WNA and PMC were supported by the National Institute for Health Research Health Protection Research Unit (NIHR HPRU) in Environmental Change and Health at the London School of Hygiene and Tropical Medicine in partnership with Public Health England (PHE), and in collaboration with the University of Exeter, University College London, and the Met Office. Whilst carrying out its work, the Commission received invaluable technical advice and input from a number of individuals including Michele Acuto (UCL), John Ashton (E3G), Sukaina Bharwani (Stockholm Environment InstituteOxford), Isobel Braithwaite (Global Climate and Health Alliance), Michael Depledge (University of Exeter), Helen Fry (University College London), Josh Karliner (Health Care Without Harm), and Duan Maosheng (Tsinsghua University). Olivia Stevenson (University College London) provided ongoing guidance and policy expertise to the Commission. Neil Morisetti (University College London) provided ongoing guidance and strategic input throughout the Commission's process. Elaine Fletcher and Marina Maiero from WHO's Department of Public Health, Environmental and Social Determinants of Health, and Bettina Menne from WHO's Regional Office for Europe provided both formal and informal advice and assistance to the Commission. The Commission also worked with various practitioner commissioners who reviewed its progress independently, and provided policy insight and guidance on how the final report could be most useful to decision makers. The practitioner commissioners included Diarmid Campbell-Lendrum (WHO), Matthew Pencharz (Greater London Authority), Virginia Murray (PHE), and Martin Frick (German Federal Foreign Office). Various experts in the fields of finance and economics provided invaluable guidance during the initial preparation stages for section 4, for which the authors are most grateful. These include Bernie Bulkin (Ludgate Investment), Mark Campanale (Carbon Tracker Initiative), Martin Rushton-Turner (Swiss Re), Michael Mainelli (Z/Yen), Andrew Scott (Overseas Development Institute), Adrian Gault (Committee on Climate Change), Paul Dickinson (CDP, formerly Carbon Disclosure Project), Jim Watson (UK Energy Research Centre), and Simon Buckle (Organization for Economic Cooperation and Development). Administrative, communications, and design support was provided by Ron Finaly, and by Ayesha Ally, Anila Babla, Faye Basset, Rosie Bartlett, Helen Hopkins, Kate Hoyland, and Maxine Lenza at UCL. 
1 Costello A, Abbas M, Allen A, et al. Managing the health effects of climate change: Lancet and University College London Institute for Global Health Commission. Lancet 2009; 373: $1693-733$.

2 IPCC. Summary for policymakers. In: Field CB, Barros VR, Dokken DJ, et al, eds. Climate change 2014: impacts, adaptation, and vulnerability. Part A: global and sectoral aspects Cambridge, UK, and New York, NY, USA: Cambridge University Press, 2014: 1-32.

3 Cubasch U, Wuebbles D, Chen D, et al. Introduction. In: Stocker TF, Qin D, Plattner G-K, et al, eds. Climate change 2013: the physical science basis contribution of Working Group I to the Fifth Assessment Report of the Intergovernmental Panel on Climate Change. Cambridge, UK and New York, NY, USA: Cambridge University Press, 2013: 119-58.

4 British Petroleum. BP statistical review of world energy June 2014. London: BP, 2014.

5 Ciais P, Sabine C, Bala G, et al. Carbon and Other Biogeochemical Cycles. In: Stocker TF, Qin D, Plattner G-K, et al, eds. Climate change 2013: the physical science basis contribution of Working Group I to the Fifth Assessment Report of the Intergovernmental Panel on Climate Change. Cambridge, UK and New York, NY, USA: Cambridge University Press, 2013: 465-570.

6 National Oceanic and Atmospheric Administration. Trends in atmospheric carbon dioxide. 2014. http://www.esrl.noaa.gov/gmd/ccgg/trends/weekly.html (accessed Dec 22, 2014).

7 Balla G. Digesting 400 ppm for global mean $\mathrm{CO}_{2}$ concentration. Curr Sci 2013; 104: 1471-72.

8 IPCC. Summary for Policymakers. In: Stocker TF, Qin D, Plattner G-K, et al, eds. Climate change 2013: the physical science basis contribution of Working Group I to the Fifth Assessment Report of the Intergovernmental Panel on Climate Change. Cambridge, UK and New York, NY, USA: Cambridge University Press, 2013: 1-30.

9 McMillan M, Shepherd A, Sundal A, et al. Increased ice losses from Antarctica detected by CryoSat-2. Geophys Res Lett 2014; 41: 3899-905.

10 Riahi K, Rao S, Krey V, et al. RCP 8.5-A scenario of comparatively high greenhouse gas emissions. Clim Change 2011; 109: 33-57.

11 Stott PA, Stone DA, Allen MR. Human contribution to the European heatwave of 2003. Nature 2004; 432: 610-14.

12 Rahmstorf S, Coumou D. Increase of extreme events in a warming world. Proc Natl Acad Sci USA 2011; 108: 17905-09.

13 Otto F, Massey N. Oldenborgh Gv, Jones R, Allen M. Reconciling two approaches to attribution of the 2010 Russian heat wave. Geophys Res Lett 2012; 39: L04702.

14 Peterson T, Hoerling M, Stott P, Herring S. Explaining extreme events of 2012 from a climate perspective. Bull Am Meteor Soc 2013; 94: S1-106.

15 Herring S, Hoerling M, Peterson T, Stott P. Explaining extreme events of 2013 from a climate perspective. Bull Am Meteor Soc 2014; 95: S1-96.

16 Peterson T, Stott P, Herring S. Explaining extreme events of 2011 from a climate perspective. Bull Am Meteor Soc 2012; 93: 1041-67.

17 Pall P, Aina T, Stone DA, et al. Anthropogenic greenhouse gas contribution to flood risk in England and Wales in autumn 2000. Nature 2011; 470: 382-85.

18 World Bank. Turn down the heat: why a $4^{\circ} \mathrm{C}$ warmer world must be avoided. 2012. https://openknowledge.worldbank.org/handle/10986/11860 (accessed May 10, 2015).

19 Silver N. The signal and the noise: the art and science of prediction. London: Penguin UK, 2012.

20 McMaster R, Baber C. Multi-agency operations: cooperation during flooding. Appl Ergon 2012; 43: 38-47.

21 Overview and Scrutiny Management Committee. Scrutiny inquiry into the summery emergency 2007. Gloucestershire: Gloucestershire County Council, 2007.

22 Rockström J, Steffen W, Noone K, et al. Planetary boundaries: exploring the safe operating space for humanity. Ecol Soc 2009; 14: 32.

23 Lenton TM, Held H, Kriegler E, et al. Tipping elements in the Earth's climate system. Proc Natl Acad Sci USA 2008; 105: 1786-93.

24 Haines A, Ebi KL, Smith KR, Woodward A. Health risks of climate change: act now or pay later. Lancet 2014; 384: 1073-75.

25 Anderson K, Bows A. Beyond 'dangerous' climate change: emission scenarios for a new world. Philos Trans A Math Phys. Eng Sci 1934; 2011: 20-44.

26 WHO. Health in the Green Economy. Geneva: World Health Organisation, 2011.

27 Watts G. The health benefits of tackling climate change: an Executive Summary for the Lancet Series. Nov 25, 2009. http://www.thelancet.com/pb/assets/raw/Lancet/stories/series/health-and-climate-change.pdf (accessed May 10, 2015)

28 WHO, World Bank. Access to modern energy services for health facilities in resource-constrained settings. Geneva: World Health Organization, 2015.

29 Haines A, McMichael AJ, Smith KR, et al. Public health benefits of strategies to reduce greenhouse-gas emissions: overview and implications for policy makers. Lancet 2009; 374: 2104-14.

30 Walker BH, Gunderson LH, Kinzig AP, Folke C, Carpenter SR, Schultz L. A handful of heuristics and some propositions for understanding resilience in social-ecological systems. Ecol Soc 2006; 11: 13

31 Smith KR, Woodward A, Campell-Lendrum D, et al. Human health-impacts adaptation and co-benefits. Climate change 2014: impacts, adaptation, and vulnerability Working Group II contribution to the IPCC 5th Assessment Report. Cambridge, UK and New York, NY, USA: Cambridge University Press, 2014.

32 Hales S, Kovats S, Lloyd S, Campbell-Lendrum D. Quantitative risk assessment of the effects of climate change on selected causes of death, 2030s and 2050s. Geneva: World Health Organization, 2014

33 Adger WN, Pulhin JM, Barnett J, et al. Human security. In: Field CB, Barros VR, Dokken DJ, et al, eds. Climate change 2014: impacts, adaptation, and vulnerability. Part A: global and sectoral aspects contribution of Working Group II to the Fifth Assessment Report of the Intergovernmental Panel of Climate Change. Cambridge, UK and New York, NY, USA: Cambridge University Press; 2014: 755-91.

34 Barrett CB. Food security and sociopolitical stability. Oxford: Oxford University Press, 2013.

35 Bradshaw S, Fordham M. Women, girls and disasters: a review for DFID. London: Department for International Development (DFID), 2013.

36 Jonkman SN, Kelman I. An analysis of the causes and circumstances of flood disaster deaths. Disasters 2005; 29: 75-97.

37 WHO. Gender, climate change and health. Geneva: World Health Organization, 2014

38 Patz JA, Campbell-Lendrum D, Holloway T, Foley JA. Impact of regional climate change on human health. Nature 2005; 438: 310-17.

39 Aström C, Orru H, Rocklöv J, Strandberg G, Ebi KL, Forsberg B. Heat-related respiratory hospital admissions in Europe in a changing climate: a health impact assessment. BMJ Open 2013; 3: e001842.

40 Russo S, Dosio A, Graversen RG, et al. Magnitude of extreme heat waves in present climate and their projection in a warming world. J Geophys Res D Atmospheres 2014; 199: 12 $500-512$.

41 Coumou D, Robinson A. Historic and future increase in the global land area affected by monthly heat extremes. Environ Res Lett 2013; 8: 034018.

42 Ryazantzev S. Demographic and socio-economic consequences of heat wave and forest fires of 2010 in European Russia. Ecol Life 2011; 5: 80-85.

43 van Donkelaar A, Martin RV, Levy RC, et al. Satellite-based estimates of ground-level fine particulate matter during extreme events: a case study of the Moscow fires in 2010. Atmos Environ 2011; 45: 6225-32.

44 Revitch B, Shaposhnikov D. Climate change, heat and cold waves as risk factors of increased mortality in Russia. Ecoforum 2012; 2: 122-38.

45 Barriopedro D, Fischer EM, Luterbacher J, Trigo RM, García-Herrera R. The hot summer of 2010: redrawing the temperature record map of Europe. Science 2011; 332: 220-24

46 Ebi K, Mills D. Winter mortality in a warming climate: a reassessment. Wiley Interdiscip Rev Clim Change 2013; 4: $203-12$.

47 Healy JD. Excess winter mortality in Europe: a cross country analysis identifying key risk factors. J Epidemiol Community Health 2003; 57: 784-89.

48 Woodward A. Heat, cold and climate change. J Epidemiol Community Health 2014; 68: 595-96.

49 Staddon P, Montgomery H, Depledge M. Climate warming will not decrease winter mortality. Nature Clim Change 2014; 4: 190-94.

50 Seto KC, Güneralp B, Hutyra LR. Global forecasts of urban expansion to 2030 and direct impacts on biodiversity and carbon pools. Proc Natl Acad Sci USA 2012; 109: 16083-88.

51 O'Neill B, Kriegler E, Ebi K, et al. The roads ahead: narratives for shared socioeconomic pathways describing world futures in the 21st century. Glob Environ Change 2015; published online Feb 12. DOI:10.1016/j.gloenvcha.2015.01.004.

52 Samir K, Lutz W. The human core of the shared socioeconomic pathways: population scenarios by age, sex and level of education for all countries to 2100 . Glob Environ Change 2014; published online July 4. DOI:10.1016/j.gloenvcha.2014.06.004.

53 Kriegler E, O'Neill BC, Hallegatte S, et al. The need for and use of socio-economic scenarios for climate change analysis: a new approach based on shared socio-economic pathways. Glob Environ Change 2012; 22: 807-22.

54 Bhatt S, Gething PW, Brady OJ, et al. The global distribution and burden of dengue. Nature 2013; 496: 504-07.

55 Kovats RS, Hajat S. Heat stress and public health: a critical review. Annu Rev Public Health 2008; 29: 41-55.

56 Quinn T, Adger N. Climate change when you are getting on in life. Environ Plann A 2011; 43: 2257-60.

57 Lutz W, Muttarak R, Striessnig E. Environment and development. Universal education is key to enhanced climate adaptation. Science 2014; 346: $1061-62$.

58 Kjellstrom T, Holmer I, Lemke B. Workplace heat stress, health and productivity — an increasing challenge for low and middle-income countries during climate change. Global Health Action 2009; 2: 10.3402/gha.v2i0.2047.

59 Parsons K. Human thermal environment: the effects of hot, moderate and cold temperatures on human health, comfort and performance, 3rd edn. New York: CRC Press, 2014

60 Hémon D, Jougla E. Surmortalité liée à la Canicule d'Août 2003: Rapport d'Étape. Estimation de la Surmortalite et Principales Caracteristiques Epidemiologiques. Rapport remis au Ministre de la Santé, de la Famille et des Personnes Handicapées. Paris: Institut National de la Santé et de la Recherche Médicale (INSERM), 2003.

61 Centers for Disease Control and Prevention (CDC). Heat-related deaths among crop workers-United States, 1992-2006. MMWR Morb Mortal Wkly Rep 2008; 57: 649-53. 
62 Wesseling C, Crowe J, Hogstedt C, Jakobsson K, Lucas R, Wegman DH, and the First International Research Workshop on the Mesoamerican Nephropathy. Resolving the enigma of the mesoamerican nephropathy: a research workshop summary. Am J Kidney Dis 2014; 63: 396-404.

63 DARA and the Climate Vulnerability Forum. Climate vulnerability monitor 2012: a guide to the cold calculus of a hot planets. Barcelona: Fundacion DARA Internacional, 2012.

64 United Nations Development Programme (UNDP). Human development report 2011. Sustainability and equity: a better future for all. London: UNDP, 2011.

65 Dunne JP, Stouffer RJ, John JG. Reductions in labour capacity from heat stress under climate warming. Nature Clim Change 2013 ; 3: 563-66.

66 Porter JR, Xie L, Challinor AJ, et al. Food security and food production systems. In: Field CB, Barros VR, Dokken DJ, et al. Climate change 2014: impacts, adaptation, and vulnerability. Part A: global and sectoral aspects contribution of Working Group II to the Fifth Assessment Report of the Intergovernmental Panel on Climate Change. Cambridge, UK and New York, NY, USA: Cambridge University Press, 2014: 485-533.

67 Sherwood SC, Huber M. An adaptability limit to climate change due to heat stress. Proc Natl Acad Sci USA 2010; 107: 9552-55.

68 WHO. World malaria report. Geneva: World Health Organization, 2012.

69 Ndyomugyenyi R, Magnussen P. Trends in malaria-attributable morbidity and mortality among young children admitted to Ugandan hospitals, for the period 1990-2001. Ann Trop Med Parasitol 2004; 98: 315-27.

70 Siraj AS, Santos-Vega M, Bouma MJ, Yadeta D, Ruiz Carrascal D, Pascual M. Altitudinal changes in malaria incidence in highlands of Ethiopia and Colombia. Science 2014; 343: $1154-58$.

71 Sutherst RW. Global change and human vulnerability to vector-borne diseases. Clin Microbiol Rev 2004; 17: 136-73.

72 WHO, World Meteorological Organisation. Atlas of health and climate. Geneva: World Health Organization, 2012.

73 Hopp J, Foley J. Worldwide fluctuations in dengue fever case related to climate variability. Clim Res 2003; 25: 85-94.

74 Lipp EK, Huq A, Colwell RR. Effects of global climate on infectious disease: the cholera model. Clin Microbiol Rev 2002; 15: 757-70.

75 WHO. Burden on disease from air pollution in 2012. 2014. http://www.who.int/phe/health_topics/outdoorair/databases/FINAL_HAP_AAP_BoD_24March2014.pdf (accessed Oct 7, 2014).

76 Jacob DJ, Winner DA. Effect of climate change on air quality. Atmos Environ 2009; 43: 51-63.

77 Giorgi F, Meleux F. Modelling the regional effects of climate change on air quality. C R Geosci 2007; 339: 721-33.

78 Schär C, Vidale PL, Lüthi D, et al. The role of increasing temperature variability in European summer heatwaves. Nature 2004; 427: 332-36.

79 Wu S, Mickley LJ, Leibensperger EM, Jacob DJ, Rind D, Streets DG. Effects of 2000-2050 global change on ozone air quality in the United States. J Geophys Res, D, Atmospheres 2008; 113: D06302.

80 Tagaris E, Manomaiphiboon K, Liao K-J, et al. Impacts of global climate change and emissions on regional ozone and fine particulate matter concentrations over the United States. $J$ Geophys Res, D, Atmospheres 2007; 112: D14312.

81 Murazaki K, Hess P. How does climate change contribute to surface ozone change over the United States? J Geophys Res, D, Atmospheres 2006; 111: D05301.

82 Mickley LJ, Jacob DJ, Field BD, Rind D. Effects of future climate change on regional air pollution episodes in the United States. Geophys Res Lett $2004 ; 31$ : L24103.

83 Knowlton K, Rosenthal JE, Hogrefe C, et al. Assessing ozone-related health impacts under a changing climate. Environ Health Perspect 2004; 112: 1557-63.

84 Jiang H, Liao H, Pye HOT, et al. Projected effect of 2000-2050 changes in climate and emissions on aerosol levels in China and associated transboundary transport. Atmos Chem Phys 2013; 13: 7937-60.

85 Wang Y, Shen L, Wu S, Mickley L, He J, Hao J. Sensitivity of surface ozone over China to 2000-2050 global changes of climate and emissions. Atmos Environ 2013; 75: 374-82.

86 Jiang Z, Zhang X, Wang J. Projection of climate change in China in the 21st century by IPCC-AR4 models. Geograph Res 2008; 27: 787-99.

87 Lim SS, Vos T, Flaxman AD, et al. A comparative risk assessment of burden of disease and injury attributable to 67 risk factors and risk factor clusters in 21 regions, 1990 2010: a systematic analysis for the Global Burden of Disease Study 2010. Lancet 2012; 380: 2224-60.

88 Lobell DB, Banziger M, Magorokosho C, Vivek B. Nonlinear heat effects on African maize as evidenced by historical yield trials. Nature Clim Change 2011; 1: 42-45.

89 Lobell DB, Schlenker W, Costa-Roberts J. Climate trends and global crop production since 1980. Science 2011; 333: 616-20.

90 Grace K, Davenport F, Funk C, Lerner AM. Child malnutrition and climate in Sub-Saharan Africa: An analysis of recent trends in Kenya. Appl Geogr 2012; 35: 405-13.

91 Taylor RG, Scanlon B, Doll P, et al. Ground water and climate change. Nature Clim Change 2013; 3: 322-29.

92 Schewe J, Heinke J, Gerten D, et al. Multimodel assessment of water scarcity under climate change. Proc Natl Acad Sci USA 2014; 111: 3245-50.

93 Ahern M, Kovats RS, Wilkinson P, Few R, Matthies F. Global health impacts of floods: epidemiologic evidence. Epidemiol Rev 2005; 27: $36-46$.

94 Dasgupta S, Laplante B, Meisner C, Wheeler D, Yan J. The impact of sea level rise on developing countries: a comparative analysis. Clim Change 2009; 93: 379-88

95 Nicholls R, Marinova N, Lowe J, et al. Sea-level rise and its possible impacts given a 'beyond $4^{\circ} \mathrm{C}$ world' in the twenty-first century. Philos Trans $R$ Soc A 1934; 2011: 161-81.

96 Paranjothy S, Gallacher J, Amlôt R, et al. Psychosocial impact of the summer 2007 floods in England. BMC Public Health 2011 ; 11: 145.

97 Jongman B, Ward PJ, Aerts JCJH. Global exposure to river and coastal flooding: Long term trends and changes. Glob Environ Change 2012; 22: 823-35.

98 Olsson L, Opondo M, Tschakert P, et al. Livelihoods and poverty. In: Field CB, Barros VR, Dokken DR, et al, eds. Climate change 2014: impacts, adaptation, and vulnerability. Part A: global and sectoral aspects contribution of Working Group II to the Fifth Assessment Report of the Intergovernmental Panel on Climate Change. Cambridge, UK and New York, NY: Cambridge University Press, 2014: 793-832.

99 Gleditsch NP. Whither the weather? Climate change and conflict. J Peace Res 2012; 49: 3-9.

100 McMichael C, Barnett J, McMichael AJ. An ill wind? Climate change, migration, and health. Environ Health Perspect 2012; 120: 646-54.

101 Black R, Arnell NW, Adger WN, Thomas D, Geddes A. Migration, immobility and displacement outcomes following extreme events. Environ Sci Pol 2013; 27 (suppl 1): S32-43.

102 Frumkin H, McMichael AJ. Climate change and public health: thinking, communicating, acting. Am J Prev Med 2008; 35: 403-10.

103 Frumkin H, Hess J, Luber G, Malilay J, McGeehin M. Climate change: the public health response. Am J Public Health 2008; 98: 435-45.

104 O'Brien K. Global environmental change II: From adaptation to deliberate transformation. Prog Hum Geogr 2012; 36: 667-76.

105 Pelling M. Adaptation to climate change: from resilience to transformation. London: Routledge, 2011.

106 Adger WN. Vulnerability. Glob Environ Change 2006; 16: 268-81.

107 Patz J, Gibbs H, Foley J, Rogers J, Smith K. Climate change and global health: quantifying a growing ethical crisis. EcoHealth 2007; 4: 397-405.

108 IPCC. Glossary of terms. In: Field CB, Stocker TF, Qin D, eds. Managing the risks of extreme events and disasters to advance climate change adaptation. A special report of Working Groups I and II of the Intergovernmental Panel on Climate Change. London, UK and New York, NY: Cambridge University Press, 2012 : 555-64.

109 Adger WN. Social and ecological resilience: are they related? Prog Hum Geogr 2000; 24: 347-64.

110 Hackmann H, St Clair AL. Transformative cornerstones of social science research for global change. Paris: International Social Science Council, 2012.

111 Pascal M, Laaidi K, Ledrans M, et al. France's heat health watch warning system. Int J Biometeorol 2006; 50: 144-53.

112 Fouillet A, Rey G, Wagner V, et al. Has the impact of heat waves on mortality changed in France since the European heat wave of summer 2003 ? A study of the 2006 heat wave. Int $J$ Epidemiol 2008; 37: 309-17.

113 Ebi KL, Burton I. Identifying practical adaptation options: an approach to address climate change-related health risks. Environ Sci Policy 2008; 11: 359-69.

114 Matthies F, Bickler G, Marin NC, Hales S. Heat-health action plans: guidance. Copenhagen: World Health Organization Regional Office for Europe, 2008.

115 Pugh TAM, Mackenzie AR, Whyatt JD, Hewitt CN. Effectiveness of green infrastructure for improvement of air quality in urban street canyons. Environ Sci Technol 2012; 46: 7692-99.

116 UN Economic and Social Commission for Asia and the Pacific, UN Office for Disaster Risk Reduction. Reducing vulnerability and exposure to disasters. The Asia-Pacific disaster report 2012. Bangkok: ESCAP and UNISDR, 2012.

117 Nicholls RJ, Lowe JA. Benefits of mitigation of climate change for coastal areas. Glob Environ Change 2004; 14: $229-44$.

118 Etzold B, Ahmed AU, Hassan SR, Neelormi S. Clouds gather in the sky, but no rain falls. Vulnerability to rainfall variability and food insecurity in Northern Bangladesh and its effects on migration. Clim Dev 2013; 6: 18-27.

119 McGranahan G, Balk D, Anderson B. The rising tide: assessing the risks of climate change and human settlements in low elevation coastal zones. Environ Urban 2007; 19: 17-37.

120 Foresight. Migration and global environmental change: future challenges and opportunities. London: UK Government Office for Science, 2011.

121 Michel-Kerjan E. Catastrophe economics: the national flood insurance program. J Econ Perspect 2010; 24: $165-86$.

122 Lafferty KD. Calling for an ecological approach to studying climate change and infectious diseases. Ecology 2009; 90: 932-33.

123 Zinsstag J, Schelling E, Wyss K, Mahamat MB. Potential of cooperation between human and animal health to strengthen health systems. Lancet 2005; 366: 2142-45.

124 Allison EH, Perry AL, Badjeck M-C, et al. Vulnerability of national economies to the impacts of climate change on fisheries. Fish Fish 2009 ; 10: $173-96$.

125 Dulvy N, Allison E. A place at the table? Nature Rep Clim Change 2009; 3: 68-70.

126 Gephart J, Pace M, D’Odorico P. Freshwater savings from marine protein consumption. Environ Res Lett 2014; 9: 014005.

127 Foley JA, Ramankutty N, Brauman KA, et al. Solutions for a cultivated planet. Nature 2011; 478: 337-42.

128 Bajželj B, Richards K, Allwood J, et al. Importance of food-demand management for climate mitigation. Nature Clim Change 2014; 4: 924-29. 
129 UN Environment Programme (UNEP). Avoiding future famines: strengthening the ecological foundation of food security through sustainable food systems. Nairobi: UNEP, 2012.

130 Food and Agricultural Organization (FAO), International Fund for Agricultural Development, World Food Programme. The state of food insecurity in the world: how does international price volatility affect domestic economies and food security? Rome: FAO, 2011.

131 Food and Agricultural Organization (FAO), Organization for Economic Cooperation and Development. Price volatility in food and agricultural markets: policy responses. Rome: FAO, 2011.

132 Gilbert CL, Morgan CW. Food price volatility. Phil Trans R Soc B 2010; 365: 3023-34

133 UN Conference on Trade and Development (UNCTAD). Promoting low-carbon investment. New York and Geneva: UNCTAD, 2013.

134 Cochrane K, Young C, De Soto D, Bahri T. Climate change implications for fisheries and aquaculture - overview of current scientific knowledge. Rome: Food and Agricultural Organization, 2009.

135 Alston J, Marra M, Pardey P, Wyatt T. Research returns redux: a meta-analysis of the returns to agricultural R\&D. Aust J Agric Resour Econ 2000; 44: 185-215.

136 von Braun J, Ahmed A, Asenso-Okyere K, et al. High food prices: the what, who, and how of proposed policy actions. Washington DC: International Food Policy Research Institute, 2008.

137 Rosegrant MW, Cline SA. Global food security: challenges and policies. Science 2003; 302: 1917-19.

138 UN High Level Task Force on the Global Food Security Crisis. Scaling up nutrition: a framework for action. 2010. http://siteresources.worldbank.org/NUTRITION/Resources/2818461131636806329/PolicyBriefNutrition.pdf (accessed May 10, 2015).

139 Hugo G. Future demographic change and its interactions with migration and climate change. Glob Environ Change 2011; 21: S21-33.

140 Martin SF, Warner K. Climate change, migration, and development. In: Omelaniuk I, ed. Global perspectives on migration and development. New York: Springer Books, 2012: $153-72$.

141 Collinson S. Developing adequate humanitarian responses. Background papers of the study team on climate change and migration. Washington DC: The German Marshall Fund of the United States, 2010.

142 Oppenheimer M, Campos M, Warren R, et al. Emergent risks and key vulnerabilities. Climate change 2014: impacts, adaptation, and vulnerability Working Group II Contribution to the IPCC 5th Assessment Report. Cambridge, UK and New York, NY: Cambridge University Press; 2014. 1039-99.

143 Confalonieri U, Menne B, Akhtar R, et al. Human health. In: Parry MC, Palutikof OF, van der Linden JP, et al, eds. Climate change 2007: impacts, adaptation and vulnerability contribution of Working Group II to the Fourth Assessment Report of the Intergovernmental Panel on Climate Change. Cambridge: Cambridge University Press; 2007: 391-431.

144 Warner K, Afifi T, Kälin W, et al. Changing climate, moving people: framing migration, displacement and planned relocation. Policy brief no 8. Bonn: UN University Institute for Environment and Human Security, 2013.

145 Raleigh C. The search for safety: The effects of conflict, poverty and ecological influences on migration in the developing world. Glob Environ Change $2011 ; 21$ (suppl 1): S82-93.

146 O’Brien K, Pelling M, Patwardhan A, et al. Toward a sustainable and resilient future. In: Field CB, Stocker TF, Qin D, et al, eds. Managing the risks of extreme events and disasters to advance climate change adaptation. A special report of Working Groups I and II of the Intergovernmental Panel on Climate Change. Cambridge, UK and New York, NY: Cambridge University Press, 2012: 437-86.

147 Berry HL, Bowen K, Kjellstrom T. Climate change and mental health: a causal pathways framework. Int J Public Health 2010; 55: 123-32.

148 Fritze JG, Blashki GA, Burke S, Wiseman J. Hope, despair and transformation: climate change and the promotion of mental health and wellbeing. Int J Ment Health Syst 2008; 2: 13.

149 Albrecht G, Sartore GM, Connor L, et al. Solastalgia: the distress caused by environmental change. Australas Psychiatry 2007; 15 (suppl 1): S95-98.

150 Hanigan IC, Butler CD, Kokic PN, Hutchinson MF. Suicide and drought in New South Wales, Australia, 1970-2007. Proc Natl Acad Sci USA 2012; 109: 13950-55.

151 Keshavarz M, Karami E, Vanclay F. The social experience of drought in rural Iran. Land Use Policy 2013; 30: 120-29.

152 Kessler RC, Galea S, Gruber MJ, Sampson NA, Ursano RJ, Wessely S. Trends in mental illness and suicidality after Hurricane Katrina. Mol Psychiatry 2008; 13: 374-84.

153 Reser JP, Swim JK. Adapting to and coping with the threat and impacts of climate change. Am Psychol 2011; 66: $277-89$.

154 Johnson CA. Governing climate displacement: the ethics and politics of human resettlement. Env Polit 2012; 21: 308-28.

155 Lal PN, Mitchell T, Aldunce P, et al. National systems for managing the risks from climate extremes and disasters. In: Field CB, Stocker TF, Qin D, et al, eds. Managing the risks of extreme events and disasters to advance climate change adaptation. A special report of Working Groups I and II of the Intergovernmental Panel on Climate Change. Cambridge, UK and New York, NY: Cambridge University Press; 2012: 339-92.

156 Barnett J, Webber M. Migration as adaptation: opportunities and limits. In: McAdam J, ed. Climate change and displacement: multidisciplinary perspectives. Oxford: Hart Publishing, 2010: 55.

157 Warner K, Afifi T. Where the rain falls: evidence from 8 countries on how vulnerable households use migration to manage the risk of rainfall variability and food insecurity. Clim Devel 2014; 6: $1-17$.

158 Bronen R, Chapin FS 3rd. Adaptive governance and institutional strategies for climate-induced community relocations in Alaska. Proc Natl Acad Sci USA 2013 ; 110: 9320-25.

159 Shuman EK. Global climate change and infectious diseases. N Engl J Med 2010; 362: 1061-63.

160 Ramasamy R, Surendran SN. Possible impact of rising sea levels on vector-borne infectious diseases. BMC Infect Dis 2011; 11: 18.

161 Moore S, Shrestha S, Tomlinson KW, Vuong H. Predicting the effect of climate change on African trypanosomiasis: integrating epidemiology with parasite and vector biology. $J R$ Soc Interface 2012; 9: 817-30.

162 Keesing F, Belden LK, Daszak P, et al. Impacts of biodiversity on the emergence and transmission of infectious diseases. Nature 2010; 468: 647-52.

163 Ebi K, Berry P, Campbell-Lendrum D, et al. Protecting health from climate change: vulnerability and adaptation assessment. Geneva: World Health Organization and Pan American Health Organization, 2012.

164 Cheng JJ, Berry P. Health co-benefits and risks of public health adaptation strategies to climate change: a review of current literature. Int J Public Health 2013; 58: 305-11.

165 Heltberg R, Siegel PB, Jorgensen SL. Addressing human vulnerability to climate change: toward a 'no-regrets' approach. Glob Environ Change 2009; 19: 89-99.

166 Keim ME. Building human resilience: the role of public health preparedness and response as an adaptation to climate change. Am J Prev Med 2008; 35: 508-16.

167 Jamison DT, Summers LH, Alleyne G, et al. Global health 2035: a world converging within a generation. Lancet 2013; 382: 1898-955.

168 Parry M, Arnell N, Berry P, et al. Assessing the costs of adaptation to climate change: a review of the UNFCCC and other recent estimates. London: Imperial College London and International Institute for Environment and Development, 2009.

169 Jones KE, Patel NG, Levy MA, et al. Global trends in emerging infectious diseases. Nature 2008; 451: 990-93.

170 Grace D, Mutua F, Ochungo P, Kruska R. Mapping of poverty and likely zoonoses hotspots. London: International Livestock Research Institute, 2012.

171 World Bank. The costs to developing countries of adapting to climate change: new methods and estimates. Washington DC: World Bank, 2010.

172 Dye C. After 2015: infectious diseases in a new era of health and development. Philos Trans R Soc Lond B Biol Sci 2014; 369: 20130426.

173 World Bank. People, pathogens and our planet: the economics of one health. Washington DC: World Bank, 2012.

174 Semenza JC, Suk JE, Estevez V, Ebi KL, Lindgren E. Mapping climate change vulnerabilities to infectious diseases in Europe. Environ Health Perspect 2012; 120: 385-92.

175 Teutsch SM, Churchill RE. Principles and practice of public health surveillance, 2nd edn. New York, NY: Oxford University Press, 2000.

176 Colls A, Ash N, Ikkala N. Ecosystem-based adaptation: a natural response to climate change. Switzerland: International Union for Conservation of Nature, 2009.

177 Pramova E, Locatelli B, Brockhaus M, Fohlmeister S. Ecosystem services in the national adaptation programmes of action. Clim Pol 2012; 12: 393-409.

178 Pramova E, Locatelli B, Djoudi H, Somorin OA. Forests and trees for social adaptation to climate variability and change. Wiley Interdiscip Rev Clim Chang $2012 ; 3: 581-96$.

179 Spalding MD, Ruffo S, Lacambra C, et al. The role of ecosystems in coastal protection: adapting to climate change and coastal hazards. Ocean Coast Manage 2014 ; 90: 50-57.

180 Mimura N, Pulwarty R, Duc D, et al. Adaptation planning and implementation. Climate change 2014: impacts, adaptation, and vulnerability Working Group II Contribution to the IPCC 5th Assessment Report. Cambridge, UK and New York, NY: Cambridge University Press, 2014.

181 The Royal Society. Resilience to extreme weather. London: The Royal Society Science Policy Centre, 2014.

182 Gill SE, Handley JF, Ennos AR, Pauleit S. Adapting cities for climate change: the role of the green infrastructure. Built Environ 2007; 33: 115-33.

183 Munang R, Thiaw I, Alverson K, Mumba M, Liu J, Rivington M. Climate change and Ecosystem-based Adaptation: a new pragmatic approach to buffering climate change impacts. Curr Opin Environ Sustain 2013; 5: 67-71.

184 Drewniak B, Snyder P, Steiner A, Twine T, Wuebbles D. Simulated changes in biogenic VOC emissions and ozone formation from habitat expansion of Acer Rubrum (red maple). Environ Res 2014; 9: 014006.

185 Stone B Jr, Vargo J, Liu P, et al. Avoided heat-related mortality through climate adaptation strategies in three US cities. PLoS One 2014; 9: e100852.

186 Huang C, Vaneckova P, Wang X, Fitzgerald G, Guo Y, Tong S. Constraints and barriers to public health adaptation to climate change: a review of the literature. Am J Prev Med 2011; 40: 183-90.

187 Wilbanks T, Leiby P, Perlack R, Ensminger JT, Wright S. Toward an integrated analysis of mitigation and adaptation: some preliminary findings. Mitig Adapt Strategies Glob Change 2007; 12: 713-25. 
188 California Natural Resources Agency. 2009 California climate adaptation strategy: a report to the Governor of the state of California in response to Executive Order S-13-2008. Sacramento: California Natural Resources Agency, 2009.

189 Feiock RC. Metropolitan Governance and Institutional Collective Action. Urban Aff Rev 2008; 44: 356-77.

190 UNFCCC. Third synthesis report on technology needs identified by Parties not included in Annex I to the Convention. Document FCCC/SBSTA/2013/Inf7 Subsidiary Body for Scientific and Technological Advice, thirty-ninth session. Warsaw: UNFCCC, 2013.

191 Leiserowitz A, Maibach E, Roser-Renouf C, Feinberg G, Rosenthal S, Marlon J. Public perceptions of the health consequences of global warming. New Haven: Yale University and George Mason University, 2014.

192 Moser SC, Dilling L. Creating a climate for change: communicating climate change and facilitating social change. Cambridge: Cambridge University Press, 2007.

193 Noble I, Huq S, Ayers J, et al. Adaptation needs and options. Climate change 2014: impacts, adaptation, and vulnerability Working Group II Contribution to the IPCC 5th Assessment Report. Cambridge, UK and New York, NY: Cambridge University Press, 2014.

194 Graus W, Blomen E, Worrell E. Global energy efficiency improvement in the long term: a demand-and supply-side perspective. Energy Efficiency 2011; 4: 435-63.

195 International Energy Agency (IEA). Redrawing the energy-climate map. World energy outlook special report. Paris: IEA, 2013.

196 Vaughan N, Lenton T. A review of climate geoengineering proposals. Clim Change 2011; 109: 745-90.

197 Lackner KS, Brennan S, Matter JM, Park AH, Wright A, van der Zwaan B. The urgency of the development of CO2 capture from ambient air. Proc Natl Acad Sci USA 2012; 109: 13156-62.

198 Fischedick M, Schaeffer R, Adedoyin A, et al. Mitigation potential and costs. In: Edenhofer O, Pichs-Madruga R, Sokona Y, et al, eds. IPCC special report on renewable energy sources and climate change mitigation. Cambridge, UK and New York, NY: Cambridge University Press, 2011.

199 Bvd Z. The role of nuclear power in mitigating emissions from electricity generation. Energy Strat Rev 2013; 1: $296-301$.

200 Scovronick N, Adair-Rohani H, Borgford-Parnell N, et al. Reducing global health risks through mitigation of short-lived climate pollutants: scoping report for policymakers. Geneva: World Health Organization and Climate and Clean Air Coalition, 2015.

201 Summary for policymakers. In: Edenhofer O, Pichs-Madruga R, Sokona Y, et al, eds. Climate change 2014: mitigation of climate change contribution of Working Group III to the Fifth Assessment Report of the Intergovernmental Panel on Climate Change. Cambridge, UK and New York, NY: Cambridge Unive rsity Press, 2014.

202 Victor D, Zhou D, Ahmed E, et al. Introductory Chapter. In: Edenhofer O, Pichs-Madruga R, Sokona Y, et al, eds. Climate change 2014: mitigation of climate change contribution of Working Group III to the Fifth Assessment Report of the Intergovernmental Panel on Climate Change. Cambridge, UK and New York, NY: Cambridge University Press, 2014.

203 Bruckner T, Bashmakov I, Mulugetta Y, et al. Energy Systems. In: Edenhofer O, Pichs-Madruga R, Sokona Y, et al, eds. Climate change 2014: mitigation of climate change contribution of Working Group III to the Fifth Assessment Report of the Intergovernmental Panel on Climate Change. Cambridge, UK and New York, NY: Cambridge University Press, 2014.

204 Stafford Smith M, Horrocks L, Harvey A, Hamilton C. Rethinking adaptation for a $4^{\circ} \mathrm{C}$ world. Philos Trans A Math Phys Eng Sci 2011; 369: 196-216.

205 Basedau M, Lay J. Resource curse or rentier peace? The ambiguous effects of oil wealth and oil dependence on violent conflict. J Peace Res 2009 ; 46: 757-76.

206 Schaeffer R, Szkloa A, Pereira-de-Lucena A, et al. Energy sector vulnerability to climate change: a review. Energy 2012; 38: 1-12.

207 Schaeffer M, Hare W, Rahmstorf S, Vermeer M. Long-term sea-level rise implied by $1 \cdot 5^{\circ} \mathrm{C}$ and $2^{\circ} \mathrm{C}$ warming levels. Nature Clim Change 2012; 2: $867-70$.

208 Czisch G. Scenarios for a future electricity supply: cost-optimised variations on supplying Europe and its neighbours with electricity from renewable energies. Stevenage: Institution of Engineering and Technology, 2011.

209 International Energy Agency (IEA). World energy outlook 2013. Paris: IEA, 2013.

210 Barrett J, Le Quéré, Lenzen M, Peters G, Roelich K, Wiedmann T. Consumption-based emissions reporting. Memorandum submitted by UKERC (CON 19). 2011. http://www.publications.parliament.uk/pa/cm201012/cmselect/cmenergy/writev/consumpt/con20.htm (accessed May 10, 2015).

211 Blanco G, Gerlagh R, Suh S, et al. Drivers, trends and mitigation. In: Edenhofer O, Pichs-Madruga R, Sokona Y, et al, eds. Climate change 2014: mitigation of climate change contribution of Working Group III to the Fifth Assessment Report of the Intergovernmental Panel on Climate Change. Cambridge, UK and New York, NY: Cambridge University Press, 2014.

212 World Bank. World development indicators_-GDP per capita (constant 2005 US\$). Washington, DC: World Bank, 2015.

213 World Bank. World development indicators- $\mathrm{CO}_{2}$ emissions (metric tons per capita). Tennessee: World Bank, 2015.

214 Open Working Group proposal for Sustainable Development Goals. New York: UN Department of Economic and Social Affairs, Division for Sustainable Development, 2014.

215 Markandya A, Armstrong BG, Hales S, et al. Public health benefits of strategies to reduce greenhouse-gas emissions: low-carbon electricity generation. Lancet 2009; 374: 2006-15.

216 Markandya A, Wilkinson P. Electricity generation and health. Lancet 2007; 370: 979-90.

217 Wilkinson P, Smith KR, Davies M, et al. Public health benefits of strategies to reduce greenhouse-gas emissions: household energy. Lancet 2009; 374: 1917-29.

218 Woodcock J, Edwards P, Tonne C, et al. Public health benefits of strategies to reduce greenhouse-gas emissions: urban land transport. Lancet 2009; 374: 1930-43.

219 Davies M, Oreszczyn T. The unintended consequences of decarbonising the built environment: a UK case study. Energy Build 2012; 46: 80-85.

220 Proust K, Newell B, Brown H, et al. Human health and climate change: leverage points for adaptation in urban environments. Int J Environ Res Public Health 2012; 9: 2134-58.

221 Shaw MR, Overpeck JT, Midgley GF. Cross-chapter box on ecosystem based approaches to adaptation — emerging opportunities. In: Field CB, Barros VR, Dokken DJ, et al, eds. Climate change 2014: impacts, adaptation, and vulnerability. Part A: global and sectoral aspects contribution of Working Group II to the Fifth Assessment Report of the Intergovernmental Panel of Climate Change. Cambridge, UK and New York, NY, USA: Cambridge University Press, 2014: 101-03.

222 NHS Sustainable Development Unit. Saving carbon, improving health: NHS carbon reduction strategy. Cambridge: Sustainable Development Unit, 2009.

223 Public Health England and NHS England. Module: carbon hotspots. Sustainable development strategy for the health and care system 2014-2020. London: Sustainable Development Unit, 2014

224 US Environmental Protection Agency (EPA). Inventory of US greenhouse gas emissions and sinks: 1990-2009. Washington, DC: EPA, 2011.

225 Global Green and Healthy Hospitals Network. Greenhouse Gas Emissions Reduction and Availability of Energy-Saving Practices in the Special Context of a Hospital Environment: Yonsei University Health System. 2014. http://greenhospitals.net/en/case-studies/ (accessed Dec 7, 2014).

226 Health G. Gundersen reaches first days of energy independence: first health system in nation to achieve this distinction. 2014. http://www.gundersenenvision.org/gundersen-reachesfirst-days-of-energy-independence (accessed Dec 7, 2014).

227 Sustainable Development Unit. NHS, Public Health and Social Care. A cross England health system statement for the UN Climate Summit. Cambridge: Sustainable Development Unit, 2014.

228 Jensen HT, Keogh-Brown MR, Smith RD, et al. The importance of health co-benefits in macroeconomic assessments of UK greenhouse gas emission reduction strategies. Clim Change 2013; 121: 223-37.

229 West J, Fiore A, Horowitz L. Scenarios of methane emission reductions to 2030: abatement costs and co-benefits to ozone air quality and human mortality. Clim Change 2012; 114: $441-61$.

230 Institute for Sustainable Development and International Relations, Sustainable Development Solutions Network. Pathways to deep decarbonization: interim 2014 report. Washington, DC: SDSN and IDDRI, 2014.

231 Clarke L, Jiang K, Akimoto K, et al. Assessing transformation pathways. In: Edenhofer O, Pichs-Madruga R, Sokona Y, et al, eds. Climate change 2014: mitigation of climate change contribution of Working Group III to the Fifth Assessment Report of the Intergovernmental Panel on Climate Change. Cambridge, UK and New York, NY, USA: Cambridge University Press, 2014.

232 Krey V, Masera G, Blanford T, et al. Annex II: metrics \& methodology. In: Edenhofer O, Pichs-Madruga R, Sokona Y, et al, eds. Climate change 2014: mitigation of climate change contribution of Working Group III to the Fifth Assessment Report of the Intergovernmental Panel on Climate Change. Cambridge, UK and New York, NY, USA: Cambridge University Press, 2014.

233 Mills B, Schleich J. Residential energy-efficient technology adoption, energy conservation, knowledge, and attitudes: an analysis of European countries. Energy Pol 2012; 49: 61628 .

234 Gilligan J, Dietz T, Gardner G, Stern P, Vandenbergh M. The behavioural wedge. Significance 2010; 7: 17-20.

235 Mohareb E, Kennedy C. Scenarios of technology adoption towards low-carbon cities. Energy Pol 2014; 66: 685-93.

236 Verbeek P. Ethiek en technologie: moreel actorschap en subjectiviteit in een technologische cultuur. Ethische Perspectiven 2006; 16: 267-89.

237 International Energy Agency. Energy technology perspectives 2012. Paris: IEA, 2012.

238 International Energy Agency. Coal medium-term market report 2012. Paris: IEA, 2012.

239 Mills E. Weighing the risks of climate change mitigation strategies. Bull At Sci 2012; 68: 67-78.

240 Lowe R. Defining and meeting the carbon constraints of the 21st Century. Build Res Inform 2000; 28: 159-75.

241 Geels F. Technological transitions and system innovations: a co-evolutionary and socio-technical analysis. Cheltenham: Edward Elgar, 2005.

242 Dechezlepretre A, Glachant M, Hascic I, Johnstone N, Meniere Y. Invention and transfer of climate change-mitigation technologies: a global analysis. Rev Environ Econ Pol 2011; 5: 109-30.

243 Karakosta C, Doukas H, Psarras J. Technology transfer through climate change: setting a sustainable energy pattern. Renew Sustain Energy Rev 2010 ; 14 : 1546-57. 
244 Jakob M, Steckel J. How climate change mitigation could harm development in poor countries. Wiley Interdiscip Rev Clim Change 2014; 5: 161-68.

245 Chambwera M, Heal G, Dubeux C, et al. Economics of adaptation. In: Field CB, Barros VR, Dokken DJ, et al, eds. Climate change 2014: impacts, adaptation, and vulnerability. Part A: global and sectoral aspects contribution of Working Group II to the Fifth Assessment Report of the Intergovernmental Panel of Climate Change. Cambridge, UK and New York, NY, USA: Cambridge University Press, 2014: 945-77.

246 Webster PJ. Meteorology: improve weather forecasts for the developing world. Nature 2013; 493: 17-19.

247 WHO Regional Office for Europe. Climate change and health: a tool to estimate health and adaptation costs. Copenhagen: World Health Organization, 2013.

248 WHO Regional Office for Europe. Climate, environment and health action plan and information system: policy monitoring and assessment. Copenhagen: World Health Organzation, 2011.

249 WHO. Global health expenditure database. 2014. http://apps.who.int/nha/database/World_Map/Index/en?id=REPORT_4_WORLD_MAPS\&mapType=3\&ws=0 (accessed Dec 22, 2014).

250 WHO. World health statistics 2014. http://www.who.int/mediacentre/news/releases/2014/world-health-statistics-2014/en/ (accessed Sept 7, 2014).

251 Organisation of Economic Co-operation and Development. The cost of air pollution: health impacts of road transport. Paris: OECD, 2014.

252 European Commission. Communication from the Commission to the European Parliament, the Council, the European Economic and Social Committee and the Committee of the Regions: a roadmap for moving to a competitive low carbon economy in 2050. Brussels: European Commission, 2011.

253 International Renewable Energy Agency. REmap 2030: a renewable energy roadmap. Abu Dhabi: IRENA, 2014.

254 West JJ, Smith SJ, Silva RA, et al. Co-benefits of global greenhouse gas mitigation for future air quality and human health. Nature Clim Chang 2013 ; 3: 885-89.

255 Thompson T, Rausch S, Saari R, Selin N. A systems approach to evaluating the air quality co-benefits of US carbon policies. Nature Clim Change 2014; 4: 917-23.

256 Patz JA, Frumkin H, Holloway T, Vimont DJ, Haines A. Climate change: challenges and opportunities for global health. JAMA 2014; 312: 1565-80.

257 Liddell C, Morris C. Fuel poverty and human health: A review of recent evidence. Energy Pol 2010; 38: 2987-97.

258 Nicol S, Roys M, Davidson M, Ormandy D, Ambrose P. Quantifying the economic cost of unhealthy housing —a case study from England. In: Braubach M, Jacobs DE, Ormandy D, eds. Environmental burden of disease associated with inadequate housing: a method guide to the quantification of health effects of selected housing risks in the WHO European Region. Copenhagen: World Health Organization Regional Office for Europe, 2011: 197-208.

259 Copenhagen Economics. Multiple benefits of investing in energy efficient renovation of buildings: impact on public finances. Copenhagen: Renovate Europe, 2012.

260 International Energy Agency. World energy outlook. Paris: IEA, 2012.

261 The New Climate Economy. Better growth, better climate. New York: The Global Commission on the Economy and Climate, 2014.

262 International Energy Agency. World energy investment outlook. Paris: IEA, 2014.

263 Buchner B, Herve-Mignucci M, Trabacchi C, et al. The global landscape of climate finance. San Francisco: Climate Policy Initiative, 2013.

264 Watkiss P, Downing T. The social cost of carbon: valuation estimates and their use in UK policy. Integr Assess J 2008; 8: 85-105.

265 Grubb M. Planetary economics: energy, climate change and the three domains of sustainable development. London: Routledge, 2014.

266 Arent DJ, Tol RSJ, Faust E, et al. Key economic sectors and services. In: Field CB, Barros VR, Dokken DJ, et al, eds. Climate change 2014: impacts, adaptation, and vulnerability. Part A: global and sectoral aspects contribution of Working Group II to the Fifth Assessment Report of the Intergovernmental Panel of Climate Change. Cambridge, UK and New York, NY, USA: Cambridge University Press, 2014: 659-708.

267 Stern N. Stern Review on the economics of climate change. London: HM Treasury, 2006.

268 Nordhaus W. A review of the Stern Review on the economics of climate change. J Econ Lit 2007; XLV: 703-724.

269 Weitzmann M. Fat-tailed uncertainty in the economics of catastrophic climate change. Rev Environ Econ Policy 2011; 5: 275-92.

270 Stern N. The structure of economic modeling of the potential impacts of climate change: grafting gross underestimation of risk onto already narrow science models. $J$ Econ Lit 2013 ; 51: 838-59.

271 Goulder L, Williams R. The choice of discount rate for climate change policy evaluation. Clim Change Econ 2012; 3: 18.

272 International Energy Agency. Mind the gap: quantifying principal-agent problems in energy efficiency. Paris: IEA, 2007.

273 European Commission. Energy economic developments in Europe: European economy. Brussels: European Commission, 2014.

274 Capros P, De Vita A, Tasios D, et al. EU Energy, transport and GHG emissions: trends to 2050-reference scenario. Luxembourg: European Commission, 2013.

275 Sovereign Wealth Funds Institute. Fund rankings 2013. http://www.swfinstitute.org/fund-rankings/ (accessed Aug 25, 2014).

276 Fulton M, Capalino R. Investing in the clean trillion: closing the clean energy investment gap. Boston: Ceres, 2014.

277 Kaminker C, Kawanishi O, Stewart F, Caldecott B, Howarth N. Institutional investors and green infrastructure investments: selected case studies. Paris: Organization for Economic Co-operation and Development, 2013.

278 Macmillan I, Prakash I, Shoult R. The cash paradox: how record cash reserves are influencing corporate behaviour. July, 2014. http://dupress.com/articles/excess-cash-growth-strategies/ (accessed Dec 20, 2014).

279 UN. Millennium Development Goal 8, the challenge we face: MDG Gap Task Force Report 2013. New York: United Nations, 2013.

280 Nachmany M, Fankhauser S, Townshend T, et al. The GLOBE climate legislation study: a review of climate legislation study: a review of climate change legislation in 66 countries. London: GLOBE International and the Grantham Research Institute, London School of Economics, 2014.

281 World Bank Group. State and trends of carbon pricing. Washington, DC: World Bank, 2014.

282 Parry IWH, Heine D, Lis E. Getting the prices right: from principle to practice. Washington, DC: International Monetary Fund, 2014.

283 Schöb R. The Double Dividend Hypothesis of Environmental Taxes. Working Paper no.946. Munich: Centre for Economic Studies \& the ifo Group, 2003.

284 International Energy Agency. World Energy Outlook. Paris; 2010.

285 Victor D. The politics of fossil-fuel subsidies: global subsidies initiative \& the international institute for sustainable development. Geneva: Global Subsidies Initiative, International Institute for Sustainable Development, 2009.

286 International Monetary Fund. World economic outlook. Washington, DC: IMF, 2010.

287 Mazzucato M. The entrepreneurial state: debunking public $v s$ private sector myths. London: Anthem Press, 2013.

288 Ravenel P, Brites J, Dichamp G, Monteillet C, Yaker MF, Enmanuel CA. The impacts of sustainable public procurement: eight illustrative case studies. Paris: UNEP Sustainable Consumption and Production Branch, 2012.

289 UN Framework Convention on Climate Change (UNFCCC). United Nations Framework Convention on Climate Change. Geneva: IUCC, 1992.

290 Depledge J. The global climate change regime. In: Ekins P, Bradshaw M, Watson J, eds. Global energy: issues, potentials and policy implications. Oxford: Oxford University Press, 2015.

291 Bodansky D. The United Nations Framework Convention on Climate Change: a commentary. Yale J Int Law 1993; 18: 451-558.

292 Susskind L. Environmental diplomacy, negotiating more effective global agreements. New York: Oxford University Press, 1994.

293 Hulme M. Why we disagree about climate change: understanding controversy, inaction and opportunity. Cambridge: Cambridge University Press, 2009.

294 Rapley CG, de Meyer K, Carney J, et al. Time for change? climate science reconsidered. Report of the UCL Policy Commission on Communicating Climate Science. London: UCL, 2014.

295 Spence A, Poortinga W, Pidgeon N. The psychological distance of climate change. Risk Anal 2012; 32: 957-72.

296 Unruh GC. Understanding carbon lock-in. Energy Pol 2000; 28: 817-30.

297 Brulle R. Institutionalizing delay: foundation funding and the creation of US climate change counter-movement organizations. Clim Change 2014; 122: 681-94.

298 Bulkeley H. Betsill. M. Cities and climate change: urban sustainability and global environmental governance. New York: Routledge, 2003.

299 Boutiligier S. Cities, networks, and global environmental governance. London: Routledge, 2013.

300 Roman M. Governing from the middle: the C40 Cities Leadership Group. Corp Gov 2010; 10: 73-84.

301 Curtis S. Global Cities and the Transformation of the International System. Rev Int Stud 2011; 37: 1923-47.

302 Gordon DJ. Between local innovation and global impact: cities, networks, and the governance of climate change. Can Foreign Pol J 2013 ; $19: 288-307$.

303 Rvd P Melissen J. City diplomacy: the expanding role of cities in international politics. The Hague: Netherlands Institute of International Relations, 2007.

304 Center PR. Climate change and financial instability seen as top global threats. Washington, DC: Pew Research Center, 2013.

305 Darier É, Schüle R. 'Think globally, act locally’? Climate change and public participation in Manchester and Frankfurt. Local Environ 1999; 4: $317-29$.

306 Poortinga W, Pidgeon NF. Exploring the dimensionality of trust in risk regulation. Risk Anal 2003; 23: 961-72.

307 Pretty J. The consumption of a finite planet: well-being, convergence, divergence and the nascent green economy. Environ Resour Econ 2013; 55: 475-99.

308 Hulme M. Reducing the future to climate: a story of climate determinism and reductionism. Osiris 2011a; 26: 245-66.

309 Webb J. Climate change and society: the chimera of behaviour change technologies. Sociology 2012; 46: 109-25. 
310 Wolf J, Moser SC. Individual understandings, perceptions, and engagement with climate change: insights from in-depth studies across the world. Wiley Interdiscip Rev Clim Chang 2011; 2: 547-69.

311 Höijer B. Emotional anchoring and objectification in the media reporting on climate change. Public Underst Sci 2010; 19: 717-31.

312 Witte K, Allen M. A meta-analysis of fear appeals: implications for effective public health campaigns. Health Educ Behav 2000; 27: 591-615.

313 Markowitz EM, Shariff AF. Climate change and moral judgement. Nature Climate Change 2012; 2: 243-47.

314 Green D, Billy J, Tapim A. Indigenous Australians' knowledge of weather and climate. Clim Change 2010; 100: $337-54$.

315 Giddens A. The politics of climate change. Cambridge: John Wiley and Sons, 2009.

316 Vignola R, Klinsky S, Tam J, McDaniels T. Public perception, knowledge and policy support for mitigation and adaption to climate change in Costa Rica: comparisons with North American and European studies. Mitig Adapt Strategies Glob Change 2013; 18: 303-23.

317 World Bank Group. Public attitudes toward climate change: findings from a multi-country poll. Background note to the world development report 2010. Washington, DC: World Bank, 2009.

318 Marteau TM, Hollands GJ, Fletcher PC. Changing human behavior to prevent disease: the importance of targeting automatic processes. Science 2012; 337: 1492-95. 